\title{
Deuteration and evolution in the massive star formation process ${ }^{\star, \star \star}$
}

\section{The role of surface chemistry}

\author{
F. Fontani ${ }^{1}$, G. Busquet ${ }^{2,3}$, Aina Palau ${ }^{4}$, P. Caselli ${ }^{5}$, Á. Sánchez-Monge ${ }^{6}$, J. C. Tan ${ }^{7,8}$, and M. Audard ${ }^{9}$ \\ 1 INAF - Osservatorio Astrofisico di Arcetri, L.go E. Fermi 5, 50125 Firenze, Italy \\ e-mail: fontani@arcetri.astro.it \\ 2 Instituto de Astrofísica de Andalucía, CSIC, Glorieta de la Astronomía, 18008 Granada, Spain \\ 3 INAF - Istituto di Astrofisica e Planetologia Spaziali, via Fosso del Cavaliere 100, 00133 Roma, Italy \\ ${ }^{4}$ Centro de Radioastronomía y Astrofísica, Universidad Nacional Autónoma de México, PO Box 3-72, 58090 Morelia, Michoacán, \\ Mexico \\ 5 Max-Planck-Institut für extraterrestrische Physik (MPE), Giessenbachstr., 85741 Garching, Germany \\ 6 I. Physikalisches Institut der Universität zu Köln, Zülpicher Strasse 77, 50937 Köln, Germany \\ 7 Department of Astronomy, University of Florida, Gainesville, FL 32611, USA \\ 8 Department of Physics, University of Florida, Gainesville, FL 32611, USA \\ 9 Department of Astronomy, University of Geneva, Ch. d'Ecogia 16, 1290 Versoix, Switzerland
}

Received 5 August 2014 / Accepted 27 October 2014

\section{ABSTRACT}

\begin{abstract}
Context. An ever growing number of observational and theoretical evidence suggests that the deuterated fraction (column density ratio between a species containing D and its hydrogenated counterpart, $D_{\text {frac }}$ ) is an evolutionary indicator both in the low- and the highmass star formation process. However, the role of surface chemistry in these studies has not been quantified from an observational point of view.

Aims. Because many abundant species, such as $\mathrm{NH}_{3}, \mathrm{H}_{2} \mathrm{CO}$, and $\mathrm{CH}_{3} \mathrm{OH}$, are actively produced on ice mantles of dust grains during the early cold phases, their $D_{\text {frac }}$ is expected to evolve differently from species formed only (or predominantly) in the gas, such as $\mathrm{N}_{2} \mathrm{H}^{+}, \mathrm{HNC}, \mathrm{HCN}$, and their deuterated isotopologues. The differences are expected to be relevant especially after the protostellar birth, in which the temperature rises, causing the evaporation of ice mantles.

Methods. To compare how the deuterated fractions of species formed only in the gas and partially or uniquely on grain surfaces evolve with time, we observed rotational transitions of $\mathrm{CH}_{3} \mathrm{OH},{ }^{13} \mathrm{CH}_{3} \mathrm{OH}, \mathrm{CH}_{2} \mathrm{DOH}$, and $\mathrm{CH}_{3} \mathrm{OD}$ at $3 \mathrm{~mm}$ and $1.3 \mathrm{~mm}$, of NH $\mathrm{NH}_{2} \mathrm{D}$ at $3 \mathrm{~mm}$ with the IRAM-30 m telescope, and the inversion transitions $(1,1)$ and $(2,2)$ of $\mathrm{NH}_{3}$ with the GBT, towards most of the cores already observed in $\mathrm{N}_{2} \mathrm{H}^{+}, \mathrm{N}_{2} \mathrm{D}^{+}$, $\mathrm{HNC}$, and DNC.

Results. $\mathrm{NH}_{2} \mathrm{D}$ is detected in all but two cores, regardless of the evolutionary stage. $D_{\text {frac }}\left(\mathrm{NH}_{3}\right)$ is on average above 0.1 and does not change significantly from the earliest to the most evolved phases, although the highest average value is found in the protostellar phase $(\sim 0.3)$. Few lines of $\mathrm{CH}_{2} \mathrm{DOH}$ and $\mathrm{CH}_{3} \mathrm{OD}$ are clearly detected, and then only towards protostellar cores or externally heated starless cores. In quiescent starless cores, we have only one doubtful detection of $\mathrm{CH}_{2} \mathrm{DOH}$.

Conclusions. This work clearly confirms an expected different evolutionary trend of the species formed exclusively in the gas $\left(\mathrm{N}_{2} \mathrm{D}^{+}\right.$ and $\left.\mathrm{N}_{2} \mathrm{H}^{+}\right)$and those formed partially $\left(\mathrm{NH}_{2} \mathrm{D}\right.$ and $\left.\mathrm{NH}_{3}\right)$ or totally $\left(\mathrm{CH}_{2} \mathrm{DOH}\right.$ and $\left.\mathrm{CH}_{3} \mathrm{OH}\right)$ on grain mantles. It also reinforces the idea that $D_{\text {frac }}\left(\mathrm{N}_{2} \mathrm{H}^{+}\right)$is the best tracer of massive starless cores, while high values of $D_{\text {frac }}\left(\mathrm{CH}_{3} \mathrm{OH}\right)$ seem fairly good tracers of the early protostellar phases, where the evaporation or sputtering of the grain mantles is most efficient.
\end{abstract}

Key words. stars: formation - molecular data - submillimeter: ISM - ISM: molecules

\section{Introduction}

Theory and observations suggest that the abundance of deuterated molecules in dense star-forming cores is related to the core evolution. The formation of deuterated molecules is favoured by the combination of low temperatures $(T \leq 20 \mathrm{~K})$ and high densities $\left(n \geq 10^{4} \mathrm{~cm}^{-3}\right)$, which on one hand boosts the depletion

\footnotetext{
* Tables 3-6, 8, and Appendices are available in electronic form at http://www. aanda.org

$\star \star$ IRAM $30 \mathrm{~m}$ data (final reduced data used in the paper, in FITS format) are only available at the CDS via anonymous ftp to cdsarc.u-strasbg. fr (130.79.128.5) or via http://cdsarc.u-strasbg.fr/viz-bin/qcat?]/A+A/575/A87
}

of $\mathrm{CO}$ and other neutrals and, on the other, makes the relative abundance between a species containing D and its hydrogenated counterpart (the so-called deuterated fraction, $D_{\text {frac }}$ ) higher by three to four orders of magnitude with respect to the $[\mathrm{D} / \mathrm{H}]$ interstellar abundance $\left(\sim 10^{-5}\right.$, e.g. Oliveira et al. 2003), due to the endothermicity of their backward reactions (see e.g. Millar et al. 1989; Gerlich et al. 2002). After protostellar birth, the young stellar object formed at the core centre heats up its surrounding material, and the temperature enhancement favours the progressive destruction of deuterated species and, consequently, makes $D_{\text {frac }}$ decrease (see e.g. Caselli et al. 2002). Observations of low-mass star-forming cores have confirmed this theoretical scenario: both the column density ratio $D_{\text {frac }}\left(\mathrm{N}_{2} \mathrm{H}^{+}\right)$and 
the column density of ortho- $\mathrm{H}_{2} \mathrm{D}^{+}$, the parent species of most of the deuterated molecules formed in the gas (e.g. $\mathrm{DCO}^{+}$, $\mathrm{N}_{2} \mathrm{D}^{+}$, DNC), increase in starless cores close to the onset of gravitational collapse, and then, after the formation of the protostar, they decrease as the core evolves (Crapsi et al. 2005; Emprechtinger et al. 2009; Caselli et al. 2008). Growing observational evidence suggests that high values of $D_{\text {frac }}$ are also typical in high-mass star-forming cores (e.g. Fontani et al. 2006; Pillai et al. 2007, 2011; Miettinen et al. 2011), and that $D_{\text {frac }}$ of some species could be also an evolutionary indicator in the intermediate- and high-mass regime (e.g. Busquet et al. 2010; Fontani et al. 2011; Sakai et al. 2012).

To investigate the relation between $D_{\text {frac }}$ and core evolution in the high-mass regime in a systematic way, our team started a survey of deuterated molecules in about 30 dense cores that were carefully selected and almost equally divided among the three evolutionary phases in which we can roughly divide the high-mass star formation process observationally (see e.g. Beuther et al. 2007 and Tan et al. 2014): high-mass starless cores (HMSCs), high-mass protostellar objects (HMPOs) and ultracompact HII regions (UC HIIs). In brief, the targets were selected as follows: The HMSCs had to be dense molecular cores not associated with indicators of star formation; the HMPOs had to show outflows, infrared sources, and/or faint $\left(S_{3.6 \mathrm{~cm}}<1 \mathrm{mJy}\right)$ radio continuum emission; the UCHIIs had to be associated with stronger $\left(S_{3.6 \mathrm{~cm}} \geq 1 \mathrm{mJy}\right)$ radio continuum. In selecting the sources, we rejected cores that are blended with nearby cores to avoid confusion and make the emission of the targeted core dominant.

In the first study, we (Fontani et al. 2011, hereafter Paper I) presented the results obtained from spectroscopic observations of millimetre rotational transitions of $\mathrm{N}_{2} \mathrm{H}^{+}$and $\mathrm{N}_{2} \mathrm{D}^{+}$obtained with the IRAM-30 m telescope, where we showed that $D_{\text {frac }}\left(\mathrm{N}_{2} \mathrm{H}^{+}\right)$is $\sim 0.26$ in HMSCs, and drops by about an order of magnitude in the HMPO and UC HII stages. These results are consistent with the fact that deuteration of $\mathrm{N}_{2} \mathrm{H}^{+}$starts from the reaction $\mathrm{H}_{2} \mathrm{D}^{+}+\mathrm{N}_{2} \rightarrow \mathrm{N}_{2} \mathrm{D}^{+}+\mathrm{H}_{2}$, which is efficient only at temperatures $\leq 20 \mathrm{~K}$ (Gerlich et al. 2002). In a subsequent study focused on DNC/HNC, Fontani et al. (2014, Paper II) showed that $D_{\text {frac }}(\mathrm{HNC})$ also decreases from the pre- to the protostellar phase, but much more moderately, indicating that the ratio $\mathrm{N}_{2} \mathrm{D}^{+}$-to- $\mathrm{N}_{2} \mathrm{H}^{+}$is more appropriate to identifying massive starless cores. This is consistent with the prediction that DNC can also easily form when the gas gets warmer, because the route reaction for the deuteration of $\mathrm{HNC}$ is linked to $\mathrm{CH}_{2} \mathrm{D}^{+}$, which can stay abundant up to temperatures of $70 \mathrm{~K}$ (e.g. Leurini et al. 2006). However, $\mathrm{N}_{2} \mathrm{H}^{+}$, $\mathrm{HNC}$ and their deuterated isotopologues can form mainly (HNC, DNC) or solely $\left(\mathrm{N}_{2} \mathrm{H}^{+}, \mathrm{N}_{2} \mathrm{D}^{+}\right)$in the gas phase. Other important molecules, such as $\mathrm{NH}_{3}, \mathrm{H}_{2} \mathrm{CO}, \mathrm{CH}_{3} \mathrm{OH}$ and their deuterated forms, can be produced on dust grain surfaces (e.g. Aikawa et al. 2005), and theoretical models show that this can make relevant differences in their $D_{\text {frac }}$, especially during the protostellar phase in which grain mantles evaporate (Aikawa et al. 2012).

In this work we investigate the role of surface chemistry by means of measurements of $D_{\text {frac }}\left(\mathrm{NH}_{3}\right)$ and $D_{\text {frac }}\left(\mathrm{CH}_{3} \mathrm{OH}\right)$. Because methanol and its deuterated forms can be produced only on grain surfaces (see e.g. Parise et al. 2002; Garrod et al. 2007), $D_{\text {frac }}\left(\mathrm{N}_{2} \mathrm{H}^{+}\right)$and $D_{\text {frac }}\left(\mathrm{CH}_{3} \mathrm{OH}\right)$ represent the two "extreme conditions" under which deuteration can occur: only on grain surfaces $\left(\mathrm{CH}_{3} \mathrm{OH}\right)$ and only in gas $\left(\mathrm{N}_{2} \mathrm{H}^{+}\right)$. Therefore, the results obtained in this work and in Paper I can be used as reference for the deuteration process of any other species formed potentially both in the gas and on dust grains. In Sect. 2 we present the
Table 1. Observed sources.

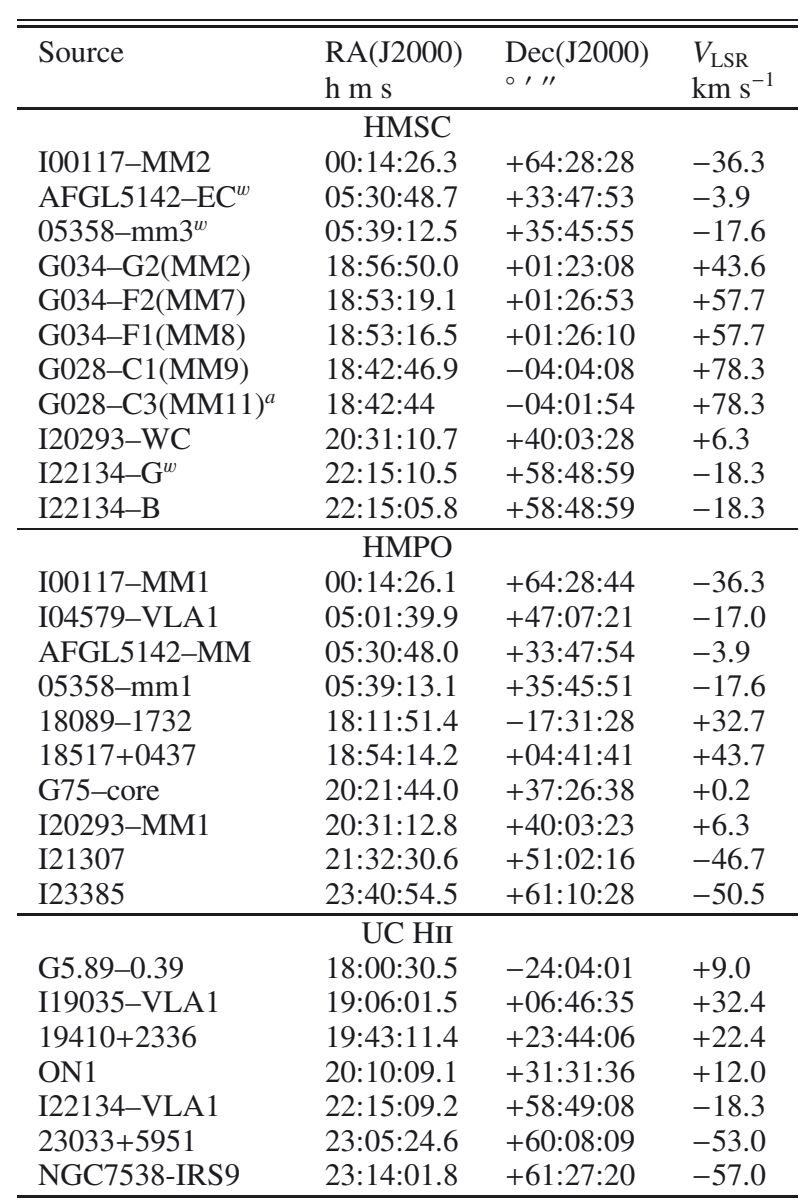

Notes. Column 4 shows the velocity at which we centred the spectra, corresponding to the systemic velocity. More information (e.g. source distances, bolometric luminosities of the associated star forming regions, reference papers) are given in Table A.1 of Paper I. ${ }^{(a)}$ Source not included in Paper I, selected from Butler \& Tan (2009). See also Butler et al. (2014); ${ }^{(w)}$ "warm" ( $\left.T \geq 20 \mathrm{~K}\right)$ HMSCs externally heated (see Paper I).

source sample and give an overview of the technical details of the observations. The main results are presented and discussed in Sects. 3 and 4, respectively. A summary with the main conclusions of the work is given in Sect. 5 .

\section{Source list, observations and data reduction}

\subsection{Source list}

We targeted the same sources as studied in Paper I, to avoid possible biases due to the source selection when comparing the deuterated fractions. Table 1 contains the list of the observed sources selected as explained briefly in Sect. 1. In particular, three HMSCs have been classified as "warm" cores because they show evidence of heating from external sources (see Paper I for details). More information extracted from the literature about the star-forming regions in which the sources lie are given in Table A.1 of Paper I. To the list of HMSCs reported in Paper I, we have added the source G028-C3, selected by applying the same selection criteria as for the other HMSCs. 
Table 2. Observed transitions and technical parameters.

\begin{tabular}{|c|c|c|c|c|c|}
\hline Molecular line & $\begin{array}{l}\text { Line rest frequency } \\
(\mathrm{GHz})\end{array}$ & $\begin{array}{l}H P B W \\
\left({ }^{\prime \prime}\right)\end{array}$ & $\begin{array}{c}\Delta v \\
\left(\mathrm{~km} \mathrm{~s}^{-1}\right)\end{array}$ & $\begin{array}{l}T_{\text {sys }} \\
(\mathrm{K})\end{array}$ & $\eta_{\mathrm{MB}}$ \\
\hline \multicolumn{6}{|c|}{ IRAM-30 m Telescope } \\
\hline ortho- $\mathrm{NH}_{2} \mathrm{D}\left(1_{1,1}-1_{0,1}\right)$ & 85.9263 & $\sim 28^{1}$ & 0.136 & $\sim 85-120$ & 0.85 \\
\hline para- $\mathrm{NH}_{2} \mathrm{D}\left(1_{1,1}-1_{0,1}\right)$ & 110.1536 & $\sim 22$ & 0.106 & $\sim 95-125$ & 0.83 \\
\hline $\mathrm{CH}_{3} \mathrm{OH}(3 \mathrm{~mm}$-band $)$ & $89.11-96.89^{a}$ & $27^{b}$ & $\sim 0.62^{c}$ & $\sim 100-120$ & 0.84 \\
\hline $\mathrm{CH}_{3} \mathrm{OH}(1 \mathrm{~mm}$-band $)$ & $216.0-223.78^{a}$ & $11^{b}$ & $\sim 0.26^{c}$ & $\sim 200-300$ & 0.66 \\
\hline \multicolumn{6}{|c|}{ Green Bank Telescope } \\
\hline $\mathrm{NH}_{3}(1,1)$ & 23.6945 & $\sim 32$ & $\sim 0.15$ & $\sim 50-100$ & $\sim 0.81$ \\
\hline $\mathrm{NH}_{3}(2,2)$ & 23.7226 & $\sim 32$ & $\sim 0.15$ & $\sim 50-100$ & $\sim 0.81$ \\
\hline
\end{tabular}

Notes. ${ }^{(a)}$ Total spectral window covered by the FTS correlator. Please see Tables B.1 and B.2 to see the transitions detected in it. ${ }^{(b)}$ Telescope HPBW at the central frequency of the spectral window. ${ }^{(c)}$ Maximum spectral resolution obtained with FTS.

\subsection{IRAM-30 m observations}

Run-1: towards all sources in Table 1, observations of the ortho- and para- $\mathrm{NH}_{2} \mathrm{D}\left(1_{1,1}-1_{0,1}\right)$ line were obtained simultaneously to the $\mathrm{N}_{2} \mathrm{D}^{+}$and $\mathrm{N}_{2} \mathrm{H}^{+}$observations described in Paper I. Table 2 lists the main observational parameters. We refer to Sect. 2 of Paper I for any other technical detail related to these observations.

Run-2: we performed $\mathrm{CH}_{3} \mathrm{OH}$ and $\mathrm{CH}_{2} \mathrm{DOH}$ observations towards all sources observed in Paper I from 6 to 9 February 2013. We simultaneously observed two bands at 3 and $1.3 \mathrm{~mm}$, covering some important rotational transitions of $\mathrm{CH}_{3} \mathrm{OH}$, ${ }^{13} \mathrm{CH}_{3} \mathrm{OH}$ and $\mathrm{CH}_{2} \mathrm{DOH}$. Table 2 presents the observed spectral windows and some main technical observational parameters. The atmospheric conditions were very stable during the whole observing period, with precipitable water vapour usually below $\sim 2 \mathrm{~mm}$. The observations were made in wobblerswitching mode. Pointing was checked almost every hour on nearby quasars or bright HII regions. The data were calibrated with the chopper wheel technique (see Kutner \& Ulich 1981), with a calibration uncertainty of $\sim 20 \%$. The spectra were obtained in antenna temperature units, $T_{\mathrm{A}}^{*}$, and then converted to main beam brightness temperature, $T_{\mathrm{MB}}$, via the relation $T_{\mathrm{A}}^{*}=T_{\mathrm{MB}}\left(B_{\text {eff }} / F_{\text {eff }}\right)$. The spectra were obtained with the fast Fourier transform spectrometers (FTS), thereby providing a broad band of $\sim 8 \mathrm{GHz}$ simultaneously at 3 and $1.3 \mathrm{~mm}$ (see Table 2 for details). All calibrated spectra were analysed using the GILDAS ${ }^{1}$ software developed at the IRAM and the Observatoire de Grenoble. The rest frequencies used for the line identification have been taken from the Cologne Molecular Database for Spectroscopy ${ }^{2}$ (CDMS; Müller et al. 2001, 2005)

\subsection{GBT observations}

The ammonia $(1,1)$ and $(2,2)$ inversion transitions (rest frequencies 23.6944955 and $23.7226336 \mathrm{GHz}$, respectively) were observed with the $100 \mathrm{~m}$ Robert C. Byrd Green Bank Telescope ${ }^{3}$ (GBT) during 13 and 21 March and 4 and 21 April 2013. The GBT spectrometer backend was configured to simultaneously observe the two transitions in separate spectral windows, using

\footnotetext{
1 The GILDAS software is available at http://www.iram.fr/ IRAMFR/GILDAS

2 http://www. astro.uni-koeln.de/cdms

3 The National Radio Astronomy Observatory is a facility of the National Science Foundation operated under cooperative agreement by Associated Universities, Inc.
}

bands of $50 \mathrm{MHz}$ and spectral resolution of $12.2070 \mathrm{kHz}$, which corresponds to $0.154 \mathrm{~km} \mathrm{~s}^{-1}$ for both lines. The main observational parameters are listed in Table 2. The data were taken using in-band frequency switching with a throw of 7.5 MHz. The beam FWHM was approximately $32^{\prime \prime}$. The pointing was checked at hourly intervals on a nearby quasar, with corrections approximately $2^{\prime \prime}-3$ ". Flux calibration was performed on $3 \mathrm{C} 123$ and NGC 7027. The absolute flux accuracy is $10 \%$ to $20 \%$. Data reduction and calibrations were done using the GBTIDL ${ }^{4}$ package and subsequently converted to CLASS format.

\section{Results and derivation of physical parameters}

\section{1. $\mathrm{NH}_{3}$ and $\mathrm{NH}_{2} \mathrm{D}$}

\subsubsection{Detection summary and parameters derived directly from the fits}

$\mathrm{NH}_{3}$ : the $\mathrm{NH}_{3}(1,1)$ and $(2,2)$ inversion lines were detected with excellent signal-to-noise ratio in all sources observed. The spectra of all HMSCs, HMPOs, and UC HIIs are shown in Figs. A.1-A.3, respectively. Both transitions consist of 18 hyperfine components, grouped in five lines: the main one at the centre of the spectrum, and four satellites symmetrically placed in frequency with respect to the main one (see Ho \& Townes 1983 for details). The spectra have been fit considering this hyperfine structure when the satellites are detected. When they are not, we adopted a simplified approach in which we fitted the main line with a Gaussian curve. This simplified method was used for eight of the $(2,2)$ spectra observed, in which the satellites have not been detected. The fit procedure has given good results (with very low residuals, see Figs. A.1-A.3) using both methods. The simplified approach tends to overestimate the intrinsic line width, because the main line is in reality a blending of several hyperfine components. To quantify this, we have taken a $(2,2)$ spectrum with hyperfine structure fit nicely (one spectrum per evolutionary group), applied the simplified method, and compared the derived line width with the one obtained from the accurate method (the hyperfine fit method). From this comparison, we quantify an overestimate of at most the $10 \%$ of the true intrinsic line width. Nevertheless, because the column density in this approach is computed from the integral of the line (see Sects. 3.1.2 and 3.1.3), this overestimation does not influence the calculation of either the column density or the deuterated fraction.

4 GBTIDL is an interactive package for reducing and analysing spectral line data taken with the GBT. See http://gbtidl .nrao. edu/ 
The line parameters derived from these fit procedures are listed in Tables 3 and 4. The accurate method has given a well-constrained value of the optical depth of the main component of the $(1,1)$ line $\left(\tau_{\mathrm{m}}(1,1) / \Delta \tau_{\mathrm{m}}(1,1) \geq 3\right)$ for all objects except for I04579-VLA1, in which the line is optically thin. The average $\tau_{\mathrm{m}}(1,1)$ is $\sim 1$ with no significant differences between the three evolutionary groups, while $\tau_{\mathrm{m}}(2,2)$ is usually smaller than 1 . The average line widths of the $(1,1)$ lines are $\sim 1.7, \sim 2.3$, and $\sim 2.6 \mathrm{~km} \mathrm{~s}^{-1}$ for the HMSC, HMPO, and UC HII groups (standard deviations $0.5,0.6$, and $0.7 \mathrm{~km} \mathrm{~s}^{-1}$, respectively), and tend to increase with evolution, as expected (Sánchez-Monge et al. 2013).

$\mathrm{NH}_{2} \mathrm{D}$ : the ortho- $\mathrm{NH}_{2} \mathrm{D}\left(1_{1,1}-1_{0,1}\right)$ line has been detected in all the observed sources except in two HMPOs (I04579-VLA1 and I21307). The detection rate is thus $\sim 92 \%$. The para$\mathrm{NH}_{2} \mathrm{D}\left(1_{1,1}-1_{0,1}\right)$ line has been detected in 13 out of 26 sources observed (detection rate of $50 \%$ ). The spectra of both lines are shown in Figs. A.4 and A.5. In this work we use the ortho$\mathrm{NH}_{2} \mathrm{D}\left(1_{1,1}-1_{0,1}\right)$ line to derive the physical parameters of our interest because of its higher detection rate and signal-to-noise ratio. The line of the para- species will be used to test whether the ortho-/para- ratio assumed to derive the total column density in Sect. 3.1.3 is correct. Like ammonia, the $\mathrm{NH}_{2} \mathrm{D}$ lines have been fit by taking their hyperfine structure driven by the quadrupole moment of the deuterium and nitrogen nuclei into account (see Olberg et al. 1985, for details).

In general, the procedure has provided good fits to the spectra, except in a few cases in which deviations from the LTE (symmetric) pattern are seen (e.g. G028-C1, I20293-WC, I20293-MM1, 23033+5951, see Fig. A.4). To check if (and how) our simplified local thermodynamic equilibrium (LTE) approach gives results that are different from those of a non-LTE analysis, we ran the non-LTE radiative transfer code RADEX $^{5}$ (Van der Tak et al. 2007) in order to reproduce the measured line ratios of the two lines (ortho- $\mathrm{NH}_{2} \mathrm{D}$ and para- $\mathrm{NH}_{2} \mathrm{D}$ ). The molecular data were taken from the LAMDA database (Schöier et al. 2005) using the collisional rate coefficients with $\mathrm{H}_{2}$ of Daniel et al. (2014). We built grids of models with kinetic temperatures in the range $8-25 \mathrm{~K}, \mathrm{H}_{2}$ volume densities in the range $10^{3}-10^{8} \mathrm{~cm}^{-3}$, and total column densities of $10^{12}-10^{15} \mathrm{~cm}^{-2}$. We assumed line width of $1.5 \mathrm{~km} \mathrm{~s}^{-1}$ and an ortho-to-para- ratio of 3 . The "best estimate" of the column densities that we find are roughly consistent with the values measured from the LTE approach, but since we only have one line ratio, we cannot properly distinguish between the different nonLTE models. Therefore, with only one line ratio, all we can say is that the column densities of $\mathrm{NH}_{2} \mathrm{D}$ derived assuming LTE conditions are consistent with the values expected from a non-LTE approach.

The average optical depth of the main hyperfine component derived from this fitting procedure is about one in all three evolutionary groups. For the sources for which the mentioned fitting procedure did not give good results (because of poor signal-to-noise ratio), we fit the lines with Gaussians. As for the $\mathrm{NH}_{3}$ lines, this simplified method could overestimate the line widths by at most $\sim 10 \%$, and we find yet an increasing trend of the line widths going from the HMSC phase to the HMPO and UC HII phases, for which mean values (and standard deviations) are: $1.4(0.6), 2.5(1.3)$ and $2.4(1) \mathrm{km} \mathrm{s}^{-1}$, respectively. All line parameters are listed in Table 5.

\footnotetext{
5 http://www. sron.rug.nl/ vdtak/radex/
}

\subsection{2. $\mathrm{NH}_{3}$ rotation temperature and total column density}

From the $\mathrm{NH}_{3}(1,1)$ and $(2,2)$ line parameters, we obtained rotation temperatures, $T_{\text {rot }}$, adopting two methods: for the nine sources having $\tau_{(2,2)} / \Delta \tau_{(2,2)} \geq 3$ and $\tau_{(2,2)}>0.1$, we have first derived the excitation temperature of the $(1,1)$ and $(2,2)$ lines ( $T_{\mathrm{ex} 1,1}$ and $T_{\mathrm{ex} 2,2}$, respectively) independently using Eq. (A.2) of Busquet et al. (2009), and, from these, the column densities of the two levels, $N_{(2,2)}$ and $N_{(1,1)}$, from the relations given in Anglada et al. (1995). Although Eq. (A.2) in Busquet et al. (2009) is derived for the $(1,1)$ line, it is also valid for the $(2,2)$ line given the small difference in frequency between the two transitions. Then, the rotation temperature has been derived from the relation:

$T_{\text {rot }}=\frac{-41.5}{\ln \left[(3 / 5)\left(N_{(2,2)} / N_{(1,1)}\right)\right]}$.

For sources with an optically thin $(2,2)$ line, or with $\tau_{(2,2)}$ not determined because the satellites are undetected, $T_{\text {ex } 2,2}$ is assumed to be equal to $T_{\mathrm{ex} 1,1}$. This hypothesis is justified by the good agreement between the two excitation temperatures in the sources in which they can both be measured (see Sect. 4.2). Under this assumption, we have applied Eq. (A.4) in Busquet et al. (2009), which utilizes the peak intensity of the main hyperfine component of the $(2,2)$ line.

In both methods, the total $\mathrm{NH}_{3}$ column density, $N\left(\mathrm{NH}_{3}\right)$, has been calculated from Eq. (A.6) in Busquet et al. (2009). Both $T_{\text {rot }}$ and $N\left(\mathrm{NH}_{3}\right)$ are listed in Table 7 . Rotation temperatures range from 11.7 to $29 \mathrm{~K}$, and on average they are $\sim 17, \sim 22$, and $\sim 22 \mathrm{~K}$ for HMSCs, HMPOs, and UC HIIs, respectively (standard deviations are 2.6, 3.5, and $4 \mathrm{~K}$, respectively). Separately, quiescent and "warm" HMSCs have mean temperatures of 16 and $20 \mathrm{~K}$ (standard deviations of 2.6 and $1.2 \mathrm{~K}$, respectively), which confirms the higher gas temperature in the "warm" cores. Total $\mathrm{NH}_{3}$ column densities range from $5.6 \times 10^{13}$ to $3.6 \times 10^{15} \mathrm{~cm}^{-2}$, and the average values are $9.4 \times 10^{14}, 9.3 \times 10^{14}$ and $1.6 \times$ $10^{15} \mathrm{~cm}^{-2}$ in the HMSC, HMPO and UC HII groups, respectively. We assumed a filling factor of one because available VLA interferometer ammonia maps of some of the targets show that the ammonia emission is extended and fills most of the GBT beam. Nevertheless, we stress that the emission from the target cores is clearly dominant with respect to the emission of nearby condensations (see Sanchez-Monge et al. 2013).

\subsection{3. $\mathrm{NH}_{2} \mathrm{D}$ total column density}

The $\mathrm{NH}_{2} \mathrm{D}$ column densities were computed from the line parameters of the ortho- $\mathrm{NH}_{2} \mathrm{D}$ line following Eq. (1) in Busquet et al. (2010), which assumes the same $T_{\mathrm{ex}}$ for all the hyperfine components. The value of $T_{\text {ex }}$ was computed as described in Sect. 3.1.2 for sources where the opacity of the main component is well-constrained. For the others, we have assumed $T_{\mathrm{ex}}=$ $7.5 \mathrm{~K}$, which is the average value derived from the sources with well-constrained opacity and obtained the column density from Eq. (A4) of Caselli et al. (2002), which is valid for optically thin lines.

Again, we assumed a unity filling factor because there are few high angular resolution observations of this line towards the targets from which the emitting region of $\mathrm{NH}_{2} \mathrm{D}$ can be determined. This assumption is critical, since the ortho- $\mathrm{NH}_{2} \mathrm{D}$ line has a critical density of $\sim 10^{6} \mathrm{~cm}^{-3}$, so higher than that of the inversion transitions of $\mathrm{NH}_{3}\left(\sim 10^{3-4} \mathrm{~cm}^{-3}\right)$. However, while by neglecting the beam dilution the absolute values of the column densities can certainly be affected, the evolutionary trend of the 
F. Fontani et al.: Deuteration in massive star formation

Table 7. Rotation temperatures, total column densities of $\mathrm{NH}_{3}$ and $\mathrm{NH}_{2} \mathrm{D}$, and ammonia deuterated fraction derived as explained in Sect. 3.1 .

\begin{tabular}{|c|c|c|c|c|}
\hline Source & $\begin{array}{l}T_{\text {rot }} \\
(\mathrm{K})\end{array}$ & $\begin{array}{l}N_{\mathrm{NH}_{3}} \\
\left(\times 10^{14} \mathrm{~cm}^{-2}\right)\end{array}$ & $\begin{array}{l}N_{\mathrm{NH}_{2} \mathrm{D}} \\
\left(\times 10^{14} \mathrm{~cm}^{-2}\right)\end{array}$ & $D_{\text {frac }}\left(\mathrm{NH}_{3}\right)$ \\
\hline $\begin{array}{l}\text { I00117-MM2 } \\
\text { AFGL5142-EC } \\
\text { 05358-mm3 } \\
\text { G034-G2 } \\
\text { G034-F2 } \\
\text { G034-F1 } \\
\text { G028-C1 } \\
\text { G028-C3 } \\
\text { I20293-WC } \\
\text { I22134-G } \\
\text { I22134-B } \\
\end{array}$ & $\begin{array}{l}17.9(0.6) \\
20(1) \\
21.1(0.3) \\
15.2(0.4) \\
-^{a} \\
-^{a} \\
17.7(0.3) \\
11.7(0.4) \\
19.4(0.4) \\
18.2(0.4) \\
14.9(0.5) \\
\end{array}$ & \begin{tabular}{l}
\multicolumn{1}{c}{ HMSCs } \\
$4.22(0.06)$ \\
$10.39(0.03)$ \\
$9.27(0.02)$ \\
$12.12(0.04)$ \\
$-^{a}$ \\
$-^{a}$ \\
$20.70(0.02)$ \\
$8.29(0.04)$ \\
$13.96(0.02)$ \\
$2.98(0.06)$ \\
$2.76(0.06)$ \\
\end{tabular} & $\begin{array}{l}2.62(0.05) \\
4.31(0.07) \\
4.62(0.07) \\
2.40(0.02) \\
2.1(0.02) \\
0.12(0.02) \\
0.47(0.03) \\
0.07(0.02) \\
0.78(0.02) \\
0.12(0.03) \\
0.16(0.01) \\
\end{array}$ & $\begin{array}{l}0.62(0.02) \\
0.41(0.01) \\
0.498(0.008) \\
0.198(0.002) \\
- \\
- \\
0.023(0.002) \\
0.009(0.004) \\
0.519(0.002) \\
0.04(0.01) \\
0.057(0.005) \\
\end{array}$ \\
\hline $\begin{array}{l}\text { I00117-MM1 } \\
\text { I04579-VLA1 } \\
\text { AFGL5142-MM } \\
05358-m m 1 \\
\text { 18089-1732 } \\
\text { 18517+0437 } \\
\text { G75-core } \\
\text { I20293-MM1 } \\
\text { I21307 } \\
\text { I23385 }\end{array}$ & $\begin{array}{l}16.4(0.7) \\
20(2) \\
21.5(0.5) \\
21.6(0.3) \\
28(1) \\
22(1) \\
26.9(0.6) \\
17(1) \\
20(1) \\
23(1) \\
\end{array}$ & \begin{tabular}{l}
\multicolumn{1}{c}{ HMPOs } \\
$2.05(0.05)$ \\
$0.56(0.03)$ \\
$10.65(0.02)$ \\
$8.53(0.03)$ \\
$35.55(0.02)$ \\
$5.32(0.05)$ \\
$8.94(0.07)$ \\
$15.82(0.03)$ \\
$2.99(0.05)$ \\
$2.53(0.05)$ \\
\end{tabular} & $\begin{array}{l}0.24(0.04) \\
\leq 0.06 \\
5.50(0.08) \\
1.63(0.07) \\
9.1(0.1) \\
7.3(0.1) \\
0.19(0.04) \\
3.07(0.02) \\
\leq 0.05 \\
0.09(0.03)\end{array}$ & $\begin{array}{l}0.12(0.02) \\
\leq 0.1 \\
0.516(0.008) \\
0.191(0.008) \\
0.255(0.003) \\
1.37(0.03) \\
0.022(0.005) \\
0.194(0.002) \\
\leq 0.02 \\
0.04(0.01) \\
\end{array}$ \\
\hline $\begin{array}{l}\text { G5.89-0.39 } \\
\text { I19035-VLA1 } \\
19410+2336 \\
\text { ON1 } \\
\text { I22134-VLA1 } \\
\text { 23033+5951 } \\
\text { NGC7538-IRS9 }\end{array}$ & $\begin{array}{l}29.0(0.3) \\
24(1) \\
18.7(0.2) \\
21.4(0.7) \\
-^{a} \\
16.4(0.2) \\
20.4(0.2)\end{array}$ & $\begin{array}{l}\text { UC HIIs } \\
17.06(0.04) \\
12.67(0.05) \\
13.47(0.05) \\
36.58(0.03) \\
-^{a} \\
10.10(0.07) \\
7.23(0.06)\end{array}$ & $\begin{array}{l}12.0(0.5) \\
0.40(0.04) \\
2.2(0.03) \\
4.57(0.08) \\
0.08(0.02) \\
2.37(0.07) \\
0.10(0.04)\end{array}$ & $\begin{array}{l}0.71(0.03) \\
0.031(0.003) \\
0.165(0.002) \\
0.125(0.002) \\
- \\
0.234(0.009) \\
0.014(0.005)\end{array}$ \\
\hline
\end{tabular}

Notes. ${ }^{(a)}$ Not observed.

column density ratio should not be affected by this assumption because the beam dilution is expected to be almost constant, and it should thus introduce only a systematic correction (see also Paper I). Also, observations at high angular resolution towards massive star forming regions (Busquet et al. 2010; Pillai et al. 2011) indicate that the emission of $\mathrm{NH}_{2} \mathrm{D}$ can be as extended as that of $\mathrm{NH}_{3}$, despite the different critical density. For example, the emitting regions of $\mathrm{NH}_{2} \mathrm{D}\left(1_{1,1}-1_{0,1}\right)$ and $\mathrm{NH}_{3}(1,1)$ in I20293-WC and I20293-MM1, both included in our survey, are approximately the same (Busquet et al. 2010). $N\left(\mathrm{NH}_{2} \mathrm{D}\right)$ is listed in Table 7.

\subsection{Methanol and deuterated methanol lines}

We focus the attention on the deuterated fraction of $\mathrm{CH}_{3} \mathrm{OH}$ and on the physical quantities relevant to deriving it (i.e. temperature and total column density). Therefore, in what follows we present the approach we adopted to identify the lines from which $D_{\text {frac }}\left(\mathrm{CH}_{3} \mathrm{OH}\right)$ will be derived (Sect. 3.2.1), the method for computing rotation temperature and total column density from the line parameters (Sect. 3.2.2), and the deuterated fraction in the sources detected in $\mathrm{CH}_{2} \mathrm{DOH}$ (Sect. 4.4).

\subsubsection{Lines detected and fit procedure}

Multiple $\mathrm{CH}_{3} \mathrm{OH}$ lines are detected in the observed spectral windows (Col. 1 of Table 2) towards all sources, while ${ }^{13} \mathrm{CH}_{3} \mathrm{OH}$ lines are clearly detected in four HMSCs, seven HMPOs, and six UC HII regions. $\mathrm{CH}_{2} \mathrm{DOH}$ lines are detected towards 6 objects only, three HMSCs and three HMPOs, and two out of the three HMSCs are "warm" cores (see Sect. 2). Moreover, in two HMPOs (AFGL5142-MM and 18089-1732), the $\mathrm{CH}_{3} \mathrm{OD}$ $\left(5_{1,5}-4_{1,4} \mathrm{~A}++\right)$ line at $1.3 \mathrm{~mm}$ has been detected, although in 18089-1732 this could be blended with emission of $\left(\mathrm{CH}_{2} \mathrm{OH}\right)_{2}$. Tables B.1 and B.2 give the line parameters obtained from Gaussian fits to the lines detected at the $3 \sigma$ level and not probably blended with other transitions.

The detection of the deuterated lines was double-checked by comparing observed and synthetic spectra. For this purpose, the observed spectra were smoothed to $1.0 \mathrm{~km} \mathrm{~s}^{-1}$ at $1 \mathrm{~mm}$ and to $2.5 \mathrm{~km} \mathrm{~s}^{-1}$ at $3 \mathrm{~mm}$, to improve the signal-to-noise ratio. The $\mathrm{CH}_{2} \mathrm{DOH}$ synthetic spectra were computed by assuming LTE and optically thin emission as in Palau et al. (2011) and using the molecular data from the Jet Propulsion Laboratory (Pickett et al. 1998). To build the synthetic spectra, we adopted a line width of $1.5 \mathrm{~km} \mathrm{~s}^{-1}$ at $1 \mathrm{~mm}$ and $2.5 \mathrm{~km} \mathrm{~s}^{-1}$ at $3 \mathrm{~mm}$ and used the rotational temperature listed in Table 8 derived from $\mathrm{CH}_{3} \mathrm{OH}$. Examples of the synthetic spectra of $\mathrm{CH} 2 \mathrm{DOH}$ overplotted on the observed spectra are shown in Fig. 1. The figure shows that several transitions are (marginally) detected at $1 \mathrm{~mm}$ in each of the four cases shown.

\subsubsection{Derivation of molecular column densities and rotation temperatures}

From the line parameters in Tables B.1 and B.2, we derived rotation temperature $\left(T_{\text {rot }}\right)$ and total column densities, $N$, of 


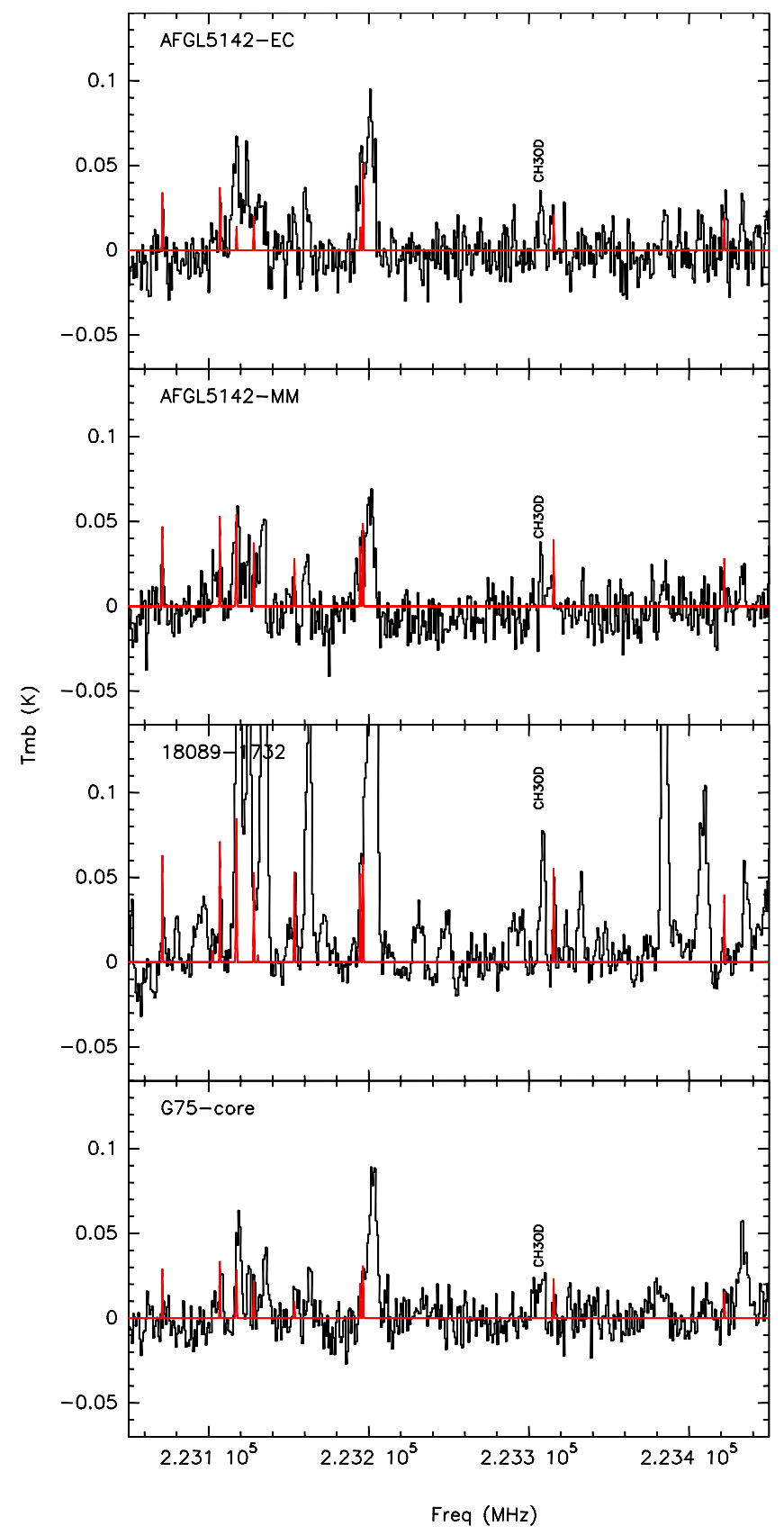

Fig. 1. Example of spectra observed at $1 \mathrm{~mm}$ with the $\mathrm{CH}_{2} \mathrm{DOH}$ synthetic spectra (red line) used for the identification of the deuterated methanol lines superimposed on them.

$\mathrm{CH}_{3} \mathrm{OH},{ }^{13} \mathrm{CH}_{3} \mathrm{OH}$ and $\mathrm{CH}_{2} \mathrm{DOH}$ from the rotation diagram method. As an example, in Fig. 2 we show the rotation diagrams obtained for 18089-1732. We included all rotation diagrams in Appendix C. The method was applied when the number of transitions detected was sufficient to build a "reliable" rotation diagram: for example, we rejected the results obtained from this method for sources in which rotation diagrams provide meaningless negative temperatures or for objects in which a few lines associated with large uncertainties and/or similar energy of the upper levels have been detected. Specifically, for $\mathrm{CH}_{2} \mathrm{DOH}$ the rotation diagram method has given acceptable results for only two sources, AFGL5142-MM and 18089-1732. However, because in AFGL5142-MM we only have two lines, and in 18089-1732 the fit results are not very accurate (bottom panel in Fig. 2), the column densities have also been derived
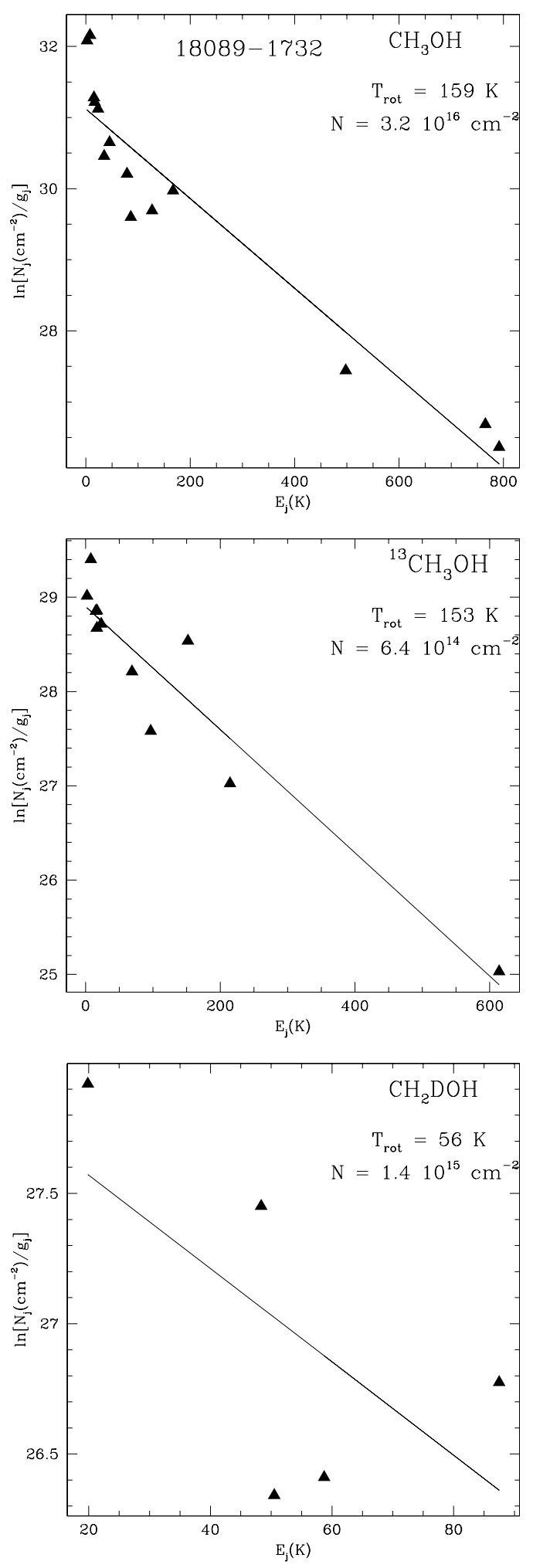

Fig. 2. Rotation diagrams obtained for 18089-1732 from lines of $\mathrm{CH}_{3} \mathrm{OH},{ }^{13} \mathrm{CH}_{3} \mathrm{OH}$ and $\mathrm{CH}_{2} \mathrm{DOH}$ (from top to bottom). Derived rotation temperatures and total column densities are shown in the top right corner of each panel.

from Eq. (A4) of Caselli et al. (2002), taking the strongest line detected and assuming the gas temperature equal to $T_{\text {rot }}$ derived from $\mathrm{CH}_{3} \mathrm{OH}$.

For ${ }^{13} \mathrm{CH}_{3} \mathrm{OH}$, we assumed that all transitions are optically thin; for $\mathrm{CH}_{3} \mathrm{OH}$, we first derived a rough estimate of the opacity by comparing two identical lines (specifically, we 
compared the $2_{(-1,2)}-1_{(-1,1)}$ and the $2_{(0,2)}-1_{(0,1)}$ transitions) of $\mathrm{CH}_{3} \mathrm{OH}$ and ${ }^{13} \mathrm{CH}_{3} \mathrm{OH}$ and assumed an LTE abundance ratio of $\left[{ }^{12} \mathrm{C}\right] /\left[{ }^{13} \mathrm{C}\right]=77$ (Wilson \& Rood 1994). From this check, we derived low opacities (values below 1) in all sources, so that we decided to compute $N$ and $T_{\text {rot }}$ assuming optically thin conditions too. As for $\mathrm{NH}_{3}$ and $\mathrm{NH}_{2} \mathrm{D}$, the source sizes of $\mathrm{CH}_{3} \mathrm{OH}$ and $\mathrm{CH}_{2} \mathrm{DOH}$ are unknown, but they are expected to be smaller than the beam size and to have a comparable extent, based on observations at high angular resolution in Orion (Peng et al. 2012). Therefore, to take the beam dilution into account, the column densities in the rotation diagrams were corrected by assuming the same source sizes as in Paper I, namely 6.5, 4.1, and 5.5" for HMSCs, HMPOs, and UC HIIs, assuming that methanol and its deuterated forms trace approximately the same material. This is a reasonable general assumption from a theoretical point of view if deuterated methanol is formed from methanol through $\mathrm{H}-\mathrm{D}$ substitution reactions on dust grains. In principle, $\mathrm{CH}_{2} \mathrm{DOH}$ could be formed following other pathways, but the $\mathrm{H}-\mathrm{D}$ substitution reaction on solid ices remains the most efficient one (Nagaoka et al. 2005). Moreover, because of the lack of direct measurements in the cores, assuming a different source size for methanol and their deuterated forms would be an arbitrary choice not supported by observations.

For the deuterated species for which only one line is detected, and for sources in which $N\left({ }^{13} \mathrm{CH}_{3} \mathrm{OH}\right)$ cannot be derived from rotation diagrams, we derived $N$ using Eq. (A4) of Caselli et al. (2002) from one transition only assuming optically thin conditions and adopting the rotation temperature derived from $\mathrm{CH}_{3} \mathrm{OH}$, available in all sources as excitation temperature. The partition functions of all species have been calculated from the approximated expressions valid for asymmetric rotors provided, e.g., in Ratajczak et al. (2011; see also Parise 2004). The results of this analysis are presented in Table 8.

\section{Discussion}

\subsection{The ortho-/para- ratio of $\mathrm{NH}_{2} \mathrm{D}$}

The total column density of $\mathrm{NH}_{2} \mathrm{D}$ has been derived from lines of ortho- $\mathrm{NH}_{2} \mathrm{D}$ taking the statistical ortho-/para- ratio (3:1) into account. In the sources also detected in the para- $\mathrm{NH}_{2} \mathrm{D}$ line at $\sim 110 \mathrm{GHz}$ (see Fig. A.5), we have verified whether the assumption is correct: First, we fitted the hyperfine structure of the para- $\mathrm{NH}_{2} \mathrm{D}$ line, and found that all detected lines are optically thin. Because most of the detected ortho- $\mathrm{NH}_{2} \mathrm{D}$ lines are either optically thin or have $\tau \leq 1$, we decided to compare the integrated areas of the two transitions under the channels with signal. These are reported in Table 6 . As we see, the ratio $\int T_{\mathrm{MB}} \mathrm{d} v[o] / \int T_{\mathrm{MB}} \mathrm{d} v[p]$ is consistent with three within the errors in most of the sources: the mean value is 2.6 , with standard deviation 0.6 , hence consistent with three.

Shah \& Wootten (2001) have found similar results in a sample of protostellar cores, in which they compare the integrated intensity of the same two transitions and derived a mean value of the ortho-/para- ratio of 3.2 (with a larger standard deviation of 1.3). Comparable values have also been found by Pillai et al. (2007) in infrared dark clouds and by Tiné et al. (2000) in the two dark molecular clouds L134N and TMC1.

\section{2. $\mathrm{NH}_{3}$ and $\mathrm{NH}_{2} \mathrm{D}$ excitation temperatures}

The excitation temperatures of the three lines examined in the previous sections have very similar mean values: $7.8,8.2$

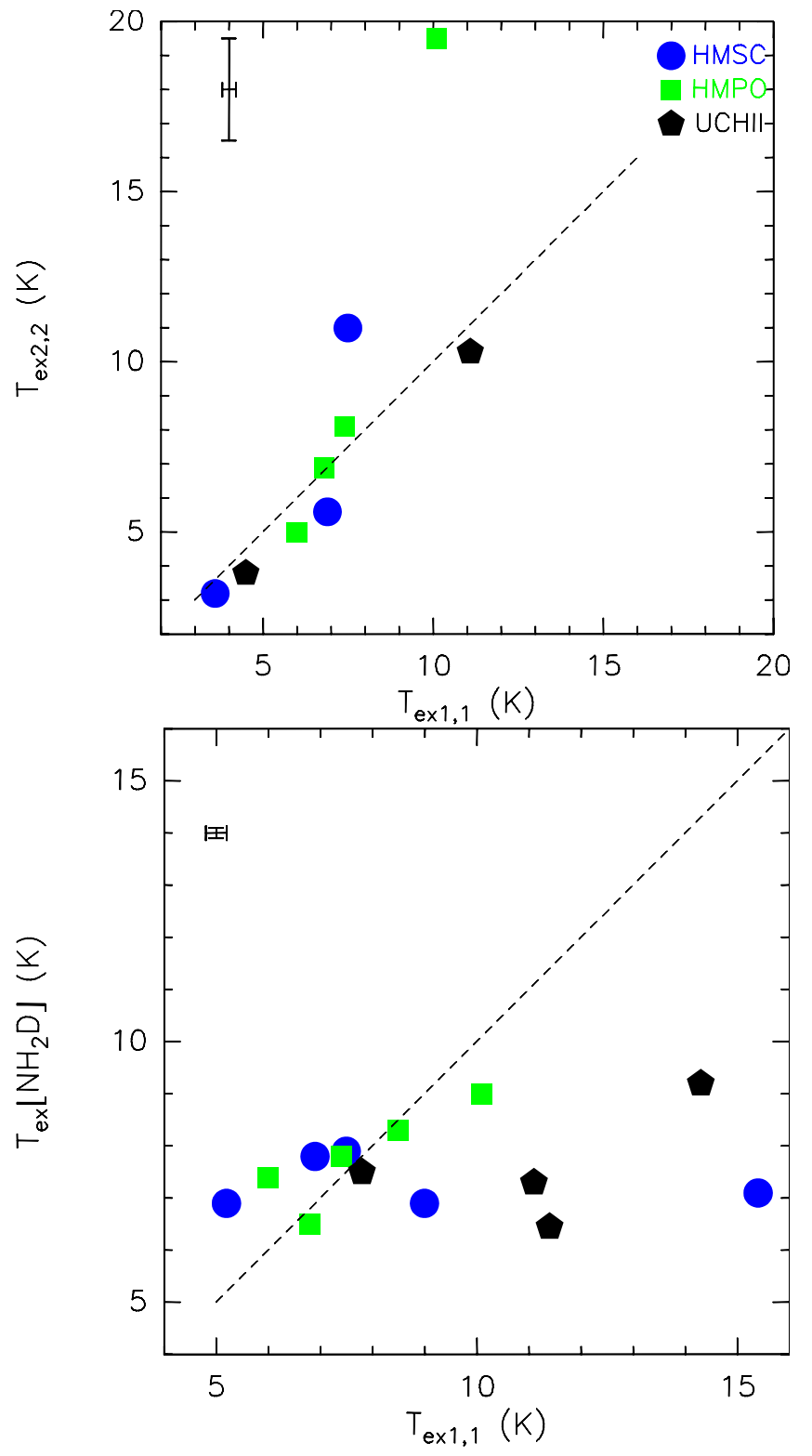

Fig. 3. Comparison between the excitation temperatures of $\mathrm{NH}_{3}(1,1)$, $T_{\mathrm{ex} 1,1}$ and both $T_{\mathrm{ex} 2,2}$ (upper panel) and $T_{\mathrm{ex}}$ of the ortho- $\mathrm{NH}_{2} \mathrm{D}$ line (lower panel). In both panels, blue circles correspond to HMSCs, green squares show HMPOs, black pentagons correspond to UC HII regions, and the dashed line indicates $y=x$. Typical error bars are indicated in the top left corner of each panel.

and $7.5 \mathrm{~K}$ for $\mathrm{NH}_{3}(1,1), \mathrm{NH}_{3}(2,2)$ and ortho- $\mathrm{NH}_{2} \mathrm{D}$, respectively. The $\mathrm{NH}_{3}(1,1)$ and $(2,2)$ lines are also well correlated (see upper panel of Fig. 3), while the excitation temperatures of the ortho- $\mathrm{NH}_{2} \mathrm{D}$ line and of $\mathrm{NH}_{3}(1,1)$ are not correlated owing to the different dispersion around the average values: in fact, $T_{\mathrm{ex}}$ of $\mathrm{NH}_{3}(1,1)$ spans a range from $\sim 3.5 \mathrm{~K}$ to $15 \mathrm{~K}$, while $T_{\text {ex }}$ of the ortho- $\mathrm{NH}_{2} \mathrm{D}$ lines is distributed tightly around the average value. This may indicate either that ortho- $\mathrm{NH}_{2} \mathrm{D}$ is in sub-thermal conditions, as suggested by the asymmetric pattern of the hyperfine structure observed in some spectra (see Sect. 3.1.1), or to our neglect of the correction for beam dilution. The former hypothesis seems plausible for the ortho- $\mathrm{NH}_{2} \mathrm{D}$ line, which has a high critical density $\left(\sim 10^{6} \mathrm{~cm}^{-3}\right)$. About the possible different beam dilution: as stated in Sect. 3.1.3, in the few cores in which both $\mathrm{NH}_{3}(1,1)$ and ortho- $\mathrm{NH}_{2} \mathrm{D}\left(1_{-1,1}-1_{0,1}\right)$ have been mapped 


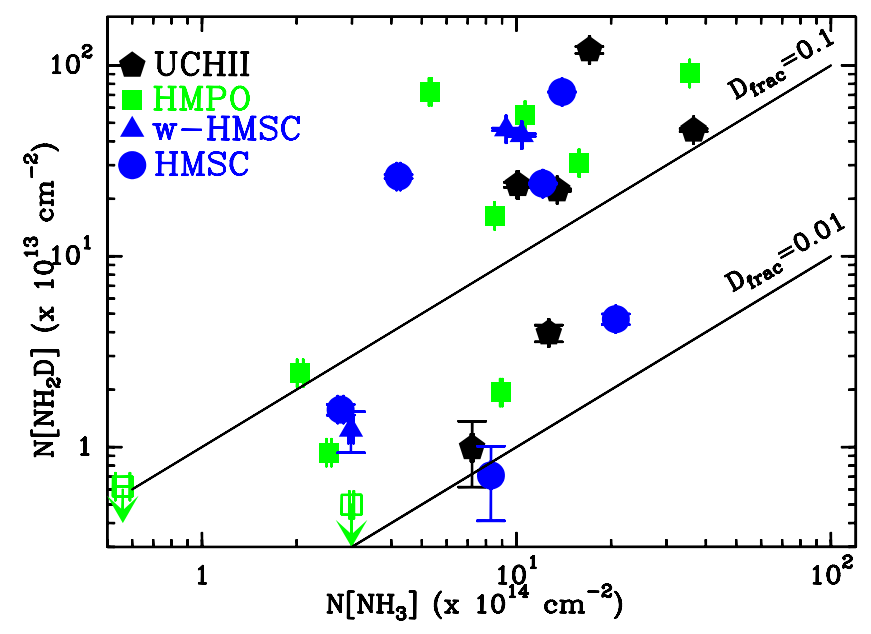

Fig. 4. Comparison between the total column density of $\mathrm{NH}_{2} \mathrm{D}$, $N\left(\mathrm{NH}_{2} \mathrm{D}\right.$ ), and $\mathrm{NH}_{3}, N\left(\mathrm{NH}_{3}\right)$. Blue symbols correspond to HMSCs (triangles: warm cores, see Sect. 2); green squares show HMPOs (open squares are upper limits); black pentagons correspond to UC HII regions. In most cases, the error bars are barely visible because comparable to (or smaller than) the size of the symbol. The straight lines represent the loci of $D_{\text {frac }}\left(\mathrm{NH}_{3}\right)=0.01$ and 0.1 .

at high angular resolution, the emissions have comparable extensions, despite the different critical densities. Therefore, subthermal conditions of the ortho- $\mathrm{NH}_{2} \mathrm{D}$ lines seem the most likely explanation of the different excitation temperatures.

\subsection{Deuterated fraction of $\mathrm{NH}_{3}$}

By dividing $N\left(\mathrm{NH}_{2} \mathrm{D}\right)$ for $N\left(\mathrm{NH}_{3}\right)$, we computed $D_{\text {frac }}\left(\mathrm{NH}_{3}\right)$. The three parameters are given in Table 7 . The average values of $D_{\text {frac }}\left(\mathrm{NH}_{3}\right)$ for HMSCs, HMPOs, and UC HIIs are $0.26(0.23$ if one excludes the "warm" HMSCs, see Sect. 2), 0.34, and 0.21, respectively. These values are consistent with those obtained by Pillai et al. (2007) in a sample of infrared-dark clouds, for which, however, the evolutionary stage of the embedded sources has not been determined. The mean $D_{\text {frac }}\left(\mathrm{NH}_{3}\right)$ is thus at the maximum in the HMPO stage, although the large disperion of the data does not allow finding a statistical difference between the three groups. This is apparent in Fig. 4, where we compare the total column densities of $\mathrm{NH}_{2} \mathrm{D}$ and $\mathrm{NH}_{3}$ : the plot shows that the three groups are not clearly separated. Kolmogorov-Smirnov tests applied to the data confirm that the difference is not statistically significant. If one compares Fig. 4 with the same plot in Paper I for $\mathrm{N}_{2} \mathrm{H}^{+}$, we note clearly that, unlike $D_{\text {frac }}\left(\mathrm{N}_{2} \mathrm{H}^{+}\right), D_{\text {frac }}\left(\mathrm{NH}_{3}\right)$ does not decrease with core evolution. Thus, it is not a tracer of pre-protostellar or young protostellar objects, because it keeps above 0.1 even in the evolved stage of UC HII region. Moreover, because the deuteration in the gas-phase for both $\mathrm{N}_{2} \mathrm{H}^{+}$and $\mathrm{NH}_{3}$ is linked to $\mathrm{H}_{2} \mathrm{D}^{+}$, our results would confirm that the formation of $\mathrm{NH}_{2} \mathrm{D}$ is largely influenced by surface chemistry.

Furthermore, $D_{\text {frac }}\left(\mathrm{NH}_{3}\right)$ does not show any clear anticorrelation with the typical indicators of evolution. This is suggested by Figs. 5 and 6 , where we plot $D_{\text {frac }}\left(\mathrm{NH}_{3}\right)$ against the gas temperature and the line widths of the $(1,1)$ transition, both known to increase with time (e.g., Sánchez-Monge et al. 2013): by applying statistical tests, we even find that $D_{\text {frac }}\left(\mathrm{NH}_{3}\right)$ could be slightly correlated with both the ammonia rotation temperature (Pearson's linear correlation coefficient $\rho \sim 0.2$ ) and line widths (Pearson's linear correlation coefficient $\rho \sim 0.4$ ). In

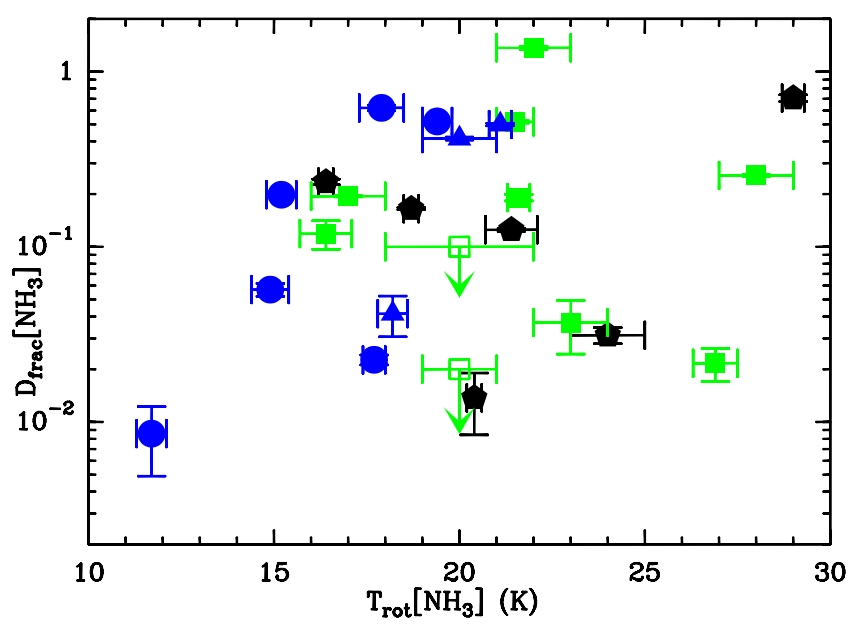

Fig. 5. $D_{\text {frac }}\left(\mathrm{NH}_{3}\right)$ against the ammonia rotation temperature. The symbols have the same meaning as in Fig. 4. No clear (anti-)correlation is found between the two parameters. In some cases, the error bars are barely visible because comparable to (or smaller than) the size of the symbol.

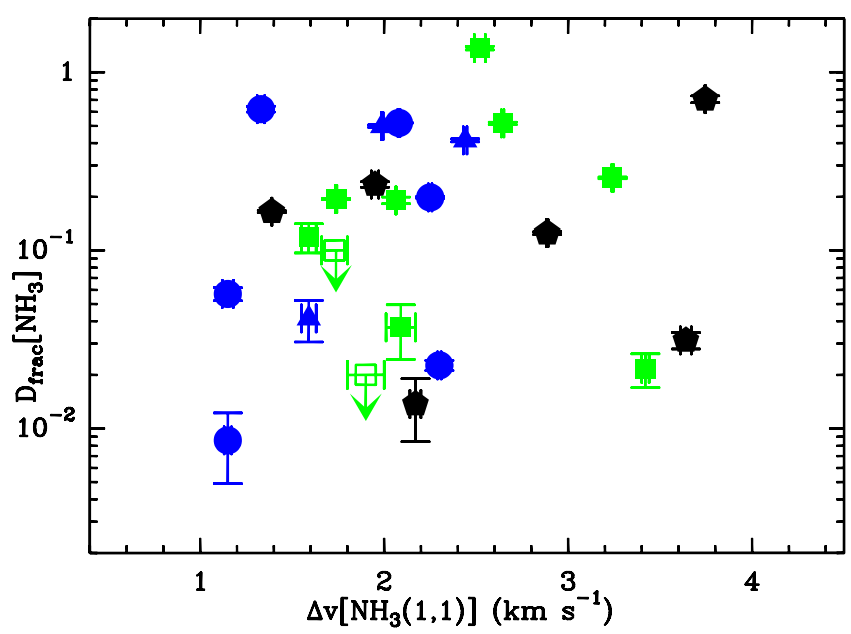

Fig. 6. $D_{\text {frac }}\left(\mathrm{NH}_{3}\right)$ against the $\mathrm{NH}_{3}(1,1)$ line width. The symbols have the same meaning as in Fig. 4. No clear (anti-)correlation is found between the two parameters, like in Fig. 5. The error bars are barely visible because comparable to (or smaller than) the size of the symbol.

contrast, $D_{\text {frac }}\left(\mathrm{N}_{2} \mathrm{H}^{+}\right)$is anti-correlated with both parameters, as shown in Fig. 2 of Paper I. We stress, however, that the $p$-value (measure of the probability of chance correlation) is 0.12 for $D_{\text {frac }}\left(\mathrm{NH}_{3}\right)$ vs. $T_{\text {rot }}$ and 0.22 for $D_{\text {frac }}\left(\mathrm{NH}_{3}\right)$ vs. $\Delta v(1,1)$. Therefore, because the significance level under which one can reject the null hypothesis is typically $p \sim 0.1$, both correlations are very weak from a statistical point of view. Nevertheless, the relevant result provided by Figs. 5 and 6 is the absence of anticorrelation, contrary to what found for $D_{\text {frac }}\left(\mathrm{N}_{2} \mathrm{H}^{+}\right)$.

\subsection{Deuterated fraction of methanol}

In the six objects detected in $\mathrm{CH}_{2} \mathrm{DOH}$, we computed $D_{\text {frac }}\left(\mathrm{CH}_{3} \mathrm{OH}\right)=N\left(\mathrm{CH}_{2} \mathrm{DOH}\right) / N\left(\mathrm{CH}_{3} \mathrm{OH}\right)$. The results are listed in the last column of Table 8 . The average $D_{\text {frac }}\left(\mathrm{CH}_{3} \mathrm{OH}\right)$ in the three HMPOs detected is $\sim 0.04$ if one uses $N\left(\mathrm{CH}_{2} \mathrm{DOH}\right)$ derived from rotation diagrams, and $\sim 0.01$ if we use the 
simplified approach from only one line (see Sect. 3.2.2). In the two "warm" HMSCs is $\sim 0.0025$. G034-G2 is the unique quiescent $\mathrm{HMSC}$ detected in $\mathrm{CH}_{2} \mathrm{DOH}$, and in this core $D_{\text {frac }}\left(\mathrm{CH}_{3} \mathrm{OH}\right)$ is $\sim 0.015$. For the cores undetected in $\mathrm{CH}_{2} \mathrm{DOH}$, the large majority of the targets observed, we have estimated upper limits of $D_{\text {frac }}\left(\mathrm{CH}_{3} \mathrm{OH}\right)$ in this way: we computed the $3 \sigma$ level in the spectrum of the $\left(2_{0,2}-1_{0,1}\right) \mathrm{e} 0$ line, which is the transition with the lowest energy of the upper level $\left(E_{\mathrm{u}} \sim 6.5 \mathrm{~K}\right)$ at $3 \mathrm{~mm}$, and estimated the upper limit to the integrated area from the relation $\int T_{\mathrm{MB}} \mathrm{d} v=3 \sigma \frac{\Delta V}{2 \sqrt{\ln 2 / \pi}}$, valid for a Gaussian line having peak temperature $=3 \sigma$. We assumed $\Delta V=1 \mathrm{~km} \mathrm{~s}^{-1}$, which is the average value of the detected $\mathrm{CH}_{2} \mathrm{DOH}$ lines both in the HMSCs and the HMPOs (see Table B.1); then, the upper limit on the $\mathrm{CH}_{2} \mathrm{DOH}$ column density was computed using the same equations as for the detected sources. We followed the same method so as to compute the upper limits on the ${ }^{13} \mathrm{CH}_{3} \mathrm{OH}$ lines, using this time the $\left(2_{0,2}-1_{0,1}++\right)$ line.

The case of the HMSC G034-G2 is quite peculiar, because it is the only quiescent starless core detected in $\mathrm{CH}_{2} \mathrm{DOH}$ (in one line only), and its $D_{\text {frac }}\left(\mathrm{CH}_{3} \mathrm{OH}\right)$ exceeds 0.01 , while the upper limits found in the other quiescent HMSCs are lower. Its detection is thus quite doubtful. We checked for possible contamination from other species by running synthetic spectra (see Sect. 3.2.1) of molecules that possess transitions at a similar frequency, and concluded that indeed contributions from lines of $\mathrm{CH}_{3} \mathrm{OOH}$, and $\mathrm{HCCCH}_{2} \mathrm{OH}$ are possible. Therefore, this detection remains doubtful.

Although the number of detections is low, and the results are affected by the faintness of the $\mathrm{CH}_{2} \mathrm{DOH}$ lines, these findings suggest that high values of $D_{\text {frac }}\left(\mathrm{CH}_{3} \mathrm{OH}\right)$ tend to be associated with "warm" HMSCs and HMPOs rather than with cores that are very young (quiescent HMSCs) or evolved (UC HIIs), although the remarkable value derived in G034-G2 (if confirmed) suggests that the story could not be so simple. Parise et al. (2006) measured values of $D_{\text {frac }}\left(\mathrm{CH}_{3} \mathrm{OH}\right)$ higher than ours by at least an order of magnitude in a sample of low-mass protostellar cores. Nevertheless, due to the higher linear resolution of their observations (most of their cores are in Perseus, at a distance of $\sim 200 \mathrm{pc}$ ), their measurements should be less affected than ours by non-deuterated gas along the line of sight. Moreover, our $D_{\text {frac }}\left(\mathrm{CH}_{3} \mathrm{OH}\right)$ are consistent with the upper limits found by Loinard et al. (2003) in high-mass protostellar objects (where, however, they observed $\mathrm{D}_{2} \mathrm{CO}$ and derived $\left[\mathrm{D}_{2} \mathrm{CO}\right] /\left[\mathrm{H}_{2} \mathrm{CO}\right]<$ $0.5 \%$ ), as well as with observations of deuterated methanol in the intermediate-mass protostar NGC 7129-FIRS2 (Fuente et al. 2014) and in Orion BN/KL (Peng et al. 2012).

\subsection{Deuteration and core evolution: the role of surface chemistry}

In Fig. 7 we report the mean values of $D_{\text {frac }}$ obtained in HMSCs, HMPOs and UC HIIs for the four molecular species investigated so far towards our source sample: $\mathrm{N}_{2} \mathrm{H}^{+}$(Paper I), HNC (Paper II), $\mathrm{NH}_{3}$ and $\mathrm{CH}_{3} \mathrm{OH}$ (this work). We show the values derived for quiescent HMSCs and "warm" HMSCs separately to underline the effect of nearby star formation. We also include the mean values (with standard deviation) of the ammonia rotation temperatures derived in this work to highlight a possible (anti-)correlation between $D_{\text {frac }}$ and gas temperature. Inspection of Fig. 7 leads to these immediate results: (i) only $D_{\text {frac }}\left(\mathrm{N}_{2} \mathrm{H}^{+}\right)$ shows a net decrease from the HMSC stage to the HMPO stage, associated to a temperature enhancement; (ii) $D_{\text {frac }}\left(\mathrm{NH}_{3}\right)$ remains nearly constant in all stages; (iii) $D_{\text {frac }}\left(\mathrm{CH}_{3} \mathrm{OH}\right)$ is at its

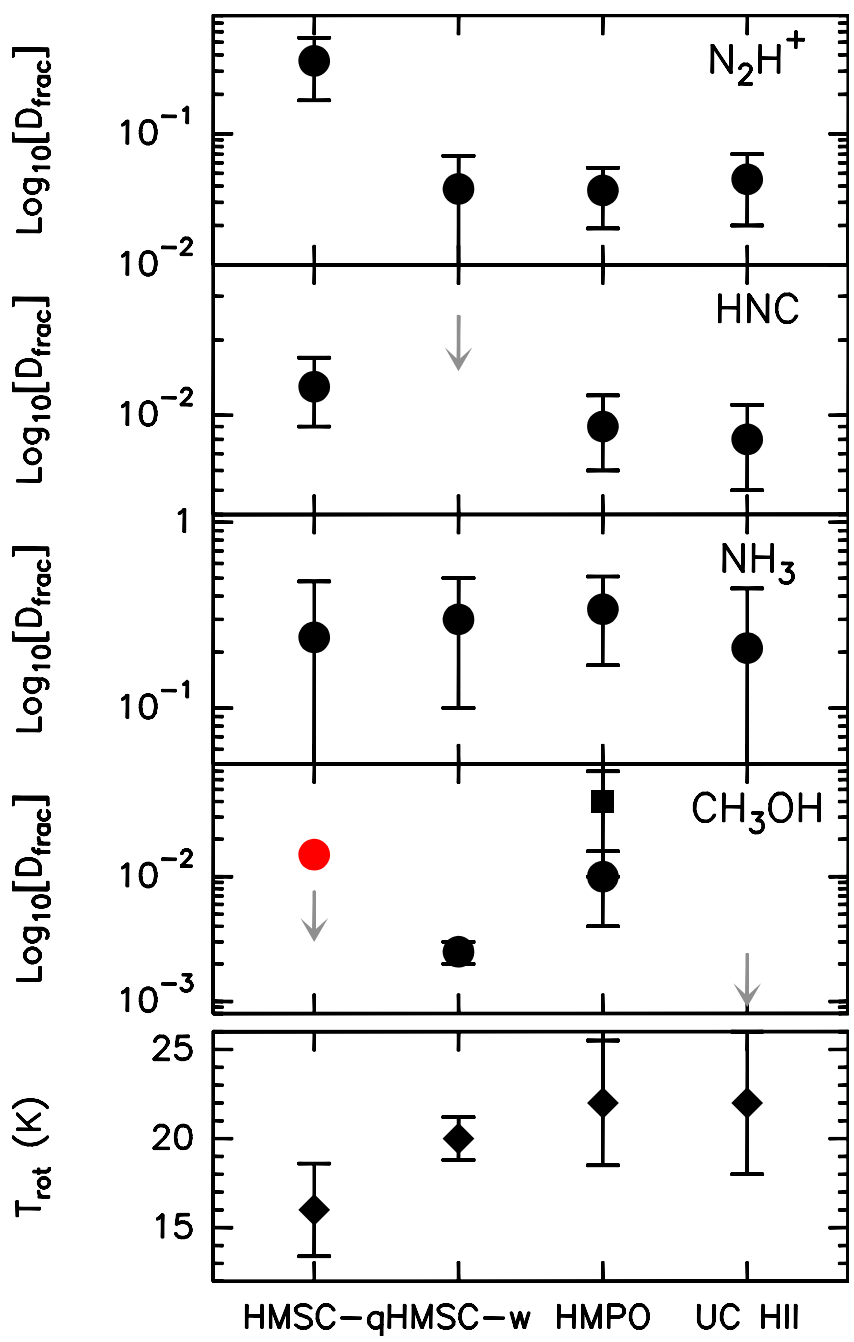

Fig. 7. Panels one to four, from top: comparison between the mean deuterated fractions (black dots) of $\mathrm{N}_{2} \mathrm{H}^{+}$(first panel, Paper I), HNC (second panel, Paper II) $\mathrm{NH}_{3}$ and $\mathrm{CH}_{3} \mathrm{OH}$ (third and fourth panels, this work). The mean values have been computed for each evolutionary group. Quiescent HMSCs (HMSC-q) and warm HMSCs (HMSC-w) have been treated separately. The error bars indicate the standard deviation. The grey arrows represent mean upper limits for those evolutionary groups in which no sources have been detected. The red dot in the fourth panel represents the doubtful $\mathrm{CH}_{2} \mathrm{DOH}$ detection in G034G2 (see Sect. 4.4), while the square indicates the mean $D_{\text {frac }}$ of HMPOs when $N\left(\mathrm{CH}_{2} \mathrm{DOH}\right)$ is derived from rotation diagrams for AFGL5142$\mathrm{MM}$ and 18089-732. Bottom panel: mean rotation temperatures (filled diamonds) derived from ammonia in the four groups (see Table 7).

maximum in the HMPO stage, although this result must be interpreted carefully due to the low number of detections and the caveats on the methods to derive $D_{\text {frac }}$ (see Sects. 3.2.2); (iv) the behaviour of $D_{\text {frac }}(\mathrm{HNC})$ is something in between $D_{\text {frac }}\left(\mathrm{N}_{2} \mathrm{H}^{+}\right)$ and $D_{\text {frac }}\left(\mathrm{NH}_{3}\right)$, because its maximum value is found in the HMSC phase, like $D_{\text {frac }}\left(\mathrm{N}_{2} \mathrm{H}^{+}\right)$, but the statistically significant decrease when going to the HMPO stage is not seen. In Paper II we have already discussed this difference, and attributed it to a slower process of destroying DNC into the warm gas with respect to $\mathrm{N}_{2} \mathrm{D}^{+}$.

As stated in Sect. 1, $D_{\text {frac }}\left(\mathrm{N}_{2} \mathrm{H}^{+}\right)$and $D_{\text {frac }}\left(\mathrm{CH}_{3} \mathrm{OH}\right)$ should represent the two "extreme" situations where deuteration can occur: only in the gas and only on grain mantles, respectively. In the classical framework, both ammonia and methanol (and 
their deuterated isotopologues) are produced efficiently on grain mantles during the pre-stellar phase through hydrogenation of $\mathrm{N}$ and CO, respectively. Specifically, hydrogenation of CO sequentially forms formaldehyde first and then methanol: thus, as time proceeds, the formation of methanol and their deuterated isotopologues is boosted, until the energy released by the nascent protostellar object in the form of radiation increases the temperature of its environment, causing the evaporation of the grain mantles and the release of these molecules into the gas. As the temperature increases and the protostar evolves towards the UC HII region phase, the deuterated species are expected to be gradually destroyed because of the higher efficiency of the backward endothermic reactions (see Caselli \& Ceccarelli 2012, for a review). The trends shown in Fig. 7 are consistent with this classic framework, and they clearly show that high deuterated fractions of ammonia cannot be used as an evolutionary indicator of a high-mass star-forming core. On the other hand, $D_{\text {frac }}\left(\mathrm{CH}_{3} \mathrm{OH}\right)$ may potentially be a tracer of the very early stages of the protostellar evolution, where the evaporation or sputtering of the grain mantles is most efficient. Our results, however, suffer from statistics that are too low and need to be reinforced by other observations of deuterated methanol at higher sensitivity.

Chemical models of low-mass star-forming cores predict how the abundance of several deuterated species varies during the evolution, including the amount formed on ices during the early cold phase (e.g. Taquet et al. 2012; Aikawa et al. 2012). Aikawa et al. (2012) show that the relative abundance ratios $\left[\mathrm{NH}_{2} \mathrm{D}\right] /\left[\mathrm{NH}_{3}\right]$ and $\left[\mathrm{CH}_{2} \mathrm{DOH}\right] /\left[\mathrm{CH}_{3} \mathrm{OH}\right]$ in the ices during the pre-stellar phase are both in between 0.01 and 0.1 . These values are consistent with the $D_{\text {frac }}\left(\mathrm{CH}_{3} \mathrm{OH}\right)$ measured in this work, and they confirm that methanol and its deuterated forms are products of the evaporation of grain mantles. On the other hand, the $D_{\text {frac }}\left(\mathrm{NH}_{3}\right)$ measured in our work $(\geq 0.1)$ is larger than the values predicted on ices by Aikawa et al. (2012), suggesting that the emission we see must include a contribution from material formed through gas-phase reactions. Awad et al. (2014) modelled the deuterium chemistry of star-forming cores using both gas-phase and grain-surface reactions, but focus on the protostellar phase, when the evaporation of the icy mantles of dust grains is at its maximum. The model that best reproduces a HMPO predicts $D_{\text {frac }}\left(\mathrm{NH}_{3}\right) \sim 10^{-3}-10^{-2}$ and $D_{\text {frac }}\left(\mathrm{CH}_{3} \mathrm{OH}\right) \leq 4 \times 10^{-3}$, both of which are smaller than our observed values. However, the abundance of deuterated species strongly depends on the density of the gas: lower density cores have lower abundances of deuterated species, owing to a lower degree of CO depletion. Therefore, higher core densities could be able to reproduce the larger deuterated fractions that we measure.

In any case, the huge dispersion of the data does not allow us to derive firmer quantitative conclusions and push us to interpret any comparison with chemical models with caution. Moreover, the chemical models of Taquet et al. (2012) and Aikawa et al. (2012) neglect the spin states of the deuterated species, which can significantly influence the deuterium fractionation depending on the ortho-to-para $\mathrm{H}_{2}$ ratio (Flower et al. 2006). Nevertheless, the clearly different trends between $D_{\text {frac }}\left(\mathrm{NH}_{3}\right)$ and $D_{\text {frac }}\left(\mathrm{N}_{2} \mathrm{H}^{+}\right)$undoubtedly indicate that gasphase chemistry cannot play a dominant role in the production of $\mathrm{NH}_{2} \mathrm{D}$.

\section{Summary and conclusions}

The deuterated fraction of species that can be formed on dust grains (in part, like $\mathrm{NH}_{3}$, or uniquely, like $\mathrm{CH}_{3} \mathrm{OH}$ ) has been investigated towards a sample of dense cores harbouring different evolutionary stages of the high-mass star formation process. As expected, the deuterated fraction of these species and those of molecules totally or predominantly formed in the gas, such as $\mathrm{N}_{2} \mathrm{H}^{+}$and $\mathrm{HNC}$, evolve differently with time and with temperature: $D_{\text {frac }}\left(\mathrm{NH}_{3}\right)$ does not show statistically significant changes with evolution, unlike $D_{\text {frac }}\left(\mathrm{N}_{2} \mathrm{H}^{+}\right)$and $D_{\text {frac }}(\mathrm{HNC})$, which decrease (especially $D_{\text {frac }}\left(\mathrm{N}_{2} \mathrm{H}^{+}\right)$) when temperature increases. Very few lines of $\mathrm{CH}_{2} \mathrm{DOH}$ and $\mathrm{CH}_{3} \mathrm{OD}$ are clearly detected, and only towards protostellar cores or externally heated starless cores. Only one line of $\mathrm{CH}_{2} \mathrm{DOH}$ could have been detected in a quiescent starless core, but the detection is doubtful. No lines of deuterated methanol species are detected in UC HII regions. This work clearly supports the scenario in which the contribution of surface chemistry to the formation of deuterated forms of ammonia is relevant, hence $D_{\text {frac }}\left(\mathrm{N}_{2} \mathrm{H}^{+}\right)$remains the best indicator of massive starless cores. High values of $D_{\text {frac }}\left(\mathrm{CH}_{3} \mathrm{OH}\right)$ seem suitable to tracing the earliest protostellar phases, at which the evaporation or sputtering of the grain mantles is most efficient, but this result needs to be supported by further, higher sensitivity observations. The data presented in this work represent an excellent starting point for higher angular resolution studies to address further questions. In particular: if the various deuterated molecules are formed with different mechanisms, do we expect a different distribution of the emission, too?

Acknowledgements. F.F. and A.P. are grateful to the IRAM-30 m staff for their help with the observations at the IRAM-30 m telescope. G.B. is grateful to Amanda Kepley for her help during the GBT observations and to Jeff Magnum for providing the procedures for converting the GBT spectra from GBTIDL to CLASS format. A.P. acknowledges the financial support from UNAM, and CONACyT, México. G.B. is supported by the Spanish MICINN grant AYA200806189-C03-01 (co-funded with FEDER funds) and by the Italian Space Agency (ASI) fellowship under contract number I/005/07/01. P.C. acknowledges the financial support of the European Research Council (ERC; project PALs 320620). A.S.-M. is supported by the Deutsche Forschungsgemeinschaft (DFG) through the collaborative research grant SFB 956 "Conditions and Impact of Star Formation", project area A6. The research leading to these results has received funding from the European Commission Seventh Framework Programme (FP/2007-2013) under grant agreement Ną 283393 (RadioNet3).

\section{References}

Aikawa, Y., Herbst, E., Roberts, H., \& Caselli, P. 2005, ApJ, 620, 330 Aikawa, Y., Wakelam, V., Hersant, F., Garrod, R. T., \& Herbst, E. 2012, ApJ, 760,40

Anglada, G., Estalella, R., Mauersberger, R., et al. 1995, ApJ, 443, 682

Awad, Z., Viti, S., Bayet, E., \& Caselli, P. 2014, MNRAS, 443, 275

Beuther, H., Churchwell, E. B., McKee, C. F., \& Tan, J. C. 2007, in Protostars and Planets V, eds. B. Reipurth, D. Jewitt, \& K. Keil (Tucson: University of Arizona Press), 165

Busquet, G. 2010, Ph.D. Thesis, University of Barcelona

Busquet, G., Palau, A., Estalella, R., et al. 2009, A\&A, 506, 1183

Busquet, G., Palau, A., Estalella, R., et al. 2010, A\&A, 517, L6

Butler, M. J., \& Tan, J. C. 2009, ApJ, 696, 484

Butler, M. J., Tan, J. C., \& Kainulainen, J. 2014, ApJ, 782, L30

Caselli, P. 2002, P\&SS, 50, 1133

Caselli, P., \& Ceccarelli, C. 2012, A\&ARv, 20, 56

Caselli, P., Walmsley, C. M., Zucconi, A., et al. 2002, ApJ, 565, 344

Caselli, P., Vastel, C., Ceccarelli, C., et al. 2008, A\&A, 492, 703

Crapsi, A., Caselli, P., Walmsley, C. M., et al. 2005, ApJ, 619, 379

Daniel, F., Faure, A., Wiesenfeld, L., et al. 2014, MNRAS, 444, 2544

Emprechtinger, M., Caselli, P., Volgenau, N. H., Stutzki, J., \& Wiedner, M. C. 2009, A\&A, 493, 89

Flower, D. R., Pineau Des Forêts, G., \& Walmsley, C. M. 2006, A\&A, 449, 621

Fontani, F., Cesaroni, R., Testi, L., et al. 2004, A\&A, 414, 299

Fontani, F., Caselli, P., Crapsi, A., et al. 2006, A\&A, 460, 709

Fontani, F., Palau, Aina, Caselli, P., et al. 2011, A\&A, 529, L7

Fontani, F., Sakai, T., Furuya, K., et al. 2014, MNRAS, 440, 448

Fuente, A., Cernicharo, J., Caselli, P., et al. 2014, A\&A, 568, A65 
Garrod, R. T., Wakelam, V., \& Herbst, E. 2007, A\&A, 467, 1103 Gerlich, D., Herbst, E., \& Roueff, E. 2002, P\&SS, 50, 1275

Ho, P. T. P., \& Townes, C. H. 1983, ARA\&A, 21, 239

Kutner, M. L., \& Ulich, B. L. 1981, ApJ, 250, 341

Leurini, S., Rolffs, R., Thorwirth, S., et al. 2006, A\&A, 454, L47

Loinard, L., Castets, A., Ceccarelli, C., et al. 2003, in SFChem 2002: Chemistry as a Diagnostic of Star Formation, Proc. of a Conf. held August 21-23, 2002 at University of Waterloo, Ontario, Canada, 351

Miettinen, O., Hennemann, M., \& Linz, H. 2011, A\&A, 534, A134

Millar, T. J., Bennett, A., \& Herbst, E. 1989, ApJ, 340, 906

Müller, H. S. P., Thorwirth, S., Roth, D. A., \& Winnewisser, G. 2001, A\&A, 370, L49

Müller, H. S. P, Schlüder, F., Stutzki, J., \& Winnewisser, G. 2005, J. Mol. Struct., 742,215

Nagaoka, A., Watanabe, N., \& Kouchi, A. 2005, ApJ, 624, L29

Olberg, M., Bester, M., Rau, G., et al. 1985, A\&A, 142, L1

Oliveira, C. M., Hébrard, G., Howk, J. C., et al. 2003, ApJ, 587, 235

Palau, A., Fuente, A., Girart, J. M., et al. 2011, ApJ, 743, L32

Parise, B. 2004, Ph.D. Thesis, Centre d'Étude Spatiale des Rayonnements

Parise, B., Ceccarelli, C., Tielens, A. G. G. M., et al. 2002, A\&A, 393, L49

Parise, B., Ceccarelli, C., Tielens, A. G. G. M., et al. 2006, A\&A, 453, 949
Peng, T.-C., Despois, D., Brouillet, N., Parise, B., \& Baudry, A. 2012, A\&A, 543, A152

Pickett, H. M., Poynter, R. L., Cohen, E. A., et al. 1998, J. Quant. Spectr. Rad. Transf., 60, 883

Pillai, T., Wyrowski, F., Hatchell, J., Gibb, A. G., \& Thompson, M. A. 2007, A\&A, 467, 207

Pillai, T., Kauffmann, J., Wyrowski, F., et al. 2011, A\&A, 530, A118

Ratajczak, A., Taquet, V., Kahane, C., et al. 2011, A\&A, 528, L13

Sánchez-Monge, Á., Palau, A., Fontani, F., et al. 2013, MNRAS, 432, 3288

Sakai, T., Sakai, N., Furuya, K., et al. 2012, ApJ, 747, 140

Schöier, F. L., van der Tak, F. F. S., van Dishoeck, E. F., \& Black, J. H. 2005, A\&A, 432, 369

Shah, R. Y., \& Wootten, A. 2001, ApJ, 554, 933

Tan, J. C., Beltrán, M. T., Caselli, P., et al. 2014, in Protostars and Planets VI (University of Arizona Press), 149

Taquet, V., Ceccarelli, C., \& Kahane, C. 2012, ApJ, 748, L3

Tiné, S., Roueff, E., Falgarone, E., Gerin, M., \& Pineau des Forêts, G. 2000, A\&A, 356, 1039

van der Tak, F. F. S., Black, J. H., Schöier, F. L., Jansen, D. J., \& van Dishoeck, E. F. 2007, A\&A, 468, 627

Wilson, T. L., \& Rood, R. 1994, ARA\&A, 32, 191

Pages 12 to 34 are available in the electronic edition of the journal at http://www . aanda. org 
Table 3. Derived line parameters of $\mathrm{NH}_{3}(1,1)$.

\begin{tabular}{|c|c|c|c|c|c|}
\hline Source & $A \times \tau_{\mathrm{m}}(1,1)$ & $\begin{array}{c}V_{\text {peak }}(1,1) \\
\left(\mathrm{km} \mathrm{s}^{-1}\right)\end{array}$ & $\begin{array}{l}\Delta v(1,1) \\
\left(\mathrm{km} \mathrm{s}^{-1}\right)\end{array}$ & $\tau_{\mathrm{m}}(1,1)$ & $\begin{array}{c}T_{\text {ex } 1,1} \\
(\mathrm{~K})\end{array}$ \\
\hline \multicolumn{6}{|c|}{ HMSCs } \\
\hline I00117-MM2 & $1.83(0.06)$ & $-36.16(0.01)$ & $1.71(0.03)$ & $0.71(0.09)$ & $15(4)$ \\
\hline AFGL5142-EC & $3.69(0.03)$ & $-2.936(0.004)$ & $2.44(0.01)$ & $0.77(0.02)$ & $7.4(0.2)$ \\
\hline 05358-mm3 & $5.32(0.01)$ & $-16.258(0.004)$ & $1.989(0.005)$ & $0.85(0.01)$ & $8.86(0.07)$ \\
\hline G034-G2 & $3.68(0.04)$ & $41.854(0.007)$ & $2.25(0.01)$ & $1.52(0.04)$ & $5.0(0.1)$ \\
\hline G028-C1 & $2.69(0.01)$ & $79.810(0.007)$ & $2.30(0.01)$ & $2.50(0.07)$ & $3.67(0.05)$ \\
\hline G028-C3 & $2.89(0.08)$ & $80.858(0.007)$ & $1.15(0.02)$ & $1.9(0.1)$ & $4.1(0.2)$ \\
\hline I20293-WC & $5.46(0.02)$ & $6.419(0.004)$ & $2.080(0.006)$ & $1.31(0.01)$ & $6.76(0.07)$ \\
\hline I22134-G & $2.41(0.07)$ & $-18.643(0.006)$ & $1.33(0.02)$ & $0.40(0.07)$ & $9(2)$ \\
\hline I22134-B & $1.72(0.08)$ & $-18.800(0.01)$ & $1.15(0.03)$ & $0.6(0.1)$ & $5.4(0.9)$ \\
\hline \multicolumn{6}{|c|}{ HMPOs } \\
\hline I00117-MM1 & $1.59(0.03)$ & $-36.32(0.01)$ & $1.59(0.04)$ & $0.13(0.03)$ & $5.2(0.6)$ \\
\hline I04579-VLA1 & $0.272(0.01)$ & $-16.73(0.03)$ & $1.73(0.07)$ & $0.1^{c}$ & ${ }^{d} d$ \\
\hline AFGL5142-MM & $3.524(0.001)$ & $-3.072(0.002)$ & $2.644(0.007)$ & $0.75(0.01)$ & $7.28(0.01)$ \\
\hline 05358-mm1 & $4.636(0.003)$ & $-16.318(0.003)$ & $2.064(0.001)$ & $0.80(0.01)$ & $8.39(0.02)$ \\
\hline $18089-1732^{a}$ & $8.301(0.006)$ & $33.02(0.01)$ & $3.241(0.004)$ & $2.53(0.01)$ & $5.9(0.1)$ \\
\hline $18517+0437$ & $1.76(0.03)$ & $43.908(0.009)$ & $2.52(0.03)$ & $0.43(0.04)$ & $6.7(0.7)$ \\
\hline G75-core & $2.99(0.04)$ & $0.067(0.009)$ & $3.42(0.02)$ & $0.50(0.03)$ & $8.6(0.6)$ \\
\hline I20293-MM1 & $8.40(0.04)$ & $6.058(0.003)$ & $1.739(0.004)$ & $1.15(0.02)$ & $9.9(0.2)$ \\
\hline I21307 & $0.61(0.05)$ & $-46.57(0.04)$ & $1.9(0.1)$ & $0.8(0.2)$ & $3.4(0.5)$ \\
\hline $\mathrm{I} 23385^{b}$ & $0.84(0.03)$ & $-50.21(0.03)$ & $2.09(0.08)$ & $0.15(0.05)$ & $8(5)$ \\
\hline \multicolumn{6}{|c|}{ UC HIIs } \\
\hline G5.89-0.39 & $5.63(0.02)$ & $8.70(0.01)$ & $3.745(0.002)$ & $0.65(0.01)$ & $11.2(0.1)$ \\
\hline I19035-VLA1 & $1.90(0.03)$ & $32.56(0.01)$ & $3.64(0.03)$ & $1.08(0.05)$ & $4.4(0.2)$ \\
\hline $19410+2336$ & $12.054(0.005)$ & $22.458(0.001)$ & $1.389(0.001)$ & $1.05(0.01)$ & $14.12(0.02)$ \\
\hline ON1 & $13.25(0.02)$ & $10.985(0.001)$ & $2.886(0.005)$ & $1.58(0.01)$ & $10.98(0.02)$ \\
\hline $23033+5951$ & $4.96(0.07)$ & $-53.444(0.006)$ & $1.95(0.02)$ & $0.98(0.04)$ & $7.7(0.4)$ \\
\hline NGC7538-IRS9 & $3.94(0.04)$ & $-57.31(0.01)$ & $2.17(0.03)$ & $1.00(0.01)$ & $6.54(0.08)$ \\
\hline
\end{tabular}

Notes. All lines have been fit taking the hyperfine structure into account as explained in Sect. 3.1.1. Cols. $2-5$ report the output parameters of the fitting procedure $\left(A \times \tau_{\mathrm{m}}=f\left[J_{v}\left(T_{\mathrm{ex}}\right)-J_{v}\left(T_{\mathrm{BG}}\right)\right]\right.$, where $f$ is the filling factor, assumed to be unity, $J_{v}\left(T_{\mathrm{ex}}\right)$ and $J_{v}\left(T_{\mathrm{BG}}\right)$ are the equivalent Rayleigh-Jeans excitation and background temperatures, respectively, and $\tau_{\mathrm{m}}$ is the opacity of the main group of hyperfine components; $V_{\text {peak }}=$ peak velocity; $\Delta v=$ full width at half maximum corrected for hyperfine splitting; $\tau_{\mathrm{m}}=$ opacity of the main group of hyperfine components) for the $(1,1)$ line, and Col. 6 lists the excitation temperature of the transition derived as explained in Sect. 3.1.2. The uncertainties obtained from either the fitting procedure (parameters in Cols. 2-5) or from the propagation of errors (Col. 6) are in parentheses. ${ }^{(a)}$ The spectrum shows two velocity components (Fig. A.2). Only the fit to the stronger component is shown; ${ }^{(b)}$ The spectrum shows two velocity components (Fig. A.2). Fontani et al. (2004) also found these two components in $\mathrm{C}^{18} \mathrm{O}$ and attributed the one centred at $\sim-50 \mathrm{~km} \mathrm{~s}^{-1}$ to the HMPO. Only the fit to this component is shown; ${ }^{(c)}$ derived from the hyperfine fit procedure; ${ }^{(d)}$ an average value of $6.5 \mathrm{~K}$, computed from the HMPOs with well-constrained opacity, is assumed. 
Table 4. Same as Table 3 for the $\mathrm{NH}_{3}(2,2)$ transitions.

\begin{tabular}{|c|c|c|c|c|c|c|c|c|}
\hline & & $A \times \tau_{\mathrm{m}}(2,2)$ & $\underset{\left(\mathrm{K} \mathrm{km} \mathrm{s}^{-1}\right)}{\int_{\mathrm{MB}} \mathrm{d} v^{a}}$ & $\begin{array}{c}V_{\text {peak }}(2,2) \\
\left(\mathrm{km} \mathrm{s}^{-1}\right)\end{array}$ & $\begin{array}{l}\Delta v(2,2) \\
\left(\mathrm{km} \mathrm{s}^{-1}\right)\end{array}$ & $\tau_{\mathrm{m}}(2,2)$ & $\begin{array}{c}T_{\text {peak } 2,2}^{b} \\
(\mathrm{~K})\end{array}$ & $\begin{array}{c}T_{\mathrm{ex} 2,2} \\
(\mathrm{~K})\end{array}$ \\
\hline \multicolumn{9}{|c|}{ HMSCs } \\
\hline I00117-MM2 & $\mathrm{G}$ & & $0.91(0.04)$ & $-36.36(0.04)$ & $1.82(0.09)$ & & $0.47(0.04)$ & $-^{e}$ \\
\hline AFGL5142-EC & HFS & $1.73(0.06)$ & & $-2.972(0.007)$ & $2.73(0.03)$ & $0.21(0.07)$ & & $11(4)$ \\
\hline 05358-mm3 & $\mathrm{T}$ & $2.31(0.01)$ & & $-16.283(0.005)$ & $2.23(0.01)$ & 0.1 & $2.15(0.05)$ & $-^{e}$ \\
\hline G034-G2 & $\mathrm{T}$ & $0.67(0.02)$ & & $41.56(0.02)$ & $2.16(0.06)$ & 0.1 & $0.71(0.03)$ & $-^{e}$ \\
\hline G028-C1 & HFS & $0.57(0.07)$ & & 79.72(0.03) & $2.22(0.09)$ & $1.3(0.3)$ & & $3.0(0.3)$ \\
\hline G028-C3 & $\mathrm{G}$ & & $0.40(0.03)$ & $80.87(0.04)$ & $1.4(0.1)$ & & $0.27(0.02)$ & $e^{e}$ \\
\hline I20293-WC & HFS & $1.8(0.1)$ & & $6.34(0.02)$ & $2.29(0.05)$ & $0.6(0.2)$ & & $5(1)$ \\
\hline I22134-G & $\mathrm{G}$ & & $1.30(0.04)$ & $-18.81(0.02)$ & $1.50(0.05)$ & & $0.81(0.03)$ & $e^{e}$ \\
\hline I22134-B & $\mathrm{G}$ & & $0.55(0.04)$ & $-18.93(0.05)$ & $1.5(0.1)$ & & $0.35(0.02)$ & $-^{e}$ \\
\hline \multicolumn{9}{|c|}{ HMPOs } \\
\hline I00117-MM1 & $\mathrm{G}$ & & $0.97(0.04)$ & $-36.48(0.03)$ & $1.67(0.08)$ & & $0.54(0.04)$ & $-^{e}$ \\
\hline I04579-VLA1 & $\mathrm{G}$ & & $0.25(0.02)$ & $-16.85(0.08)$ & $1.9(0.2)$ & & $0.12(0.05)$ & $-^{e}$ \\
\hline AFGL5142-MM & HFS & $1.80(0.06)$ & & $-3.083(0.003)$ & $2.79(0.03)$ & $0.34(0.07)$ & & $8(1)$ \\
\hline 05358-mm1 & $\mathrm{T}$ & $2.078(0.008)$ & & $-16.334(0.001)$ & $2.27(0.01)$ & 0.1 & $1.96(0.05)$ & $e^{e}$ \\
\hline $18089-1732^{c}$ & HFS & $5.58(0.03)$ & & $32.85(0.01)$ & $3.14(0.02)$ & $2.48(0.02)$ & & $4.9(0.1)$ \\
\hline $18517+0437$ & HFS & $0.94(0.07)$ & & 43.77(0.02) & $2.58(0.07)$ & $0.24(0.08)$ & & $7(3)$ \\
\hline G75-core & $\mathrm{T}$ & $1.91(0.02)$ & & $-0.12(0.01)$ & $3.76(0.03)$ & 0.1 & $1.88(0.05)$ & $e^{e}$ \\
\hline I20293-MM1 & HFS & $2.6(0.1)$ & & $5.901(0.008)$ & $2.01(0.04)$ & $0.2(0.07)$ & & $20(5)$ \\
\hline I21307 & $\mathrm{G}$ & & $0.57(0.04)$ & $-46.71(0.08)$ & $2.35(0.21)$ & & $0.23(0.02)$ & $e^{e}$ \\
\hline $\mathrm{I} 23385^{d}$ & $\mathrm{G}$ & & $0.82(0.09)$ & $-50.5(0.1)$ & $1.9(0.2)$ & & $0.42(0.03)$ & $-^{e}$ \\
\hline \multicolumn{9}{|c|}{ UC HIIs } \\
\hline G5.89-0.39 & $\mathrm{T}$ & $3.62(0.01)$ & & $8.772(0.004)$ & $4.519(0.003)$ & 0.1 & $3.65(0.05)$ & $-^{e}$ \\
\hline I19035-VLA1 & HFS & $0.79(0.07)$ & & $32.53(0.03)$ & $3.9(0.1)$ & $0.7(0.2)$ & & $3.7(0.7)$ \\
\hline $19410+2336$ & $\mathrm{~T}$ & $4.22(0.02)$ & & $22.306(0.002)$ & $1.65(0.01)$ & 0.1 & $3.82(0.05)$ & $-^{e}$ \\
\hline ON1 & HFS & $6.1(0.1)$ & & $10.941(0.007)$ & $3.09(0.02)$ & $0.82(0.05)$ & & $10.2(0.8)$ \\
\hline $23033+5951$ & $\mathrm{~T}$ & $1.31(0.02)$ & & $-53.69(0.02)$ & $2.36(0.03)$ & 0.1 & $1.22(0.02)$ & $-^{e}$ \\
\hline NGC7538-IRS9 & $\mathrm{T}$ & $1.57(0.02)$ & & $-57.47(0.02)$ & $2.53(0.04)$ & 0.1 & $1.62(0.03)$ & $-^{e}$ \\
\hline
\end{tabular}

Notes. For the sources with "HFS" in Col. 2, the line's hyperfine structure has been fit, and the same output parameters in Cols. 2-6 of Table 3 are given in Cols. 3, 5, 6, 7, 9. For the sources with "G" in Col. 2, the satellites of the $(2,2)$ line are undetected, so that the main group of hyperfine components has been fit with a single Gaussian. For these objects, we give integrated area (in $\mathrm{K} \mathrm{km} \mathrm{s}^{-1}$, Col. 4) and peak intensity (in K, Col. 8) of this Gaussian, respectively. For the sources marked with a "T" in Col. 2, we clearly detect the satellites in the $(2,2)$ transition, and performed a good fit to the hyperfine structure, but the line is optically thin. In Col. 8 we also give the peak temperature of the main group of hyperfine components, which is the parameter used to derive the $\mathrm{NH}_{3}$ total column density in this case (see Sect. 3.1.2). The uncertainties of all parameters are in parentheses. ${ }^{(a)}$ Integrated area of the main group of hyperfine components, in $\mathrm{K} \mathrm{km} \mathrm{s}^{-1}$; ${ }^{(b)}$ peak intensity of the main group of hyperfine components, in $\mathrm{K} ;{ }^{(c)}$ the spectrum shows two velocity components (Fig. A.2). Only the fit to the stronger component is shown; ${ }^{(d)}$ the spectrum shows two velocity components (Fig. A.2). Fontani et al. (2004) also found these two components in $\mathrm{C}^{18} \mathrm{O}$ and attributed the one centred at $\sim-50 \mathrm{~km} \mathrm{~s}^{-1}$ to the HMPO. Only the fit to this component is shown. ${ }^{(e)} T_{\mathrm{ex} 2,2}$ cannot be estimated. For these objects, in the calculations described in Sect. 3.1.2 we have assumed $T_{\mathrm{ex} 2,2}=T_{\mathrm{ex} 1,1}$. 
Table 5. Derived line parameters of ortho- $\mathrm{NH}_{2} \mathrm{D}\left(1_{1,1}-1_{0,1}\right)$ for all sources observed in this line.

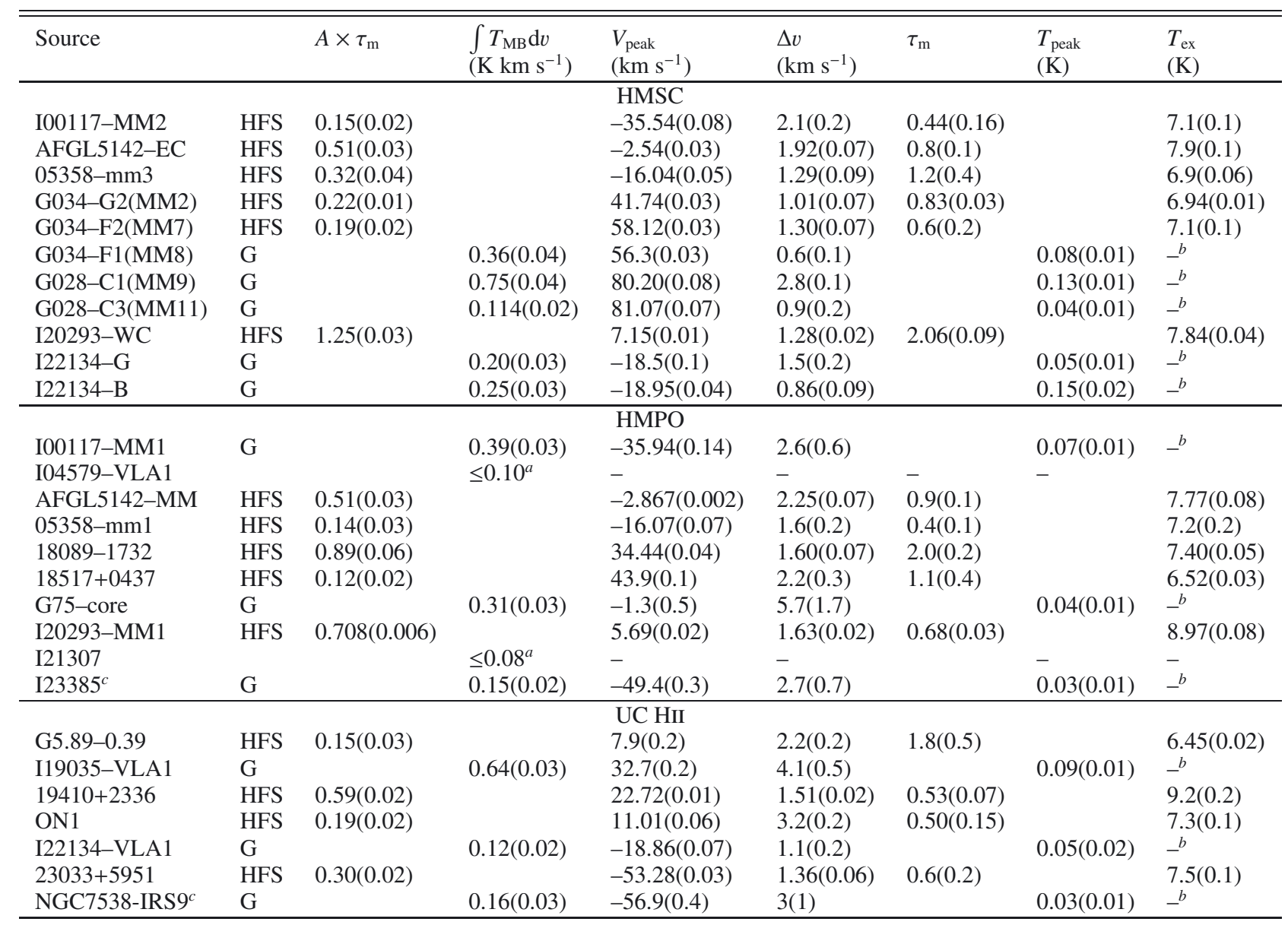

Notes. The spectra of the sources marked with a "HFS" in Col. 2 have been fit considering the hyperfine structure as described in Sect. 3.1.1. For these, Cols. 3, 5, 6 and 7 give $A \times \tau_{\mathrm{m}}$, peak velocity, line width, and $\tau_{\mathrm{m}}$, respectively (see Table 3). Column 9 lists the excitation temperatures computed as explained in Sect. 3.1.3. The sources marked with a G in Col. 2 have optically thin lines or not well-constrained opacity. These have been fit with a Gaussian function, so that Cols. 4 and 8 represent total integrated area $\left(\int T_{\mathrm{MB}} \mathrm{d} v\right.$, in K km s$\left.{ }^{-1}\right)$ and peak intensity $\left(T_{\text {peak }}\right.$, in $\left.\mathrm{K}\right)$ of this Gaussian, respectively. The uncertainties obtained from either the fitting procedure (parameters in Cols. 3-8) or from the propagation of errors (Col. 9) are in parentheses. ${ }^{(a)}$ Upper limit to the integrated line intensity from the equation $\int T_{\mathrm{MB}} \mathrm{d} v=\frac{\Delta v}{2 \sqrt{\ln 2 / \pi}} T_{\mathrm{MB}}^{\text {peak }}$, assuming the $3 \sigma \mathrm{rms}$ level of the spectrum as $T_{\mathrm{MB}}^{\text {peak }}$, and an average value of $\Delta v$ from the other sources; ${ }^{(b)} T_{\mathrm{ex}}$ cannot be derived from the fit results, therefore the average value of the sources with well-constrained opacity $(7.5 \mathrm{~K})$ is assumed; ${ }^{(c)}$ marginal detection. 
Table 6. Integrated area of the ortho- and para- $\mathrm{NH}_{2} \mathrm{D}$ lines (Cols. 1 and 2, respectively), and their ratio (Col. 3).

\begin{tabular}{|c|c|c|c|}
\hline & $\begin{array}{l}\int T_{\mathrm{MB}} \mathrm{d} v[o] \\
\left(\mathrm{K} \mathrm{km} \mathrm{s}^{-1}\right)\end{array}$ & $\begin{array}{l}\int T_{\mathrm{MB}} \mathrm{d} v[p] \\
\left(\mathrm{K} \mathrm{km} \mathrm{s}^{-1}\right)\end{array}$ & $\frac{\int T_{\mathrm{MB}} \mathrm{d} v[o]}{\int T_{\mathrm{MB}} \mathrm{d} v[p]}$ \\
\hline \multicolumn{4}{|c|}{ HMSC } \\
\hline I00117-MM2 & $0.66(0.03)$ & $0.16(0.03)$ & $4.1(0.9)$ \\
\hline AFGL5142-EC & 2.03(0.04) & $0.69(0.03)$ & $2.9(0.2)$ \\
\hline $05358-\mathrm{mm} 3$ & $0.83(0.04)$ & $0.33(0.03)$ & $2.5(0.3)$ \\
\hline G034-G2(MM2) & $0.48(0.02)$ & & \\
\hline G034-F2(MM7) & $0.55(0.03)$ & & \\
\hline G034-F1(MM8) & $0.34(0.04)$ & & \\
\hline G028-C1(MM9) & $0.74(0.02)$ & $0.28(0.03)$ & $2.6(0.4)$ \\
\hline G028-C3(MM11) & $0.12(0.02)$ & & \\
\hline I20293-WC & $2.77(0.03)$ & $1.15(0.03)$ & $2.4(0.1)$ \\
\hline I22134-G & $0.18(0.02)$ & & \\
\hline I22134-B & $0.20(0.02)$ & $0.13(0.02)$ & $1.5(0.4)$ \\
\hline \multicolumn{4}{|c|}{ HMPO } \\
\hline I00117-MM1 & $0.38(0.03)$ & & \\
\hline \multicolumn{4}{|l|}{ I04579-VLA1 } \\
\hline AFGL5142-MM & $2.25(0.03)$ & $0.75(0.03)$ & $3.0(0.2)$ \\
\hline 05358-mm1 & $0.51(0.04)$ & $0.26(0.03)$ & $2.0(0.4)$ \\
\hline 18089-1732 & $2.33(0.06)$ & $1.02(0.04)$ & $2.3(0.2)$ \\
\hline $18517+0437$ & $0.50(0.02)$ & & \\
\hline G75-core & $0.29(0.03)$ & & \\
\hline I20293-MM1 & $2.44(0.03)$ & $0.84(0.03)$ & $2.9(0.2)$ \\
\hline \multicolumn{4}{|l|}{ I21307 } \\
\hline I23385 & $0.13(0.03)$ & & \\
\hline \multicolumn{4}{|c|}{ UC HII } \\
\hline G5.89-0.39 & $0.54(0.03)$ & & \\
\hline I19035-VLA1 & $0.62(0.03)$ & & \\
\hline $19410+2336$ & $1.98(0.03)$ & $0.72(0.03)$ & $2.8(0.2)$ \\
\hline ON1 & $1.33(0.03)$ & $0.45(0.03)$ & $3.0(0.3)$ \\
\hline I22134-VLA1 & $0.11(0.02)$ & & \\
\hline $23033+5951$ & $0.88(0.03)$ & $0.36(0.02)$ & $2.4(0.2)$ \\
\hline NGC7538-IRS9 & $0.16(0.03)$ & & \\
\hline
\end{tabular}

Notes. The integrated area of the ortho-line is equal to the integrated area of the best-fit Gaussian (Table 5) within the errors. 
Table 8. Rotation temperatures and total column densities for $\mathrm{CH}_{3} \mathrm{OH},{ }^{13} \mathrm{CH}_{3} \mathrm{OH}$, and $\mathrm{CH}_{2} \mathrm{DOH}$ derived from rotation diagrams, unless when specified differently.

\begin{tabular}{|c|c|c|c|c|c|c|c|}
\hline \multirow[t]{2}{*}{ Source } & \multicolumn{2}{|c|}{$\mathrm{CH}_{3} \mathrm{OH}$} & \multicolumn{2}{|c|}{${ }^{13} \mathrm{CH}_{3} \mathrm{OH}$} & \multicolumn{2}{|c|}{$\mathrm{CH}_{2} \mathrm{DOH}$} & \multirow[b]{2}{*}{$D_{\text {frac }}\left(\mathrm{CH}_{3} \mathrm{OH}\right)$} \\
\hline & $\begin{array}{c}T_{\text {rot }} \\
\mathrm{K}\end{array}$ & $\begin{array}{c}N \\
\left(\times 10^{14}\right) \mathrm{cm}^{-2}\end{array}$ & $\begin{array}{c}T_{\text {rot }} \\
\mathrm{K}\end{array}$ & $\begin{array}{c}N \\
\left(\times 10^{13}\right) \mathrm{cm}^{-2}\end{array}$ & $\begin{array}{c}T_{\text {rot }} \\
\mathrm{K}\end{array}$ & $\begin{array}{c}N \\
\left(\times 10^{14}\right) \mathrm{cm}^{-2}\end{array}$ & \\
\hline & & & & HMSC & \multirow{11}{*}{$-^{a}$} & & \\
\hline I00117-MM2 & 19.0 & 1.80 & & $\leq 0.3$ & & $\leq 0.013$ & $\leq 0.007$ \\
\hline AFGL5142-EC & 41.5 & 61.5 & 14.1 & 5.27 & & $0.11^{a}$ & $0.002(0.001)$ \\
\hline $05358-\mathrm{mm} 3$ & 26.1 & 24.9 & 5.1 & 1.53 & & 0.08 & $0.003(0.001)$ \\
\hline G034-G2(MM2) & 6.0 & 1.75 & $-^{a}$ & $0.09^{a}$ & & 0.03 & $0.015(0.07)$ \\
\hline G034-F2(MM7) & 5.7 & 0.95 & \multirow{6}{*}{6.8} & $\leq 0.15$ & & $\leq 0.007$ & $\leq 0.007$ \\
\hline G034-F1(MM8) & 17.5 & 2.24 & & $\leq 0.3$ & & $\leq 0.01$ & $\leq 0.006$ \\
\hline G028-C1(MM9) & 14.2 & 2.69 & & 0.71 & & $\leq 0.01$ & $\leq 0.004$ \\
\hline I20293-WC & 24.4 & 3.44 & & $\leq 0.5$ & & $\leq 0.02$ & $\leq 0.005$ \\
\hline I22134-G & 18.1 & 2.87 & & $\leq 0.3$ & & $\leq 0.01$ & $\leq 0.004$ \\
\hline I22134-B & 7.8 & 0.35 & & $\leq 0.2$ & & $\leq 0.007$ & $\leq 0.02$ \\
\hline & & & & HMPO & \multirow{4}{*}{10.4} & & \\
\hline I00117-MM1 & 27.7 & 1.22 & & $\leq 0.6$ & & $\leq 0.02$ & $\leq 0.02$ \\
\hline AFGL5142-MM & 112.6 & 262.7 & 7.9 & 5.81 & & $19.0^{b} ; 2.1^{c}$ & $0.07(0.03)^{b} ; 0.008(0.004)^{c}$ \\
\hline 05358-mm1 & 84.0 & 125.1 & $-^{a}$ & $6.1^{a}$ & & $\leq 0.13$ & $\leq 0.001$ \\
\hline 18089-1732 & 158.6 & 318.1 & 153.0 & 64.2 & \multirow[t]{6}{*}{56} & $14.0^{b} ; 4.0^{c}$ & $0.04(0.02)^{b} ; 0.01(0.01)^{c}$ \\
\hline $18517+0437$ & 137.6 & 209.2 & 44.5 & 25.6 & & $\leq 0.2$ & $\leq 0.001$ \\
\hline G75-core & 108.5 & 150.6 & $-^{a}$ & $4.2^{a}$ & & 0.55 & $0.005(0.003)$ \\
\hline I20293-MM1 & 35.1 & 27.5 & $-^{a}$ & $0.9^{a}$ & & $\leq 0.04$ & $\leq 0.001$ \\
\hline I21307 & 29.4 & 6.54 & & $\leq 0.5$ & & $\leq 0.03$ & $\leq 0.004$ \\
\hline $\mathrm{I} 23385$ & 25.3 & 18.0 & $-^{a}$ & $0.3^{a}$ & & $\leq 0.02$ & $\leq 0.01$ \\
\hline \multicolumn{8}{|c|}{ UC HII } \\
\hline G5.89-0.39 & 64.1 & 128.1 & 37.9 & 14.0 & & $\leq 0.14$ & $\leq 0.001$ \\
\hline I19035-VLA1 & 30.7 & 16.4 & 28.6 & 4.80 & & $\leq 0.03$ & $\leq 0.002$ \\
\hline $19410+2336$ & 31.1 & 20.2 & 20.8 & 5.79 & & $\leq 0.03$ & $\leq 0.001$ \\
\hline ON1 & 31.3 & 32.4 & 25.5 & 8.98 & & $\leq 0.02$ & $\leq 0.0007$ \\
\hline I22134-VLA1 & 19.4 & 1.64 & & $\leq 0.3$ & & $\leq 0.02$ & $\leq 0.009$ \\
\hline $23033+5951$ & 24.2 & 12.0 & 37.4 & 8.33 & & $\leq 0.02$ & $\leq 0.002$ \\
\hline NGC7538-IRS9 & 28.7 & 17.6 & $-^{a}$ & $0.5^{a}$ & & $\leq 0.02$ & $\leq 0.001$ \\
\hline
\end{tabular}

Notes. For $\mathrm{CH}_{2} \mathrm{DOH}$, in the sources where only one line has been detected, we have computed the total column density from Eq. (A4) of Caselli et al. (2002), assuming the temperatures obtained from $\mathrm{CH}_{3} \mathrm{OH}$. ${ }^{(a)}$ Only lines with very close upper energies are detected, and the rotation diagram provides a meaningless negative $T_{\text {rot }}$. Therefore, the column density has been derived from the transition $\left(2_{0,2}-1_{0,1}\right)++$ assuming LTE conditions and $T_{\text {rot }}$ from methanol; ${ }^{(b)}$ derived from rotation diagrams; ${ }^{(c)}$ derived from the transition $\left(5_{2,3}-4_{1,4}\right)$ e1 assuming LTE conditions and $T_{\text {rot }}$ from methanol. 


\section{Appendix A: $\mathrm{NH}_{3}$ and $\mathrm{NH}_{2} \mathrm{D}$ spectra}
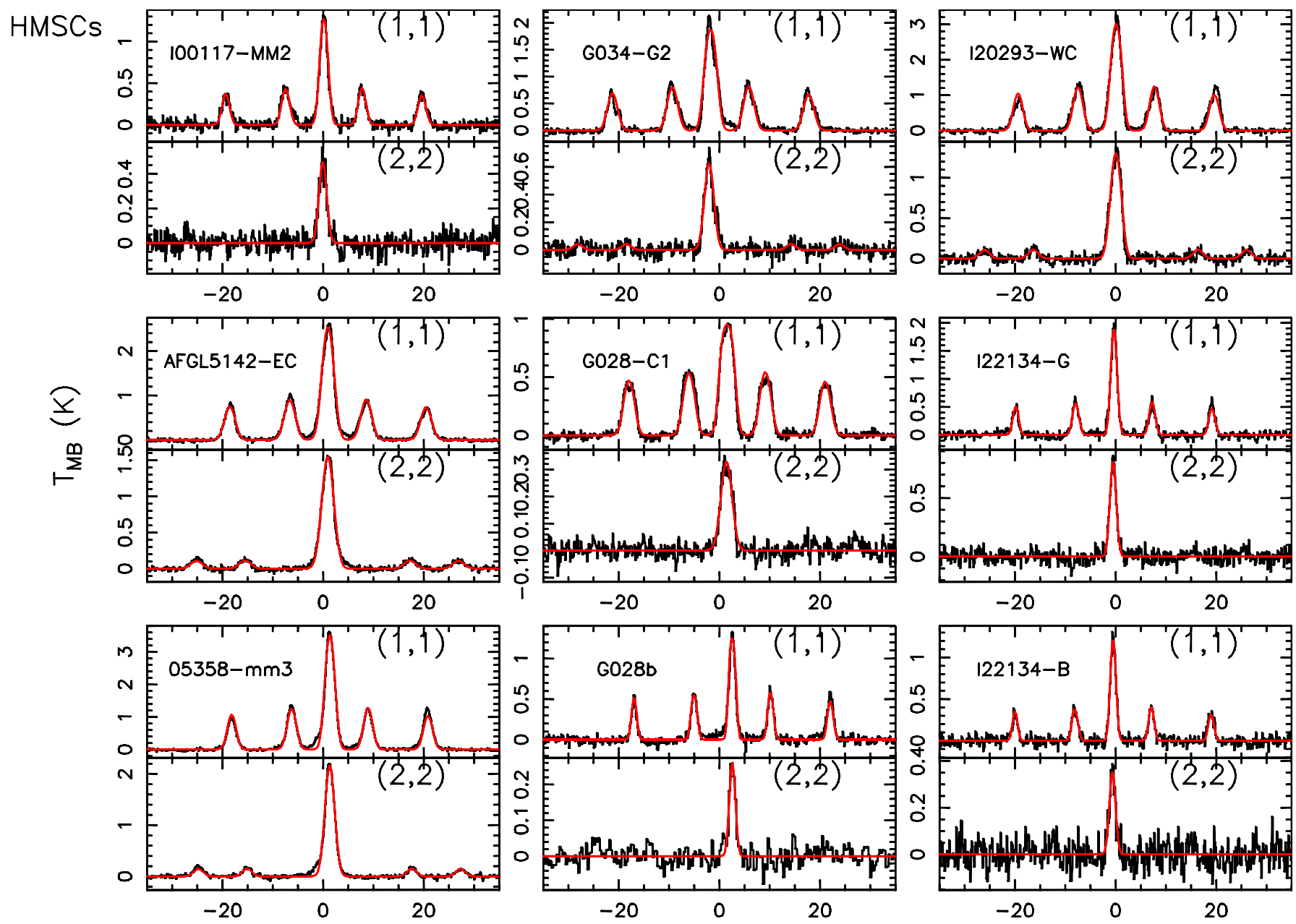

Fig. A.1. GBT spectra of $\mathrm{NH}_{3}(1,1)$ and $(2,2)$ obtained towards the sources classified as HMSCs. For each spectrum, the $x$-axis represents a velocity interval of $\pm 35 \mathrm{~km} \mathrm{~s}^{-1}$ from the systemic velocity listed in Table 1 . The $y$-axis shows the intensity scale in main beam brightness temperature units In each spectrum, the red curve indicates the best fit either obtained by fitting the hyperfine structure, when possible, or with a single Gaussian (see Sect. 3.1). 

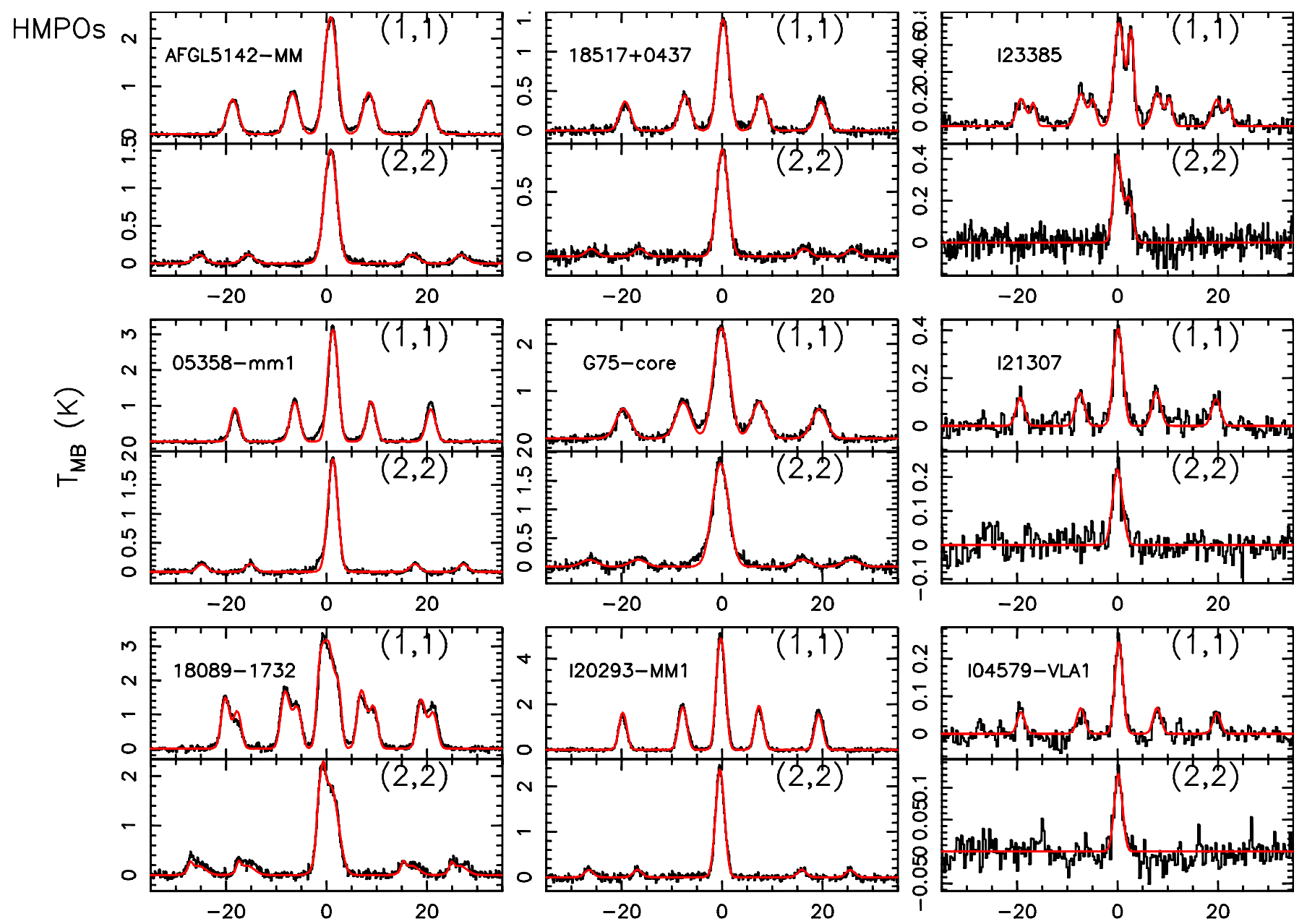

Fig. A.2. Same as Fig. A.1 for the sources classified as HMPOs. For the spectra of I23385 and 18089-1732, a fit with two velocity components has been performed. 
F. Fontani et al.: Deuteration in massive star formation
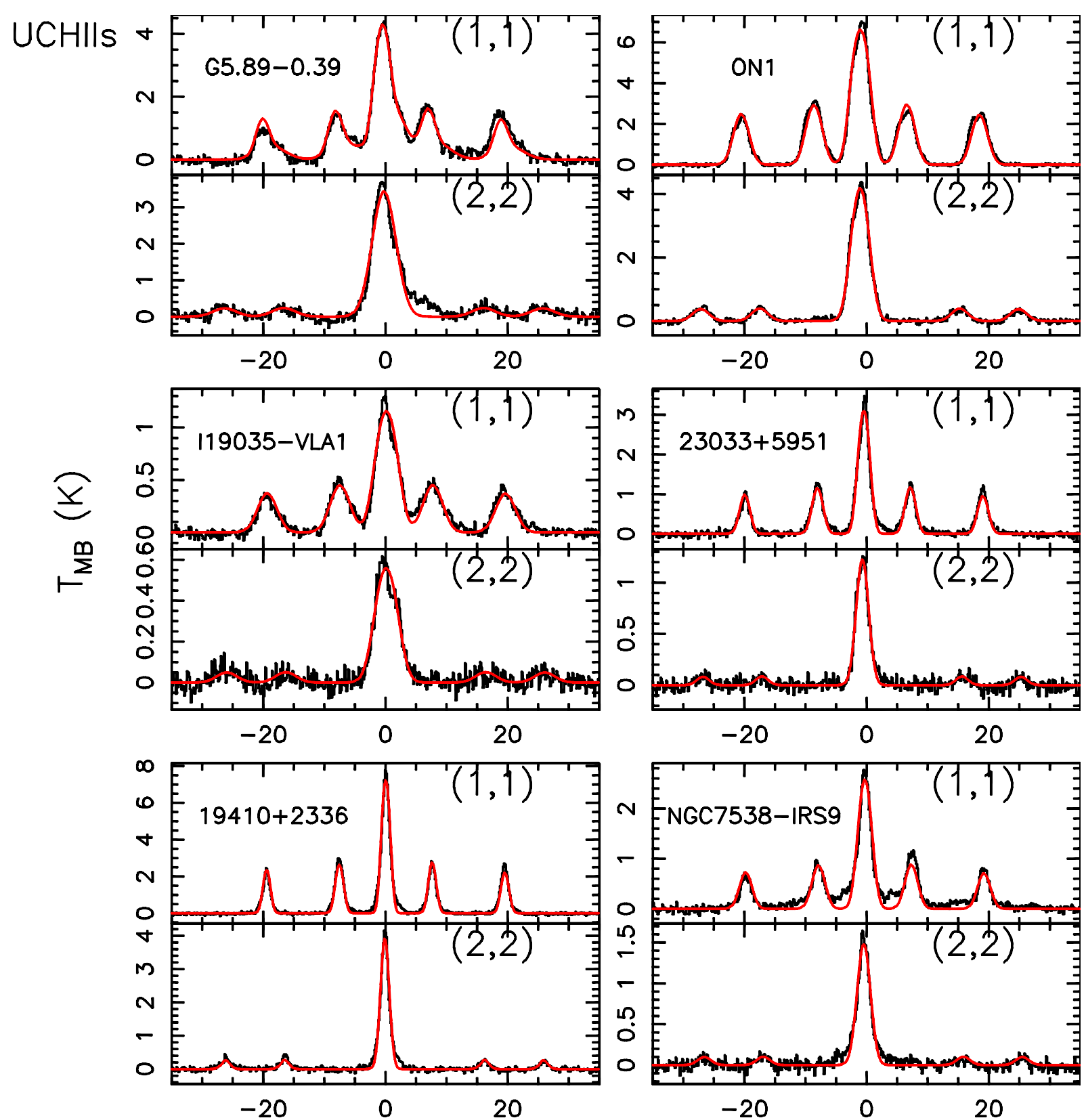

Fig. A.3. Same as Fig. A.1 for the sources classified as UC HIIs. 


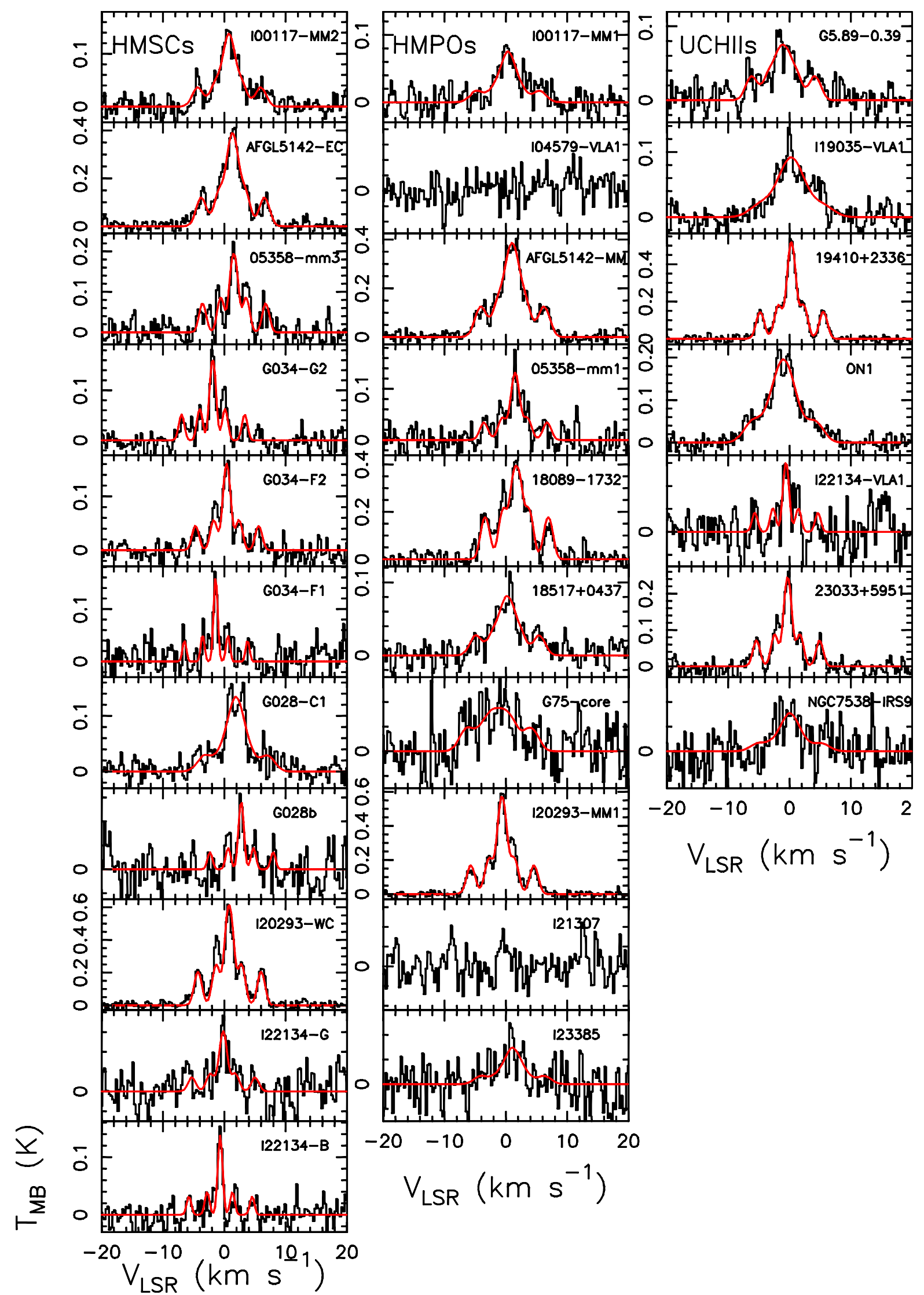

Fig. A.4. IRAM-30 m spectra of ortho- $\mathrm{NH}_{2} \mathrm{D}\left(1_{1,1}-1_{0,1}\right)$ obtained towards all sources observed. We show the HMSCs in the left column, the HMPOs in the central column, and the UC HIIs in the right column, from top to bottom in the same order as they appear in Table 1. For each spectrum, the $x$-axis represents a velocity interval of $\pm 20 \mathrm{~km} \mathrm{~s}^{-1}$ from the systemic velocity listed in Table 1 . The $y$-axis shows the intensity scale in main beam brightness temperature units. In each spectrum, the red curve indicates the best fit either obtained by fitting the hyperfine structure, when possible, or with a single Gaussian (see Sect. 3.1). 
F. Fontani et al.: Deuteration in massive star formation

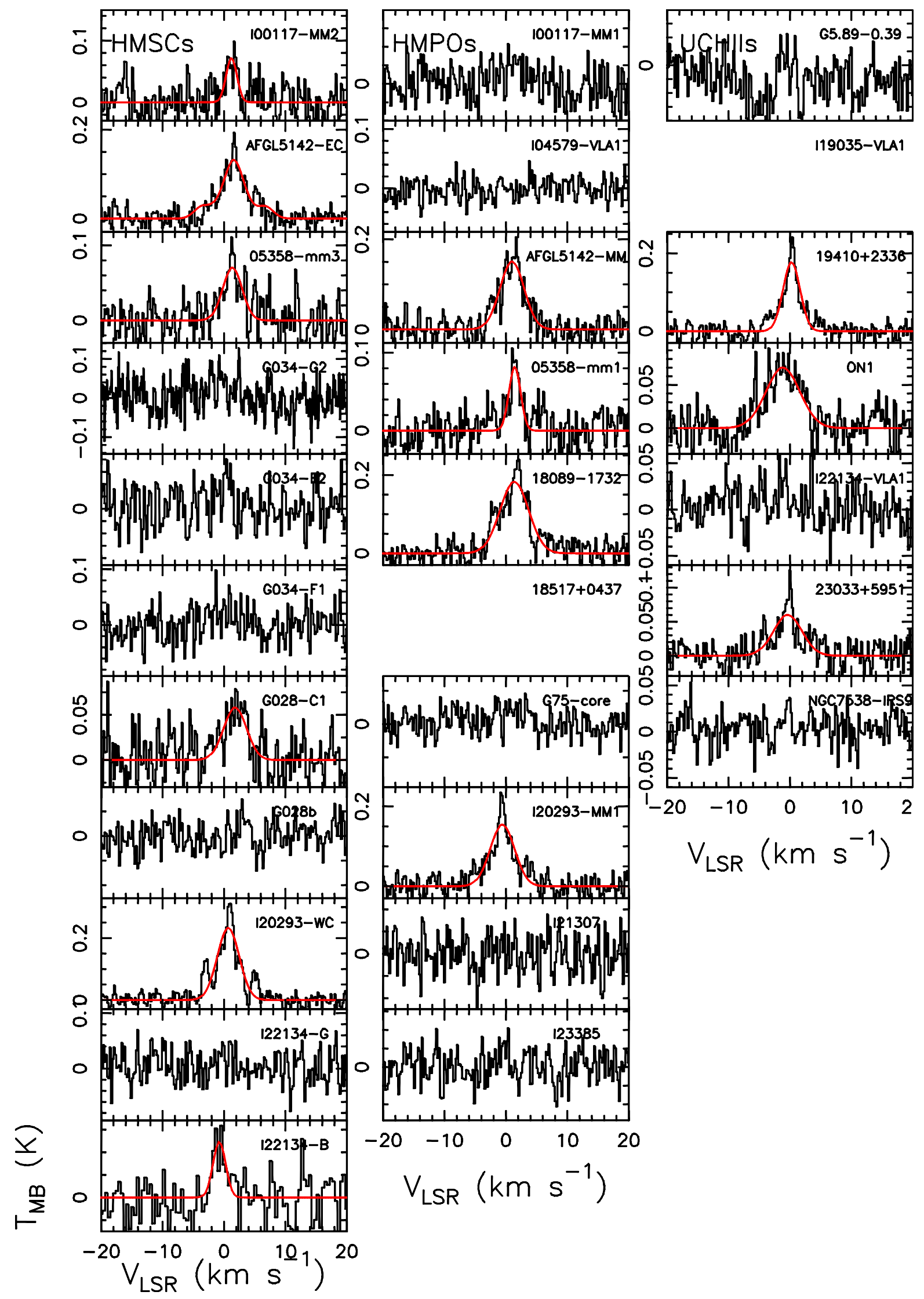

Fig. A.5. Same as Fig. A.4 for para- $\mathrm{NH}_{2} \mathrm{D}\left(1_{1,1}-1_{0,1}\right)$. Two sources $(18517+0437$ and I19035-VLA1) have not been observed. In each spectrum, the red curve indicates the best fit (see Sect. 3.1). 


\section{Appendix B: Tables}

Table B.1. Transitions of $\mathrm{CH}_{3} \mathrm{OH},{ }^{13} \mathrm{CH}_{3} \mathrm{OH}, \mathrm{CH}_{2} \mathrm{DOH}$ and $\mathrm{CH}_{3} \mathrm{OD}$ detected at $3 \mathrm{~mm}$, and line parameters derived from Gaussian fits: line integrated intensity $\left(\int T_{\mathrm{MB}} \mathrm{d} v\right)$, full width at half maximum $(\Delta V)$ and main beam temperature at line peak $\left(T_{\mathrm{pk}}\right)$.

\begin{tabular}{|c|c|c|c|c|}
\hline $\begin{array}{l}\text { Freq. } \\
\mathrm{MHz}\end{array}$ & Transition & $\begin{array}{l}\int T_{\mathrm{MB}} \mathrm{d} v \\
\mathrm{~K} \mathrm{~km} \mathrm{~s}^{-1}\end{array}$ & $\begin{array}{l}\Delta V \\
\mathrm{~km} \mathrm{~s}^{-1}\end{array}$ & $\begin{array}{l}T_{\mathrm{pk}} \\
\mathrm{K}\end{array}$ \\
\hline \multicolumn{5}{|c|}{ HMSCs } \\
\hline \multicolumn{5}{|c|}{ I00117-MM2 } \\
\hline 94405.16 & ${ }^{13} \mathrm{CH}_{3} \mathrm{OH} 2(-1,2)-1(-1,1)$ & $0.014(0.004)$ & $1.1(0.4)$ & 0.012 \\
\hline 95169.46 & $\mathrm{CH}_{3} \mathrm{OH} 8(0,8)-7(1,7)++$ & $0.031(0.006)$ & $2.4(0.5)$ & 0.012 \\
\hline 96739.36 & $\mathrm{CH}_{3} \mathrm{OH} 2(-1,2)-1(-1,1)$ & $0.35(0.02)$ & $0.7(0.2)$ & 0.45131 \\
\hline 96741.38 & $\mathrm{CH}_{3} \mathrm{OH} 2(0,2)-1(0,1)++$ & $0.48(0.02)$ & $0.7(0.2)$ & 0.62447 \\
\hline 96744.55 & $\mathrm{CH}_{3} \mathrm{OH} 2(0,2)-1(0,1)$ & $0.06(0.02)$ & $0.6(0.2)$ & 0.09 \\
\hline 96755.51 & $\mathrm{CH}_{3} \mathrm{OH} 2(1,1)-1(1,0)$ & $0.02(0.01)$ & $0.7(0.3)$ & 0.02 \\
\hline \multicolumn{5}{|c|}{ AFGL5142-EC } \\
\hline 89505.78 & $\mathrm{CH}_{3} \mathrm{OH} 8(-4,5)-9(-3,7)$ & $0.07(0.02)$ & $1.9(0.8)$ & 0.03 \\
\hline 94405.16 & ${ }^{13} \mathrm{CH}_{3} \mathrm{OH} 2(-1,2)-1(-1,1)$ & $0.08(0.01)$ & $1.5(0.2)$ & 0.05 \\
\hline 94407.13 & ${ }^{13} \mathrm{CH}_{3} \mathrm{OH} 2(0,2)-1(0,1)++$ & $0.06(0.02)$ & $1.1(0.3)$ & 0.06 \\
\hline 94411.02 & ${ }^{13} \mathrm{CH}_{3} \mathrm{OH} 2(0,2)-1(0,1)$ & $0.04(0.03)$ & $4.1(0.9)$ & 0.01 \\
\hline 94420.45 & ${ }^{13} \mathrm{CH}_{3} \mathrm{OH} 2(1,1)-1(1,0)$ & $0.014(0.007)$ & $1.7(0.6)$ & 0.01 \\
\hline 94541.76 & $\mathrm{CH}_{3} \mathrm{OH} 8(3,5)-9(2,7)$ & $0.083(0.009)$ & $1.7(0.2)$ & 0.05 \\
\hline 95169.46 & $\mathrm{CH}_{3} \mathrm{OH} 8(0,8)-7(1,7)++$ & $1.937(0.003)$ & $1.1(0.4)$ & 1.7 \\
\hline 95914.31 & $\mathrm{CH}_{3} \mathrm{OH} 2(1,2)-1(1,1)++$ & $0.6(0.2)$ & $1.4(0.5)$ & 0.4 \\
\hline 96739.36 & $\mathrm{CH}_{3} \mathrm{OH} 2(-1,2)-1(-1,1)$ & $4.3(0.1)$ & $1.6(0.4)$ & 2.6 \\
\hline 96741.38 & $\mathrm{CH}_{3} \mathrm{OH} 2(0,2)-1(0,1)++$ & $4.4(0.1)$ & $2.0(0.4)$ & 3.4 \\
\hline 96744.55 & $\mathrm{CH}_{3} \mathrm{OH} 2(0,2)-1(0,1)$ & $1.7(0.1)$ & $1.9(0.4)$ & 0.8 \\
\hline 96755.51 & $\mathrm{CH}_{3} \mathrm{OH} 2(1,1)-1(1,0)$ & $0.6(0.1)$ & $1.413(0.4)$ & 0.4 \\
\hline \multicolumn{5}{|c|}{$05358-\mathrm{mm} 3$} \\
\hline 89407.91 & $\mathrm{CH}_{2} \mathrm{DOH} 2(0,2)-1(0,1) \mathrm{e} 0$ & $0.020(0.006)$ & $1.2(0.5)$ & 0.02 \\
\hline 91586.97 & $\mathrm{CH}_{2} \mathrm{DOH} 4(1,3)-4(0,4)$ & $0.03(0.007)$ & $1.7(0.6)$ & 0.02 \\
\hline 94405.16 & ${ }^{13} \mathrm{CH}_{3} \mathrm{OH} 2(-1,2)-1(-1,1)$ & $0.040(0.007)$ & $1.0(0.2)$ & 0.03 \\
\hline 94407.13 & ${ }^{13} \mathrm{CH}_{3} \mathrm{OH} 2(0,2)-1(0,1)++$ & $0.101(0.009)$ & $2.0(0.2)$ & 0.05 \\
\hline 94411.02 & ${ }^{13} \mathrm{CH}_{3} \mathrm{OH} 2(0,2)-1(0,1)$ & $0.008(0.003)$ & $0.4(0.2)$ & 0.02 \\
\hline 94541.76 & $\mathrm{CH}_{3} \mathrm{OH} 8(3,5)-9(2,7)$ & $0.021(0.006)$ & $1.4(0.5)$ & 0.02 \\
\hline 95169.46 & $\mathrm{CH}_{3} \mathrm{OH} 8(0,8)-7(1,7)++$ & $1.400(0.005)$ & $0.839(0.004)$ & 1.6 \\
\hline 95914.31 & $\mathrm{CH}_{3} \mathrm{OH} 2(1,2)-1(1,1)++$ & $0.33(0.04)$ & $1.2(0.2)$ & 0.25 \\
\hline 96739.36 & $\mathrm{CH}_{3} \mathrm{OH} 2(-1,2)-1(-1,1)$ & $2.4(0.1)$ & $1.4(0.4)$ & 1.7 \\
\hline 96741.38 & $\mathrm{CH}_{3} \mathrm{OH} 2(0,2)-1(0,1)++$ & $4.0(0.1)$ & $1.6(0.4)$ & 2.35 \\
\hline 96744.55 & $\mathrm{CH}_{3} \mathrm{OH} 2(0,2)-1(0,1)$ & $0.9(0.1)$ & $1.5(0.4)$ & 0.55 \\
\hline 96755.51 & $\mathrm{CH}_{3} \mathrm{OH} 2(1,1)-1(1,0)$ & $0.4(0.1)$ & $1.6(0.4)$ & 0.22 \\
\hline \multicolumn{5}{|c|}{ G034-G2 } \\
\hline 89407.91 & $\mathrm{CH}_{2} \mathrm{DOH} 2(0,2)-1(0,1) \mathrm{e} 0$ & $0.02(0.01)$ & $0.8(0.2)$ & 0.03 \\
\hline 94405.16 & ${ }^{13} \mathrm{CH}_{3} \mathrm{OH} 2(-1,2)-1(-1,1)$ & $0.008(0.004)$ & $1.0(0.4)$ & 0.007 \\
\hline 94407.13 & ${ }^{13} \mathrm{CH}_{3} \mathrm{OH} 2(0,2)-1(0,1)++$ & $0.010(0.003)$ & $0.5(0.15)$ & 0.018 \\
\hline 96739.36 & $\mathrm{CH}_{3} \mathrm{OH} 2(-1,2)-1(-1,1)$ & $0.764(0.004)$ & $1.138(0.008)$ & 0.63 \\
\hline 96741.38 & $\mathrm{CH}_{3} \mathrm{OH} 2(0,2)-1(0,1)++$ & $0.909(0.004)$ & $1.009(0.005)$ & 0.84 \\
\hline 96744.55 & $\mathrm{CH}_{3} \mathrm{OH} 2(0,2)-1(0,1)$ & $0.072(0.002)$ & $0.91(0.05)$ & 0.07 \\
\hline \multicolumn{5}{|c|}{ G034-F2 } \\
\hline 96739.36 & $\mathrm{CH}_{3} \mathrm{OH} 2(-1,2)-1(-1,1)$ & $0.37(0.02)$ & $0.8(0.4)$ & 0.46 \\
\hline 96741.38 & $\mathrm{CH}_{3} \mathrm{OH} 2(0,2)-1(0,1)++$ & $0.46(0.02)$ & $0.8(0.4)$ & 0.58 \\
\hline 96744.55 & $\mathrm{CH}_{3} \mathrm{OH} 2(0,2)-1(0,1)$ & $0.05(0.02)$ & $1.4(0.4)$ & 0.034 \\
\hline \multicolumn{5}{|c|}{ G034-F1 } \\
\hline 95169.46 & $\mathrm{CH}_{3} \mathrm{OH} 8(0,8)-7(1,7)++$ & $0.043(0.005)$ & $1.3(0.2)$ & 0.03 \\
\hline 95914.31 & $\mathrm{CH}_{3} \mathrm{OH} 2(1,2)-1(1,1)++$ & $0.035(0.009)$ & $1.8(0.6)$ & 0.02 \\
\hline 96739.36 & $\mathrm{CH}_{3} \mathrm{OH} 2(-1,2)-1(-1,1)$ & $0.65(0.025)$ & $1.3(0.4)$ & 0.46 \\
\hline 96741.38 & $\mathrm{CH}_{3} \mathrm{OH} 2(0,2)-1(0,1)++$ & $0.68(0.025)$ & $1.2(0.4)$ & 0.55 \\
\hline 96744.55 & $\mathrm{CH}_{3} \mathrm{OH} 2(0,2)-1(0,1)$ & $0.11(0.025)$ & $1.7(0.4)$ & 0.06 \\
\hline 96755.51 & $\mathrm{CH}_{3} \mathrm{OH} 2(1,1)-1(1,0)$ & $0.02(0.1)$ & $1.7(0.9)$ & 0.015 \\
\hline \multicolumn{5}{|c|}{ G028-C1 } \\
\hline 94405.16 & ${ }^{13} \mathrm{CH}_{3} \mathrm{OH} 2(-1,2)-1(-1,1)$ & $0.013(0.003)$ & $0.4(0.2)$ & 0.03 \\
\hline 94407.13 & ${ }^{13} \mathrm{CH}_{3} \mathrm{OH} 2(0,2)-1(0,1)++$ & $0.039(0.005)$ & $0.9(0.1)$ & 0.04 \\
\hline 95169.46 & $\mathrm{CH}_{3} \mathrm{OH} 8(0,8)-7(1,7)++$ & $0.033(0.015)$ & $1.8(0.6)$ & 0.017 \\
\hline 96739.36 & $\mathrm{CH}_{3} \mathrm{OH} 2(-1,2)-1(-1,1)$ & $0.94(0.04)$ & $1.1(0.4)$ & 0.84 \\
\hline 96741.38 & $\mathrm{CH}_{3} \mathrm{OH} 2(0,2)-1(0,1)++$ & $1.12(0.04)$ & $1.0(0.4)$ & 1.03 \\
\hline 96744.55 & $\mathrm{CH}_{3} \mathrm{OH} 2(0,2)-1(0,1)$ & $0.32(0.04)$ & $2.9(0.4)$ & 0.1 \\
\hline
\end{tabular}


Table B.1. continued.

\begin{tabular}{|c|c|c|c|c|}
\hline $\begin{array}{l}\text { Freq. } \\
\text { MHz }\end{array}$ & Transition & $\begin{array}{l}\int_{\mathrm{K}} T_{\mathrm{MB}} \mathrm{d} v \mathrm{~s} \mathrm{~s}^{-1}\end{array}$ & $\begin{array}{l}\Delta V \\
\mathrm{~km} \mathrm{~s}^{-1}\end{array}$ & $\begin{array}{l}T_{\mathrm{pk}} \\
\mathrm{K}\end{array}$ \\
\hline 96755.51 & $\mathrm{CH}_{3} \mathrm{OH} 2(1,1)-1(1,0)$ & $0.02(0.008)$ & $0.9(0.4)$ & 0.02 \\
\hline \multicolumn{5}{|c|}{ I20293-WC } \\
\hline 95169.46 & $\mathrm{CH}_{3} \mathrm{OH} 8(0,8)-7(1,7)++$ & $0.205(0.005)$ & $0.94(0.03)$ & 0.2 \\
\hline 95914.31 & $\mathrm{CH}_{3} \mathrm{OH} 2(1,2)-1(1,1)++$ & $0.06(0.02)$ & $2.3(0.9)$ & 0.023 \\
\hline 96739.36 & $\mathrm{CH}_{3} \mathrm{OH} 2(-1,2)-1(-1,1)$ & $0.84(0.03)$ & $1.6(0.4)$ & 0.48 \\
\hline 96741.38 & $\mathrm{CH}_{3} \mathrm{OH} 2(0,2)-1(0,1)++$ & $0.73(0.03)$ & $1.0(0.4)$ & 0.66 \\
\hline 96744.55 & $\mathrm{CH}_{3} \mathrm{OH} 2(0,2)-1(0,1)$ & $0.14(0.03)$ & $1.4(0.4)$ & 0.09 \\
\hline 96755.51 & $\mathrm{CH}_{3} \mathrm{OH} 2(1,1)-1(1,0)$ & $0.05(0.03)$ & $1.6(0.4)$ & 0.03 \\
\hline \multicolumn{5}{|c|}{ I22134-G } \\
\hline 95169.46 & $\mathrm{CH}_{3} \mathrm{OH} 8(0,8)-7(1,7)++$ & $0.030(0.005)$ & $1.1(0.2)$ & 0.026 \\
\hline 96739.36 & $\mathrm{CH}_{3} \mathrm{OH} 2(-1,2)-1(-1,1)$ & $0.28(0.02)$ & $0.8(0.4)$ & 0.32 \\
\hline 96741.38 & $\mathrm{CH}_{3} \mathrm{OH} 2(0,2)-1(0,1)++$ & $0.39(0.02)$ & $0.7(0.4)$ & 0.49 \\
\hline 96744.55 & $\mathrm{CH}_{3} \mathrm{OH} 2(0,2)-1(0,1)$ & $0.06(0.02)$ & $0.7(0.4)$ & 0.08 \\
\hline 96755.51 & $\mathrm{CH}_{3} \mathrm{OH} 2(1,1)-1(1,0)$ & $0.02(0.02)$ & $0.9(0.4)$ & 0.02 \\
\hline \multicolumn{5}{|c|}{ I22134-B } \\
\hline 96739.36 & $\mathrm{CH}_{3} \mathrm{OH} 2(-1,2)-1(-1,1)$ & $0.113(0.002)$ & $0.60(0.02)$ & 0.18 \\
\hline 96741.38 & $\mathrm{CH}_{3} \mathrm{OH} 2(0,2)-1(0,1)++$ & $0.157(0.002)$ & $0.60(0.01)$ & 0.25 \\
\hline 96744.55 & $\mathrm{CH}_{3} \mathrm{OH} 2(0,2)-1(0,1)^{\prime \prime}$ & $0.018(0.002)$ & $0.57(0.07)$ & 0.03 \\
\hline \multicolumn{5}{|c|}{ HMPOs } \\
\hline \multicolumn{5}{|c|}{ I00117-MM1 } \\
\hline 95169.46 & $\mathrm{CH}_{3} \mathrm{OH} 8(0,8)-7(1,7)++$ & $0.024(0.005)$ & $1.2(0.3)$ & 0.02 \\
\hline 96739.36 & $\mathrm{CH}_{3} \mathrm{OH} 2(-1,2)-1(-1,1)$ & $0.23(0.01)$ & $0.8(0.4)$ & 0.27 \\
\hline 96741.38 & $\mathrm{CH}_{3} \mathrm{OH} 2(0,2)-1(0,1)++$ & $0.35(0.01)$ & $0.8(0.4)$ & 0.39 \\
\hline 96744.55 & $\mathrm{CH}_{3} \mathrm{OH} 2(0,2)-1(0,1)$ & $0.04(0.01)$ & $0.7(0.4)$ & 0.052 \\
\hline 96755.51 & $\mathrm{CH}_{3} \mathrm{OH} 2(1,1)-1(1,0)$ & $0.01(0.01)$ & $0.8(0.9)$ & 0.015 \\
\hline \multicolumn{5}{|c|}{ AFGL5142-MM } \\
\hline 89505.78 & $\mathrm{CH}_{3} \mathrm{OH} 8(-4,5)-9(-3,7)$ & $0.08(0.05)$ & $2.0(0.9)$ & 0.04 \\
\hline 91586.97 & $\mathrm{CH}_{2} \mathrm{DOH} 4(1,3)-4(0,4)$ & $0.021(0.007)$ & $1.4(0.4)$ & 0.014 \\
\hline 94405.16 & ${ }^{13} \mathrm{CH}_{3} \mathrm{OH} 2(-1,2)-1(-1,1)$ & $0.064(0.009)$ & $1.3(0.2)$ & 0.046 \\
\hline 94407.13 & ${ }^{13} \mathrm{CH}_{3} \mathrm{OH} 2(0,2)-1(0,1)++$ & $0.09(0.01)$ & $1.3(0.2)$ & 0.06 \\
\hline 94411.02 & ${ }^{13} \mathrm{CH}_{3} \mathrm{OH} 2(0,2)-1(0,1)$ & $0.015(0.007)$ & $1.0(0.6)$ & 0.014 \\
\hline 94420.45 & ${ }^{13} \mathrm{CH}_{3} \mathrm{OH} 2(1,1)-1(1,0)$ & $0.006(0.007)$ & $0.7(0.6)$ & 0.008 \\
\hline 94541.76 & $\mathrm{CH}_{3} \mathrm{OH} 8(3,5)-9(2,7)$ & $0.10(0.01)$ & $1.6(0.2)$ & 0.055 \\
\hline 95169.46 & $\mathrm{CH}_{3} \mathrm{OH} 8(0,8)-7(1,7)++$ & $2.403(0.008)$ & $0.935(0.004)$ & 2.4 \\
\hline 95914.31 & $\mathrm{CH}_{3} \mathrm{OH} 2(1,2)-1(1,1)++$ & $0.71(0.06)$ & $1.45(0.15)$ & 0.46 \\
\hline 96739.36 & $\mathrm{CH}_{3} \mathrm{OH} 2(-1,2)-1(-1,1)$ & $4.0(0.15)$ & $1.5(0.4)$ & 2.45 \\
\hline 96741.38 & $\mathrm{CH}_{3} \mathrm{OH} 2(0,2)-1(0,1)++$ & $4.2(0.15)$ & $1.3(0.4)$ & 3.1 \\
\hline 96744.55 & $\mathrm{CH}_{3} \mathrm{OH} 2(0,2)-1(0,1)$ & $1.6(0.15)$ & $1.7(0.4)$ & 0.87 \\
\hline 96755.51 & $\mathrm{CH}_{3} \mathrm{OH} 2(1,1)-1(1,0)$ & $0.7(0.15)$ & $1.6(0.4)$ & 0.4 \\
\hline \multicolumn{5}{|c|}{$05358-\mathrm{mm} 1$} \\
\hline 89505.78 & $\mathrm{CH}_{3} \mathrm{OH} 8(-4,5)-9(-3,7)$ & $2.66615 \mathrm{E}-02(0.317)$ & $1.751(125.117)$ & $1.43062 \mathrm{E}-02$ \\
\hline 94405.16 & ${ }^{13} \mathrm{CH}_{3} \mathrm{OH} 2(-1,2)-1(-1,1)$ & $5.01113 \mathrm{E}-02(0.008)$ & $1.129(0.184)$ & 4.17009E-02 \\
\hline 94407.13 & ${ }^{13} \mathrm{CH}_{3} \mathrm{OH} 2(0,2)-1(0,1)++$ & $5.25924 \mathrm{E}-02(0.010)$ & $1.632(0.425)$ & 3.02682E-02 \\
\hline 95914.31 & $\mathrm{CH}_{3} \mathrm{OH} 2(1,2)-1(1,1)++$ & $0.28432(0.035)$ & $1.289(0.199)$ & 0.20717 \\
\hline 96739.36 & $\mathrm{CH}_{3} \mathrm{OH} 2(-1,2)-1(-1,1)$ & $2.2854(0.107)$ & $1.366(0.391)$ & 1.5720 \\
\hline 96741.38 & $\mathrm{CH}_{3} \mathrm{OH} 2(0,2)-1(0,1)++$ & $3.7474(0.107)$ & $1.615(0.391)$ & 2.1795 \\
\hline 96744.55 & $\mathrm{CH}_{3} \mathrm{OH} 2(0,2)-1(0,1)$ & $0.91252(0.107)$ & $1.713(0.391)$ & 0.50046 \\
\hline 96755.51 & $\mathrm{CH}_{3} \mathrm{OH} 2(1,1)-1(1,0)$ & $0.33703(0.107)$ & $1.605(0.391)$ & 0.19726 \\
\hline 95169.46 & $\mathrm{CH}_{3} \mathrm{OH} 8(0,8)-7(1,7)++$ & $1.4000(0.006)$ & $0.663(0.003)$ & 1.9824 \\
\hline \multicolumn{5}{|c|}{$18089-1732$} \\
\hline 89275.41 & $\mathrm{CH}_{2}$ DOH $2(0,2)-1(0,1) \mathrm{e} 1$ & $0.01(0.01)$ & $0.7(0.3)$ & 0.014 \\
\hline 89505.78 & $\mathrm{CH}_{3} \mathrm{OH} 8(-4,5)-9(-3,7)$ & $0.18(0.09)$ & $1.4(0.8)$ & 0.12 \\
\hline 90384.31 & ${ }^{13} \mathrm{CH}_{3} \mathrm{OH} 13(1,13)-12(2,10)$ & $0.027(0.007)$ & $1.4(0.4)$ & 0.018 \\
\hline 92588.70 & ${ }^{13} \mathrm{CH}_{3} \mathrm{OH} 7(2,6)-8(1,7)-$ & $0.030(0.007)$ & $0.8(0.3)$ & 0.034 \\
\hline 93619.46 & ${ }^{13} \mathrm{CH}_{3} \mathrm{OH} 2(1,2)-1(1,1)++$ & $0.04(0.01)$ & $1.4(0.4)$ & 0.03 \\
\hline 94405.16 & ${ }^{13} \mathrm{CH}_{3} \mathrm{OH} 2(-1,2)-1(-1,1)$ & $0.095(0.008)$ & $1.8(0.2)$ & 0.05 \\
\hline 94407.13 & ${ }^{13} \mathrm{CH}_{3} \mathrm{OH} 2(0,2)-1(0,1)++$ & $0.084(0.007)$ & $1.1(0.1)$ & 0.07 \\
\hline 94411.02 & ${ }^{13} \mathrm{CH}_{3} \mathrm{OH} 2(0,2)-1(0,1)$ & $0.072(0.005)$ & $1.5(0.1)$ & 0.04 \\
\hline 94420.45 & ${ }^{13} \mathrm{CH}_{3} \mathrm{OH} 2(1,1)-1(1,0)$ & $0.048(0.005)$ & $1.3(0.2)$ & 0.03 \\
\hline 94541.76 & $\mathrm{CH}_{3} \mathrm{OH} 8(3,5)-9(2,7)$ & $0.230(0.006)$ & $1.61(0.05)$ & 0.13 \\
\hline 94814.99 & $\mathrm{CH}_{3} \mathrm{OH} 19(7,13)-20(6,14)++$ & $0.050(0.006)$ & $1.4(0.2)$ & 0.033 \\
\hline 95169.46 & $\mathrm{CH}_{3} \mathrm{OH} 8(0,8)-7(1,7)++^{\prime \prime}$ & $1.27(0.02)$ & $1.2(0.4)$ & 1.015 \\
\hline 95208.66 & ${ }^{13} \mathrm{CH}_{3} \mathrm{OH} 2(1,1)-1(1,0)-$ & $0.06(0.02)$ & $1.8(0.4)$ & 0.029 \\
\hline
\end{tabular}


Table B.1. continued.

\begin{tabular}{|c|c|c|c|c|}
\hline $\begin{array}{l}\text { Freq. } \\
\mathrm{MHz}\end{array}$ & Transition & $\begin{array}{l}\int_{\mathrm{K}} T_{\mathrm{MB} \mathrm{s}} \mathrm{d} v \\
\mathrm{~km} \mathrm{~s}^{-1}\end{array}$ & $\begin{array}{l}\Delta V \\
\mathrm{~km} \mathrm{~s}^{-1}\end{array}$ & $\begin{array}{l}T_{\mathrm{pk}} \\
\mathrm{K}\end{array}$ \\
\hline 95273.44 & ${ }^{13} \mathrm{CH}_{3} \mathrm{OH} 6(-2,5)-7(-1,7)$ & $0.05(0.02)$ & $1.7(0.4)$ & 0.027 \\
\hline 95914.31 & $\mathrm{CH}_{3} \mathrm{OH} 2(1,2)-1(1,1)++$ & $0.60(0.09)$ & $1.4(0.3)$ & 0.40 \\
\hline 96739.36 & $\mathrm{CH}_{3} \mathrm{OH} 2(-1,2)-1(-1,1)$ & $1.58(0.07)$ & $1.3(0.4)$ & 1.14 \\
\hline 96741.38 & $\mathrm{CH}_{3} \mathrm{OH} 2(0,2)-1(0,1)++$ & $1.95(0.07)$ & $1.2(0.4)$ & 1.5 \\
\hline 96744.55 & $\mathrm{CH}_{3} \mathrm{OH} 2(0,2)-1(0,1)$ & $0.87(0.07)$ & $1.4(0.4)$ & 0.58 \\
\hline 96755.51 & $\mathrm{CH}_{3} \mathrm{OH} 2(1,1)-1(1,0)$ & $0.57(0.07)$ & $1.5(0.4)$ & 0.36 \\
\hline \multicolumn{5}{|c|}{$18517+0437$} \\
\hline 89505.78 & $\mathrm{CH}_{3} \mathrm{OH} 8(-4,5)-9(-3,7)$ & $0.07(0.2)$ & $1.5(0.4)$ & 0.04 \\
\hline 94405.16 & ${ }^{13} \mathrm{CH}_{3} \mathrm{OH} 2(-1,2)-1(-1,1)$ & $0.055(0.004)$ & $1.4(0.4)$ & 0.04 \\
\hline 94407.13 & ${ }^{13} \mathrm{CH}_{3} \mathrm{OH} 2(0,2)-1(0,1)++$ & $0.066(0.004)$ & $1.1(0.4)$ & 0.06 \\
\hline 94411.02 & ${ }^{13} \mathrm{CH}_{3} \mathrm{OH} 2(0,2)-1(0,1)$ & $0.017(0.004)$ & $1.0(0.4)$ & 0.015 \\
\hline 94541.76 & $\mathrm{CH}_{3} \mathrm{OH} 8(3,5)-9(2,7)$ & $0.138(0.004)$ & $2.0(0.4)$ & 0.06 \\
\hline 95169.46 & $\mathrm{CH}_{3} \mathrm{OH} 8(0,8)-7(1,7)++$ & $0.648(0.003)$ & $0.821(0.006)$ & 0.74 \\
\hline 95914.31 & $\mathrm{CH}_{3} \mathrm{OH} 2(1,2)-1(1,1)++$ & $0.44(0.04)$ & $1.3(0.1)$ & 0.32 \\
\hline 96739.36 & $\mathrm{CH}_{3} \mathrm{OH} 2(-1,2)-1(-1,1)$ & $1.93(0.09)$ & $1.2(0.4)$ & 1.5 \\
\hline 96741.38 & $\mathrm{CH}_{3} \mathrm{OH} 2(0,2)-1(0,1)++$ & $2.70(0.09)$ & $1.2(0.4)$ & 2.12 \\
\hline 96744.55 & $\mathrm{CH}_{3} \mathrm{OH} 2(0,2)-1(0,1)$ & $0.85(0.09)$ & $1.2(0.4)$ & 0.64 \\
\hline 96755.51 & $\mathrm{CH}_{3} \mathrm{OH} 2(1,1)-1(1,0)$ & $0.46(0.09)$ & $1.4(0.4)$ & 0.31 \\
\hline \multicolumn{5}{|c|}{ G75-HCHII } \\
\hline 89505.78 & $\mathrm{CH}_{3} \mathrm{OH} 8(-4,5)-9(-3,7)$ & $0.1(0.1)$ & $0.9(0.8)$ & 0.06 \\
\hline 94405.16 & ${ }^{13} \mathrm{CH}_{3} \mathrm{OH} 2(-1,2)-1(-1,1)$ & $0.033(0.009)$ & $1.6(0.5)$ & 0.02 \\
\hline 94407.13 & ${ }^{13} \mathrm{CH}_{3} \mathrm{OH} 2(0,2)-1(0,1)++$ & $0.025(0.008)$ & $1.0(0.3)$ & 0.024 \\
\hline 94541.76 & $\mathrm{CH}_{3} \mathrm{OH} 8(3,5)-9(2,7)$ & $0.074(0.005)$ & $1.4(0.1)$ & 0.05 \\
\hline 95169.46 & $\mathrm{CH}_{3} \mathrm{OH} 8(0,8)-7(1,7)++$ & $0.934(0.006)$ & $1.98(0.02)$ & 0.44 \\
\hline 95914.31 & $\mathrm{CH}_{3} \mathrm{OH} 2(1,2)-1(1,1)++$ & $0.37(0.06)$ & $1.4(0.25)$ & 0.26 \\
\hline 96739.36 & $\mathrm{CH}_{3} \mathrm{OH} 2(-1,2)-1(-1,1)$ & $1.13(0.06)$ & $1.5(0.4)$ & 0.70 \\
\hline 96741.38 & $\mathrm{CH}_{3} \mathrm{OH} 2(0,2)-1(0,1)++$ & $2.00(0.06)$ & $1.7(0.4)$ & 1.07 \\
\hline 96744.55 & $\mathrm{CH}_{3} \mathrm{OH} 2(0,2)-1(0,1)$ & $0.81(0.06)$ & $1.8(0.4)$ & 0.42 \\
\hline 96755.51 & $\mathrm{CH}_{3} \mathrm{OH} 2(1,1)-1(1,0)$ & $0.34(0.06)$ & $1.3(0.4)$ & 0.24 \\
\hline \multicolumn{5}{|c|}{ I20293-MM1 } \\
\hline 94405.16 & ${ }^{13} \mathrm{CH}_{3} \mathrm{OH} 2(-1,2)-1(-1,1)$ & $0.033(0.008)$ & $1.6(0.5)$ & 0.02 \\
\hline 94407.13 & ${ }^{13} \mathrm{CH}_{3} \mathrm{OH} 2(0,2)-1(0,1)++$ & $0.024(0.007)$ & $0.7(0.2)$ & 0.03 \\
\hline 94541.76 & $\mathrm{CH}_{3} \mathrm{OH} 8(3,5)-9(2,7)$ & $0.04(0.01)$ & $5(1)$ & 0.007 \\
\hline 95169.46 & $\mathrm{CH}_{3} \mathrm{OH} 8(0,8)-7(1,7)++$ & $1.387(0.007)$ & $1.126(0.007)$ & 1.16 \\
\hline 95914.31 & $\mathrm{CH}_{3} \mathrm{OH} 2(1,2)-1(1,1)++$ & $0.15(0.03)$ & $1.5(0.4)$ & 0.09 \\
\hline 96739.36 & $\mathrm{CH}_{3} \mathrm{OH} 2(-1,2)-1(-1,1)$ & $1.28(0.06)$ & $1.2(0.4)$ & 1.01 \\
\hline 96741.38 & $\mathrm{CH}_{3} \mathrm{OH} 2(0,2)-1(0,1)++$ & $1.81(0.06)$ & $1.2(0.4)$ & 1.4 \\
\hline 96744.55 & $\mathrm{CH}_{3} \mathrm{OH} 2(0,2)-1(0,1)$ & $0.81(0.06)$ & $2.9(0.4)$ & 0.26 \\
\hline 96755.51 & $\mathrm{CH}_{3} \mathrm{OH} 2(1,1)-1(1,0)$ & $0.12(0.06)$ & $1.1(0.4)$ & 0.1 \\
\hline \multicolumn{5}{|c|}{ I21307 } \\
\hline 95169.46 & $\mathrm{CH}_{3} \mathrm{OH} 8(0,8)-7(1,7)++$ & $0.201(0.004)$ & $0.64(0.02)$ & 0.3 \\
\hline 95914.31 & $\mathrm{CH}_{3} \mathrm{OH} 2(1,2)-1(1,1)++$ & $0.03(0.01)$ & $1.2(0.6)$ & 0.02 \\
\hline 96739.36 & $\mathrm{CH}_{3} \mathrm{OH} 2(-1,2)-1(-1,1)$ & $0.220(0.004)$ & $0.84(0.02)$ & 0.25 \\
\hline 96741.38 & $\mathrm{CH}_{3} \mathrm{OH} 2(0,2)-1(0,1)++$ & $0.321(0.004)$ & $0.86(0.02)$ & 0.35 \\
\hline 96744.55 & $\mathrm{CH}_{3} \mathrm{OH} 2(0,2)-1(0,1)$ & $0.080(0.005)$ & $0.97(0.06)$ & 0.08 \\
\hline 96755.51 & $\mathrm{CH}_{3} \mathrm{OH} 2(1,1)-1(1,0)$ & $0.026(0.004)$ & $0.9(0.2)$ & 0.03 \\
\hline \multicolumn{5}{|c|}{$\mathrm{I} 23385$} \\
\hline 94405.16 & ${ }^{13} \mathrm{CH}_{3} \mathrm{OH} 2(-1,2)-1(-1,1)$ & $0.015(0.004)$ & $0.9(0.2)$ & 0.016 \\
\hline 94407.13 & ${ }^{13} \mathrm{CH}_{3} \mathrm{OH} 2(0,2)-1(0,1)++$ & $0.013(0.004)$ & $0.9(0.3)$ & 0.013 \\
\hline 95169.46 & $\mathrm{CH}_{3} \mathrm{OH} 8(0,8)-7(1,7)++$ & $0.464(0.005)$ & $1.15(0.02)$ & 0.38 \\
\hline 95914.31 & $\mathrm{CH}_{3} \mathrm{OH} 2(1,2)-1(1,1)++$ & $0.11(0.02)$ & $1.25(0.3)$ & 0.08 \\
\hline 96739.36 & $\mathrm{CH}_{3} \mathrm{OH} 2(-1,2)-1(-1,1)$ & $0.77(0.04)$ & $1.3(0.4)$ & 0.57 \\
\hline 96741.38 & $\mathrm{CH}_{3} \mathrm{OH} 2(0,2)-1(0,1)++$ & $1.13(0.04)$ & $1.3(0.4)$ & 0.8 \\
\hline 96744.55 & $\mathrm{CH}_{3} \mathrm{OH} 2(0,2)-1(0,1)$ & $0.33(0.04)$ & $1.8(0.4)$ & 0.2 \\
\hline 96755.51 & $\mathrm{CH}_{3} \mathrm{OH} 2(1,1)-1(1,0)$ & $0.08(0.04)$ & $0.75(0.4)$ & 0.1 \\
\hline \multicolumn{5}{|c|}{ UC HIIs } \\
\hline \multicolumn{5}{|c|}{ G5.89-0.39 } \\
\hline 94405.16 & ${ }^{13} \mathrm{CH}_{3} \mathrm{OH} 2(-1,2)-1(-1,1)$ & $0.050(0.004)$ & $1.8(0.4)$ & 0.025 \\
\hline 94407.13 & ${ }^{13} \mathrm{CH}_{3} \mathrm{OH} 2(0,2)-1(0,1)++$ & $0.100(0.004)$ & $2.0(0.4)$ & 0.04 \\
\hline 94411.02 & ${ }^{13} \mathrm{CH}_{3} \mathrm{OH} 2(0,2)-1(0,1)$ & $0.03(0.004)$ & $1.0(0.4)$ & 0.03 \\
\hline 94420.45 & ${ }^{13} \mathrm{CH}_{3} \mathrm{OH} 2(1,1)-1(1,0)$ & $0.011(0.004)$ & $1.3(0.4)$ & 0.01 \\
\hline 94541.76 & $\mathrm{CH}_{3} \mathrm{OH} 8(3,5)-9(2,7)$ & $0.052(0.004)$ & $1.4(0.4)$ & 0.03 \\
\hline 95169.46 & $\mathrm{CH}_{3} \mathrm{OH} 8(0,8)-7(1,7)++$ & $2.726(0.007)$ & $1.638(0.007)$ & 1.56 \\
\hline
\end{tabular}


Table B.1. continued.

\begin{tabular}{|c|c|c|c|c|}
\hline $\begin{array}{l}\text { Freq. } \\
\text { MHz }\end{array}$ & Transition & $\underset{\mathrm{K} \mathrm{km} \mathrm{s}^{-1}}{\int_{\mathrm{MB}} \mathrm{d} v}$ & $\begin{array}{l}\Delta V \\
\mathrm{~km} \mathrm{~s}^{-1}\end{array}$ & $\begin{array}{l}T_{\mathrm{pk}} \\
\mathrm{K}\end{array}$ \\
\hline 95914.31 & $\mathrm{CH}_{3} \mathrm{OH} 2(1,2)-1(1,1)++$ & $0.97(0.05)$ & $1.8(0.1)$ & 0.49 \\
\hline 96739.36 & $\mathrm{CH}_{3} \mathrm{OH} 2(-1,2)-1(-1,1)$ & $3.8(0.1)$ & $2.5(0.4)$ & 1.43 \\
\hline 96741.38 & $\mathrm{CH}_{3} \mathrm{OH} 2(0,2)-1(0,1)++$ & $2.4(0.1)$ & $1.4(0.4)$ & 1.66 \\
\hline 96744.55 & $\mathrm{CH}_{3} \mathrm{OH} 2(0,2)-1(0,1)$ & $1.6(0.1)$ & $1.8(0.4)$ & 0.83 \\
\hline 96755.51 & $\mathrm{CH}_{3} \mathrm{OH} 2(1,1)-1(1,0)$ & $0.9(0.1)$ & $1.9(0.4)$ & 0.47 \\
\hline \multicolumn{5}{|c|}{ I19035-VLA1 } \\
\hline 94407.13 & ${ }^{13} \mathrm{CH}_{3} \mathrm{OH} 2(0,2)-1(0,1)++$ & $0.032(0.005)$ & $1.2(0.2)$ & 0.024 \\
\hline 94411.02 & ${ }^{13} \mathrm{CH}_{3} \mathrm{OH} 2(0,2)-1(0,1)$ & $0.008(0.003)$ & $0.4(0.3)$ & 0.02 \\
\hline 94420.45 & ${ }^{13} \mathrm{CH}_{3} \mathrm{OH} 2(1,1)-1(1,0)$ & $0.014(0.006)$ & $2.0(0.8)$ & 0.007 \\
\hline 94541.76 & $\mathrm{CH}_{3} \mathrm{OH} 8(3,5)-9(2,7)$ & $0.033(0.009)$ & $4(1)$ & 0.008 \\
\hline 95169.46 & $\mathrm{CH}_{3} \mathrm{OH} 8(0,8)-7(1,7)++$ & $0.147(0.007)$ & $1.9(0.1)$ & 0.07 \\
\hline 95914.31 & $\mathrm{CH}_{3} \mathrm{OH} 2(1,2)-1(1,1)++$ & $0.12(0.02)$ & $1.7(0.4)$ & 0.065 \\
\hline 96739.36 & $\mathrm{CH}_{3} \mathrm{OH} 2(-1,2)-1(-1,1)$ & $0.98(0.045)$ & $1.5(0.4)$ & 0.62 \\
\hline 96741.38 & $\mathrm{CH}_{3} \mathrm{OH} 2(0,2)-1(0,1)++$ & $1.70(0.045)$ & $1.8(0.4)$ & 0.89 \\
\hline 96744.55 & $\mathrm{CH}_{3} \mathrm{OH} 2(0,2)-1(0,1)$ & $0.52(0.045)$ & $2.1(0.4)$ & 0.23 \\
\hline 96755.51 & $\mathrm{CH}_{3} \mathrm{OH} 2(1,1)-1(1,0)$ & $0.17(0.045)$ & $1.9(0.4)$ & 0.08 \\
\hline \multicolumn{5}{|c|}{$19410+2336$} \\
\hline 94405.16 & ${ }^{13} \mathrm{CH}_{3} \mathrm{OH} 2(-1,2)-1(-1,1)$ & $0.026(0.004)$ & $0.9(0.2)$ & 0.03 \\
\hline 94407.13 & ${ }^{13} \mathrm{CH}_{3} \mathrm{OH} 2(0,2)-1(0,1)++$ & $0.044(0.004)$ & $1.0(0.1)$ & 0.04 \\
\hline 94541.76 & $\mathrm{CH}_{3} \mathrm{OH} 8(3,5)-9(2,7)$ & $0.028(0.005)$ & $1.6(0.4)$ & 0.016 \\
\hline 95169.46 & $\mathrm{CH}_{3} \mathrm{OH} 8(0,8)-7(1,7)++$ & $1.014(0.004)$ & $0.641(0.003)$ & 1.49 \\
\hline 95914.31 & $\mathrm{CH}_{3} \mathrm{OH} 2(1,2)-1(1,1)++$ & $0.24(0.05)$ & $1.0(0.3)$ & 0.22 \\
\hline 96739.36 & $\mathrm{CH}_{3} \mathrm{OH} 2(-1,2)-1(-1,1)$ & $1.56(0.08)$ & $1.0(0.4)$ & 1.51 \\
\hline 96741.38 & $\mathrm{CH}_{3} \mathrm{OH} 2(0,2)-1(0,1)++$ & $2.32(0.08)$ & $1.0(0.4)$ & 2.16 \\
\hline 96744.55 & $\mathrm{CH}_{3} \mathrm{OH} 2(0,2)-1(0,1)$ & $0.61(0.08)$ & $1.0(0.4)$ & 0.57 \\
\hline 96755.51 & $\mathrm{CH}_{3} \mathrm{OH} 2(1,1)-1(1,0)$ & $0.21(0.08)$ & $0.8(0.4)$ & 0.27 \\
\hline \multicolumn{5}{|c|}{ 年 } \\
\hline 94405.16 & ${ }^{13} \mathrm{CH}_{3} \mathrm{OH} 2(-1,2)-1(-1,1)$ & $0.048(0.009)$ & $1.5(0.2)$ & 0.03 \\
\hline 94407.13 & ${ }^{13} \mathrm{CH}_{3} \mathrm{OH} 2(0,2)-1(0,1)++$ & $0.11(0.01)$ & $1.9(0.2)$ & 0.053 \\
\hline 94411.02 & ${ }^{13} \mathrm{CH}_{3} \mathrm{OH} 2(0,2)-1(0,1)$ & $0.010(0.004)$ & $0.9(0.5)$ & 0.011 \\
\hline 94420.45 & ${ }^{13} \mathrm{CH}_{3} \mathrm{OH} 2(1,1)-1(1,0)$ & $0.014(0.005)$ & $2.3(0.8)$ & 0.006 \\
\hline 94541.76 & $\mathrm{CH}_{3} \mathrm{OH} 8(3,5)-9(2,7)$ & $0.065(0.004)$ & $1.3(0.1)$ & 0.047 \\
\hline 95169.46 & $\mathrm{CH}_{3} \mathrm{OH} 8(0,8)-7(1,7)++$ & $0.730(0.007)$ & $0.97(0.01)$ & 0.70 \\
\hline 95914.31 & $\mathrm{CH}_{3} \mathrm{OH} 2(1,2)-1(1,1)++$ & $0.39(0.04)$ & $1.8(0.2)$ & 0.21 \\
\hline 96739.36 & $\mathrm{CH}_{3} \mathrm{OH} 2(-1,2)-1(-1,1)$ & $2.1(0.1)$ & $1.3(0.4)$ & 1.48 \\
\hline 96741.38 & $\mathrm{CH}_{3} \mathrm{OH} 2(0,2)-1(0,1)++$ & $3.9(0.1)$ & $1.8(0.4)$ & 2.01 \\
\hline 96744.55 & $\mathrm{CH}_{3} \mathrm{OH} 2(0,2)-1(0,1)$ & $1.3(0.1)$ & $2.2(0.4)$ & 0.55 \\
\hline 96755.51 & $\mathrm{CH}_{3} \mathrm{OH} 2(1,1)-1(1,0)$ & $0.5(0.1)$ & $1.9(0.4)$ & 0.23 \\
\hline \multicolumn{5}{|c|}{ I22134-VLA1 } \\
\hline 95169.46 & $\mathrm{CH}_{3} \mathrm{OH} 8(0,8)-7(1,7)++$ & $0.022(0.003)$ & $0.7(0.1)$ & 0.03 \\
\hline 95914.31 & $\mathrm{CH}_{3} \mathrm{OH} 2(1,2)-1(1,1)++$ & $0.02(0.02)$ & $1.4(0.9)$ & 0.01 \\
\hline 96739.36 & $\mathrm{CH}_{3} \mathrm{OH} 2(-1,2)-1(-1,1)$ & $0.23(0.01)$ & $0.9(0.4)$ & 0.25 \\
\hline 96741.38 & $\mathrm{CH}_{3} \mathrm{OH} 2(0,2)-1(0,1)++$ & $0.30(0.01)$ & $0.744(0.4)$ & 0.38 \\
\hline 96744.55 & $\mathrm{CH}_{3} \mathrm{OH} 2(0,2)-1(0,1)$ & $0.06(0.01)$ & $0.7(0.4)$ & 0.085 \\
\hline 96755.51 & $\mathrm{CH}_{3} \mathrm{OH} 2(1,1)-1(1,0)$ & $0.01(0.01)$ & $0.5(0.4)$ & 0.026 \\
\hline \multicolumn{5}{|c|}{$23033+5951$} \\
\hline 94405.16 & ${ }^{13} \mathrm{CH}_{3} \mathrm{OH} 2(-1,2)-1(-1,1)$ & $0.022(0.005)$ & $1.2(0.3)$ & 0.017 \\
\hline 94407.13 & ${ }^{13} \mathrm{CH}_{3} \mathrm{OH} 2(0,2)-1(0,1)++$ & $0.034(0.004)$ & $1.2(0.3)$ & 0.026 \\
\hline 95169.46 & $\mathrm{CH}_{3} \mathrm{OH} 8(0,8)-7(1,7)++$ & $0.634(0.003)$ & $0.647(0.004)$ & 0.92 \\
\hline 95914.31 & $\mathrm{CH}_{3} \mathrm{OH} 2(1,2)-1(1,1)++$ & $0.09(0.03)$ & $1.1(0.5)$ & 0.07 \\
\hline 96739.36 & $\mathrm{CH}_{3} \mathrm{OH} 2(-1,2)-1(-1,1)$ & $1.59(0.07)$ & $1.1(0.4)$ & 1.33 \\
\hline 96741.38 & $\mathrm{CH}_{3} \mathrm{OH} 2(0,2)-1(0,1)++$ & $1.94(0.07)$ & $1.0(0.4)$ & 1.75 \\
\hline 96744.55 & $\mathrm{CH}_{3} \mathrm{OH} 2(0,2)-1(0,1)$ & $0.32(0.07)$ & $1.0(0.4)$ & 0.31 \\
\hline 96755.51 & $\mathrm{CH}_{3} \mathrm{OH} 2(1,1)-1(1,0)$ & $0.1(0.2)$ & $1.1(0.9)$ & 0.09 \\
\hline \multicolumn{5}{|c|}{ NGC 7538-IRS9 } \\
\hline 94405.16 & ${ }^{13} \mathrm{CH}_{3} \mathrm{OH} 2(-1,2)-1(-1,1)$ & $0.020(0.004)$ & $1.1(0.3)$ & 0.02 \\
\hline 94407.13 & ${ }^{13} \mathrm{CH}_{3} \mathrm{OH} 2(0,2)-1(0,1)++$ & $0.019(0.004)$ & $0.7(0.2)$ & 0.03 \\
\hline 95169.46 & $\mathrm{CH}_{3} \mathrm{OH} 8(0,8)-7(1,7)++$ & $0.904(0.003)$ & $0.737(0.002)$ & 1.15 \\
\hline 95914.31 & $\mathrm{CH}_{3} \mathrm{OH} 2(1,2)-1(1,1)++$ & $0.15(0.03)$ & $1.1(0.2)$ & 0.13 \\
\hline 96739.36 & $\mathrm{CH}_{3} \mathrm{OH} 2(-1,2)-1(-1,1)$ & $0.95(0.05)$ & $1.2(0.4)$ & 0.77 \\
\hline 96741.38 & $\mathrm{CH}_{3} \mathrm{OH} 2(0,2)-1(0,1)++$ & $1.67(0.05)$ & $1.5(0.4)$ & 1.06 \\
\hline 96744.55 & $\mathrm{CH}_{3} \mathrm{OH} 2(0,2)-1(0,1)$ & $0.46(0.05)$ & $1.6(0.4)$ & 0.28 \\
\hline 96755.51 & $\mathrm{CH}_{3} \mathrm{OH} 2(1,1)-1(1,0)$ & $0.17(0.05)$ & $1.4(0.4)$ & 0.11 \\
\hline
\end{tabular}


Table B.2. Same as Table B.1 for the transitions detected at $1 \mathrm{~mm}$.

\begin{tabular}{|c|c|c|c|c|}
\hline $\begin{array}{l}\text { Freq. } \\
\mathrm{MHz}\end{array}$ & Transition & $\begin{array}{l}\int T_{\mathrm{MB}} \mathrm{d} v \\
\mathrm{~K} \mathrm{~km} \mathrm{~s}^{-1}\end{array}$ & $\begin{array}{l}\Delta V \\
\mathrm{~km} \mathrm{~s}^{-1}\end{array}$ & $\begin{array}{l}T_{\mathrm{pk}} \\
\mathrm{K}\end{array}$ \\
\hline \multicolumn{5}{|c|}{ HMSCs } \\
\hline \multicolumn{5}{|c|}{ I00117-MM2 } \\
\hline 218440.05 & $\mathrm{CH}_{3} \mathrm{OH} 4(2,2)-3(1,2)$ & $0.29(0.03)$ & $1.9(0.2)$ & 0.14 \\
\hline \multicolumn{5}{|c|}{ AFGL5142-EC } \\
\hline 216945.6 & $\mathrm{CH}_{3} \mathrm{OH} 5(1,4)-4(2,2)$ & $1.9(0.3)$ & $3.3(0.6)$ & 0.53 \\
\hline 218440.05 & $\mathrm{CH}_{3} \mathrm{OH} 4(2,2)-3(1,2)$ & 10.1(0.4) & $2.9(0.1)$ & 3.23 \\
\hline 220078.5 & $\mathrm{CH}_{3} \mathrm{OH} 8(0,8)-7(1,6)$ & $2(1)$ & $3.7(0.9)$ & 0.59 \\
\hline 223071.3 & $\mathrm{CH}_{2} \mathrm{DOH} 5(2,3)-4(1,4) \mathrm{e} 1$ & $0.02(0.01)$ & $0.4(0.8)$ & 0.06 \\
\hline 223107.3 & $\mathrm{CH}_{2}$ DOH $5(0,5)-4(0,4) \mathrm{o} 1$ & $0.03(0.02)$ & $0.6(0.3)$ & 0.04 \\
\hline 223153.7 & $\mathrm{CH}_{2} \mathrm{DOH} 5(3,2)-4(3,1) \mathrm{o} 1$ & $0.06(0.03)$ & $2.1(0.7)$ & 0.03 \\
\hline 223315.4 & $\mathrm{CH}_{2} \mathrm{DOH} 5(2,3)-4(2,2) \mathrm{e} 1$ & $0.05(0.02)$ & $2.0(0.7)$ & $0.024^{a}$ \\
\hline 223422.3 & $\mathrm{CH}_{2} \mathrm{DOH} 5(2,4)-4(2,3) \mathrm{e} 0$ & $0.09(0.02)$ & $2.6(0.6)$ & $0.032^{a}$ \\
\hline \multicolumn{5}{|c|}{$05358-\mathrm{mm} 3$} \\
\hline 216945.60 & $\mathrm{CH}_{3} \mathrm{OH} 5(1,4)-4(2,2)$ & $0.67(0.06)$ & $2.2(0.3)$ & 0.29 \\
\hline 218440.05 & $\mathrm{CH}_{3} \mathrm{OH} 4(2,2)-3(1,2)$ & $5.1(0.2)$ & $1.96(0.08)$ & 2.46 \\
\hline 220078.49 & $\mathrm{CH}_{3} \mathrm{OH} 8(0,8)-7(1,6)$ & $0.8(0.4)$ & $2(1)$ & 0.32 \\
\hline \multicolumn{5}{|c|}{ G034-G2 } \\
\hline 218440.05 & $\mathrm{CH}_{3} \mathrm{OH} 4(2,2)-3(1,2)$ & $0.11(0.02)$ & $2.4(0.6)$ & 0.045 \\
\hline \multicolumn{5}{|c|}{ G034-F2 } \\
\hline- & - & - & - & - \\
\hline \multicolumn{5}{|c|}{ G034-F1 } \\
\hline 218440.05 & $\mathrm{CH}_{3} \mathrm{OH} 4(2,2)-3(1,2)$ & $0.10(0.02)$ & $2.100(0.001)$ & 0.043 \\
\hline \multicolumn{5}{|c|}{ G028-C1 } \\
\hline 218440.05 & $\mathrm{CH}_{3} \mathrm{OH} 4(2,2)-3(1,2)$ & $0.09(0.014)$ & $1.188(0.001)$ & 0.074 \\
\hline \multicolumn{5}{|c|}{ I20293-WC } \\
\hline 218440.05 & $\mathrm{CH}_{3} \mathrm{OH} 4(2,2)-3(1,2)$ & $0.05(0.015)$ & $2.0(0.7)$ & 0.024 \\
\hline \multicolumn{5}{|c|}{ I22134-G } \\
\hline 218440.05 & $\mathrm{CH}_{3} \mathrm{OH} 4(2,2)-3(1,2)$ & $0.23(0.02)$ & $1.1(0.1)$ & 0.20 \\
\hline \multicolumn{5}{|c|}{ I22134-B } \\
\hline 218440.05 & $\mathrm{CH}_{3} \mathrm{OH} 4(2,2)-3(1,2)$ & $0.06(0.02)$ & $2.1(0.7)$ & 0.03 \\
\hline \multicolumn{5}{|c|}{ HMPOs } \\
\hline \multicolumn{5}{|c|}{ I00117-MM1 } \\
\hline 218440.05 & $\mathrm{CH}_{3} \mathrm{OH} 4(2,2)-3(1,2)$ & $0.19(0.02)$ & $1.9(0.3)$ & 0.10 \\
\hline \multicolumn{5}{|c|}{ AFGL5142-MM } \\
\hline 216945.60 & $\mathrm{CH}_{3} \mathrm{OH} 5(1,4)-4(2,2)$ & $1.9(0.2)$ & $3.2(0.5)$ & 0.55 \\
\hline 217886.39 & $\mathrm{CH}_{3} \mathrm{OH} 20(1,19)-20(0,20)$ & $0.59(0.06)$ & $5.8(0.7)$ & 0.09 \\
\hline 218440.05 & $\mathrm{CH}_{3} \mathrm{OH} 4(2,2)-3(1,2)$ & $9.9(0.4)$ & $2.7(0.1)$ & 3.46 \\
\hline 219983.99 & $\mathrm{CH}_{3} \mathrm{OH} 25(3,22)-24(4,20)$ & $0.10(0.09)$ & $2.7(0.6)$ & 0.037 \\
\hline 219993.94 & $\mathrm{CH}_{3} \mathrm{OH} 23(5,19)-22(6,17)$ & $0.04(0.03)$ & $1.7(0.5)$ & 0.02 \\
\hline 220078.49 & $\mathrm{CH}_{3} \mathrm{OH} 8(0,8)-7(1,6)$ & $2(1)$ & $3(1)$ & 0.6 \\
\hline 223071.3 & $\mathrm{CH}_{2} \mathrm{DOH} 5(2,3)-4(1,4) \mathrm{e} 1$ & $0.06(0.02)$ & $1.6(0.7)$ & $0.034^{a}$ \\
\hline 223308.57 & $\mathrm{CH}_{3} \mathrm{OD} 5(1,5)-4(1,4) \mathrm{A}++$ & $0.08(0.02)$ & $1.4(0.4)$ & $0.05^{a}$ \\
\hline \multicolumn{5}{|c|}{$05358-\mathrm{mm} 1$} \\
\hline 216945.60 & $\mathrm{CH}_{3} \mathrm{OH} 5(1,4)-4(2,2)$ & $0.92(0.07)$ & $3.3(0.4)$ & 0.26 \\
\hline 217886.39 & $\mathrm{CH}_{3} \mathrm{OH} 20(1,19)-20(0,20)$ & $0.25(0.08)$ & $8(2)$ & 0.03 \\
\hline 218440.05 & $\mathrm{CH}_{3} \mathrm{OH} 4(2,2)-3(1,2)$ & $4.6(0.2)$ & $2.5(0.2)$ & 1.75 \\
\hline 220078.49 & $\mathrm{CH}_{3} \mathrm{OH} 8(0,8)-7(1,6)$ & $1.0(0.4)$ & $3(1)$ & 0.33 \\
\hline \multicolumn{5}{|c|}{$18089-1732$} \\
\hline 216945.60 & $\mathrm{CH}_{3} \mathrm{OH} 5(1,4)-4(2,2)$ & $3.3(0.2)$ & $3.5(0.2)$ & 0.89 \\
\hline 217399.54 & ${ }^{13} \mathrm{CH}_{3} \mathrm{OH} 10(2,8)-9(3,7) \mathrm{A}++$ & $0.96(0.08)$ & $4.4(0.4)$ & 0.20 \\
\hline 217886.39 & $\mathrm{CH}_{3} \mathrm{OH} 20(1,19)-20(0,20)$ & $1.39(0.08)$ & $3.8(0.3)$ & 0.34 \\
\hline 218440.05 & $\mathrm{CH}_{3} \mathrm{OH} 4(2,2)-3(1,2)$ & $8.6(0.3)$ & $3.3(0.1)$ & 2.44 \\
\hline 219983.99 & $\mathrm{CH}_{3} \mathrm{OH} 25(3,22)-24(4,20)$ & $0.4(0.6)$ & $3.6(0.9)$ & 0.09 \\
\hline 219993.94 & $\mathrm{CH}_{3} \mathrm{OH} 23(5,19-22(6,17)$ & $0.4(0.6)$ & $4.0(0.9)$ & 0.09 \\
\hline 220078.49 & $\mathrm{CH}_{3} \mathrm{OH} 8(0,8)-7(1,6)$ & $3.7(0.7)$ & $3.7(0.8)$ & 0.93 \\
\hline 223071.3 & $\mathrm{CH}_{2} \mathrm{DOH} 5(2,3)-4(1,4) \mathrm{e} 1$ & $0.08(0.06)$ & $2.4(0.3)$ & 0.03 \\
\hline 223107.3 & $\mathrm{CH}_{2} \mathrm{DOH} 5(0,5)-4(0,4) \mathrm{o} 1$ & $0.08(0.06)$ & $1.3(0.5)$ & 0.057 \\
\hline 223153.7 & $\mathrm{CH}_{2} \mathrm{DOH} 5(3,2)-4(3,1) \mathrm{o} 1$ & $0.07(0.06)$ & $1.0(0.5)$ & 0.06 \\
\hline 222468.34 & ${ }^{13} \mathrm{CH}_{3} \mathrm{OH} 21(1,20)-21(0,21)$ & $0.06(0.1)$ & $1.7(0.5)$ & 0.03 \\
\hline
\end{tabular}

Notes. ${ }^{(a)}$ Tentative detection in between 2 and $3 \sigma \mathrm{rms} ;{ }^{(b)}$ partially blended with $\left(\mathrm{CH}_{2} \mathrm{OH}\right)_{2}$ (ethylene-glycol). 
Table B.2. continued.

\begin{tabular}{|c|c|c|c|c|}
\hline $\begin{array}{l}\text { Freq. } \\
\mathrm{MHz}\end{array}$ & Transition & $\begin{array}{l}\int_{\mathrm{K}} T_{\mathrm{MB}} \mathrm{d} v \\
\mathrm{~km} \mathrm{~s}^{-1}\end{array}$ & $\begin{array}{l}\Delta V \\
\mathrm{~km} \mathrm{~s}^{-1}\end{array}$ & $\begin{array}{l}T_{\mathrm{pk}} \\
\mathrm{K}\end{array}$ \\
\hline 223308.57 & $\mathrm{CH}_{3} \mathrm{OD} 5(1,5)-4(1,4) \mathrm{A}++$ & $0.21(0.06)$ & $2.6(0.7)$ & $0.08^{b}$ \\
\hline 223315.4 & $\mathrm{CH}_{2} \mathrm{DOH} 5(2,3)-4(2,2) \mathrm{e} 1$ & $0.06(0.04)$ & $1.2(0.7)$ & 0.05 \\
\hline \multicolumn{5}{|c|}{$18517+0437$} \\
\hline 216945.60 & $\mathrm{CH}_{3} \mathrm{OH} 5(1,4)-4(2,2)$ & $2.3(0.2)$ & $3.6(0.3)$ & 0.59 \\
\hline 217886.39 & $\mathrm{CH}_{3} \mathrm{OH} 20(1,19)-20(0,20)$ & $0.97(0.07)$ & $4.6(0.4)$ & 0.20 \\
\hline 218440.05 & $\mathrm{CH}_{3} \mathrm{OH} 4(2,2)-3(1,2)$ & $5.8(0.3)$ & $2.7(0.2)$ & 2.0 \\
\hline 219983.99 & $\mathrm{CH}_{3} \mathrm{OH} 25(3,22)-24(4,20)$ & $0.14(0.09)$ & $3.8(0.8)$ & 0.034 \\
\hline 219993.94 & $\mathrm{CH}_{3} \mathrm{OH} 23(5,19)-22(6,17)$ & $0.13(0.09)$ & $3.3(0.5)$ & 0.038 \\
\hline 220078.49 & $\mathrm{CH}_{3} \mathrm{OH} 8(0,8)-7(1,6)$ & $2.1(0.7)$ & $3.9(0.9)$ & 0.52 \\
\hline 221285.24 & ${ }^{13} \mathrm{CH}_{3} \mathrm{OH} 8(-1,8)-7(0,7)$ & $0.39(0.03)$ & $3.8(0.3)$ & 0.095 \\
\hline \multicolumn{5}{|c|}{ G75-HCHII } \\
\hline 216945.60 & $\mathrm{CH}_{3} \mathrm{OH} 5(1,4)-4(2,2)$ & $2.3(0.2)$ & $3.1(0.2)$ & 0.69 \\
\hline 217399.54 & ${ }^{13} \mathrm{CH}_{3} \mathrm{OH} 10(2,8)-9(3,7) \mathrm{A}++$ & $0.57(0.06)$ & $2.7(0.4)$ & 0.20 \\
\hline 217886.39 & $\mathrm{CH}_{3} \mathrm{OH} 20(1,19)-20(0,20)$ & $0.45(0.06)$ & $3.0(0.5)$ & 0.14 \\
\hline 218440.05 & $\mathrm{CH}_{3} \mathrm{OH} 4(2,2)-3(1,2)$ & $6.4(0.3)$ & $3.1(0.2)$ & 1.92 \\
\hline 220078.49 & $\mathrm{CH}_{3} \mathrm{OH} 8(0,8)-7(1,6)$ & $2.2(0.8)$ & $3.1(0.9)$ & 0.66 \\
\hline 223107.3 & $\mathrm{CH}_{2} \mathrm{DOH} 5(0,5)-4(0,4) \mathrm{o} 1$ & $0.07(0.03)$ & $2.2(0.9)$ & 0.03 \\
\hline 223422.3 & $\mathrm{CH}_{2} \mathrm{DOH} 5(2,4)-4(2,3) \mathrm{e} 0$ & $0.04(0.02)$ & $0.8(0.3)$ & 0.05 \\
\hline \multicolumn{5}{|c|}{ I20293-MM1 } \\
\hline 216945.60 & $\mathrm{CH}_{3} \mathrm{OH} 5(1,4)-4(2,2)$ & $0.18(0.06)$ & $2.9(0.9)$ & 0.06 \\
\hline 218440.05 & $\mathrm{CH}_{3} \mathrm{OH} 4(2,2)-3(1,2)$ & $0.22(0.03)$ & $2.7(0.4)$ & 0.075 \\
\hline 220078.49 & $\mathrm{CH}_{3} \mathrm{OH} 8(0,8)-7(1,6)$ & $0.4(0.2)$ & $5.4(0.9)$ & 0.06 \\
\hline \multicolumn{5}{|c|}{ I21307 } \\
\hline 216945.60 & $\mathrm{CH}_{3} \mathrm{OH} 5(1,4)-4(2,2)$ & $0.10(0.02)$ & $1.9(0.4)$ & 0.05 \\
\hline 218440.05 & $\mathrm{CH}_{3} \mathrm{OH} 4(2,2)-3(1,2)$ & $0.99(0.05)$ & $2.0(0.1)$ & 0.47 \\
\hline 220078.49 & $\mathrm{CH}_{3} \mathrm{OH} 8(0,8)-7(1,6)$ & $0.1(0.2)$ & $2.5(0.9)$ & 0.04 \\
\hline \multicolumn{5}{|c|}{$\mathrm{I} 23385$} \\
\hline 216945.60 & $\mathrm{CH}_{3} \mathrm{OH} 5(1,4)-4(2,2)$ & $0.22(0.04)$ & $3.0(0.8)$ & 0.07 \\
\hline 218440.05 & $\mathrm{CH}_{3} \mathrm{OH} 4(2,2)-3(1,2)$ & $1.9(0.07)$ & $2.7(0.1)$ & 0.66 \\
\hline 220078.49 & $\mathrm{CH}_{3} \mathrm{OH} 8(0,8)-7(1,6)$ & $0.3(0.2)$ & $3.2(0.9)$ & 0.08 \\
\hline \multicolumn{5}{|c|}{ UC HIIs } \\
\hline \multicolumn{5}{|c|}{ G5.89-0.39 } \\
\hline 216945.60 & $\mathrm{CH}_{3} \mathrm{OH} 5(1,4)-4(2,2)$ & $4(1)$ & $5(1)$ & 0.82 \\
\hline 217886.39 & $\mathrm{CH}_{3} \mathrm{OH} 20(1,19)-20(0,20)$ & $0.08(0.08)$ & $3.7(0.6)$ & 0.02 \\
\hline 218440.05 & $\mathrm{CH}_{3} \mathrm{OH} 4(2,2)-3(1,2)$ & $20(2)$ & $4.8(0.7)$ & 3.87 \\
\hline 220078.49 & $\mathrm{CH}_{3} \mathrm{OH} 8(0,8)-7(1,6)$ & $5.3(0.8)$ & $4.8(0.7)$ & 1.04 \\
\hline 221285.24 & ${ }^{13} \mathrm{CH}_{3} \mathrm{OH} 8(-1,8)-7(0,7)$ & $0.35(0.05)$ & $4.8(0.8)$ & 0.07 \\
\hline \multicolumn{5}{|c|}{ I19035-VLA1 } \\
\hline 216945.60 & $\mathrm{CH}_{3} \mathrm{OH} 5(1,4)-4(2,2)$ & $0.50(0.05)$ & $4.2(0.5)$ & 0.11 \\
\hline 218440.05 & $\mathrm{CH}_{3} \mathrm{OH} 4(2,2)-3(1,2)$ & $2.01(0.07)$ & $3.6(0.15)$ & 0.52 \\
\hline 220078.49 & $\mathrm{CH}_{3} \mathrm{OH} 8(0,8)-7(1,6)$ & $0.6(0.3)$ & $5.0(0.9)$ & 0.12 \\
\hline \multicolumn{5}{|c|}{$19410+2336$} \\
\hline 216945.60 & $\mathrm{CH}_{3} \mathrm{OH} 5(1,4)-4(2,2)$ & $0.55(0.04)$ & $3.3(0.3)$ & 0.16 \\
\hline 218440.05 & $\mathrm{CH}_{3} \mathrm{OH} 4(2,2)-3(1,2)$ & $0.38(0.02)$ & $2.1(0.2)$ & 0.17 \\
\hline 220078.49 & $\mathrm{CH}_{3} \mathrm{OH} 8(0,8)-7(1,6)$ & $0.6(0.4)$ & $3.8(0.9)$ & 0.14 \\
\hline \multicolumn{5}{|c|}{ ON1 } \\
\hline 216945.60 & $\mathrm{CH}_{3} \mathrm{OH} 5(1,4)-4(2,2)$ & $1.0(0.1)$ & $3.6(0.5)$ & 0.25 \\
\hline 218440.05 & $\mathrm{CH}_{3} \mathrm{OH} 4(2,2)-3(1,2)$ & $0.44(0.03)$ & $3.1(0.2)$ & 0.14 \\
\hline 220078.49 & $\mathrm{CH}_{3} \mathrm{OH} 8(0,8)-7(1,6)$ & $1.1(0.6)$ & $4.2(0.9)$ & 0.25 \\
\hline 221285.24 & ${ }^{13} \mathrm{CH}_{3} \mathrm{OH} 8(-1,8)-7(0,7)$ & $0.12(0.02)$ & $3.4(0.6)$ & 0.033 \\
\hline \multicolumn{5}{|c|}{ I22134-VLA1 } \\
\hline 218440.05 & $\mathrm{CH}_{3} \mathrm{OH} 4(2,2)-3(1,2)$ & $0.23(0.03)$ & $1.4(0.2)$ & 0.16 \\
\hline 220078.49 & $\mathrm{CH}_{3} \mathrm{OH} 8(0,8)-7(1,6)$ & $0.03(0.05)$ & $1.1(0.7)$ & 0.03 \\
\hline \multicolumn{5}{|c|}{ 23033-UCHII } \\
\hline 216945.60 & $\mathrm{CH}_{3} \mathrm{OH} 5(1,4)-4(2,2)$ & $0.21(0.04)$ & $2.9(0.7)$ & 0.07 \\
\hline 218440.05 & $\mathrm{CH}_{3} \mathrm{OH} 4(2,2)-3(1,2)$ & $1.49(0.06)$ & $2.3(0.1)$ & 0.6 \\
\hline 220078.49 & $\mathrm{CH}_{3} \mathrm{OH} 8(0,8)-7(1,6)$ & $0.3(0.3)$ & $4.7(0.9)$ & 0.06 \\
\hline \multicolumn{5}{|c|}{ NGC7538-IRS9 } \\
\hline 216945.60 & $\mathrm{CH}_{3} \mathrm{OH} 5(1,4)-4(2,2)$ & $0.45(0.04)$ & $3.1(0.3)$ & 0.14 \\
\hline 218440.05 & $\mathrm{CH}_{3} \mathrm{OH} 4(2,2)-3(1,2)$ & $2.42(0.09)$ & $2.4(0.1)$ & 0.94 \\
\hline 220078.49 & $\mathrm{CH}_{3} \mathrm{OH} 8(0,8)-7(1,6)$ & $0.5(0.3)$ & $3.3(0.9)$ & 0.15 \\
\hline
\end{tabular}




\section{Appendix C: Boltzmann plots for $\mathrm{CH}_{3} \mathrm{OH}$ and ${ }^{13} \mathrm{CH}_{3} \mathrm{OH}$}

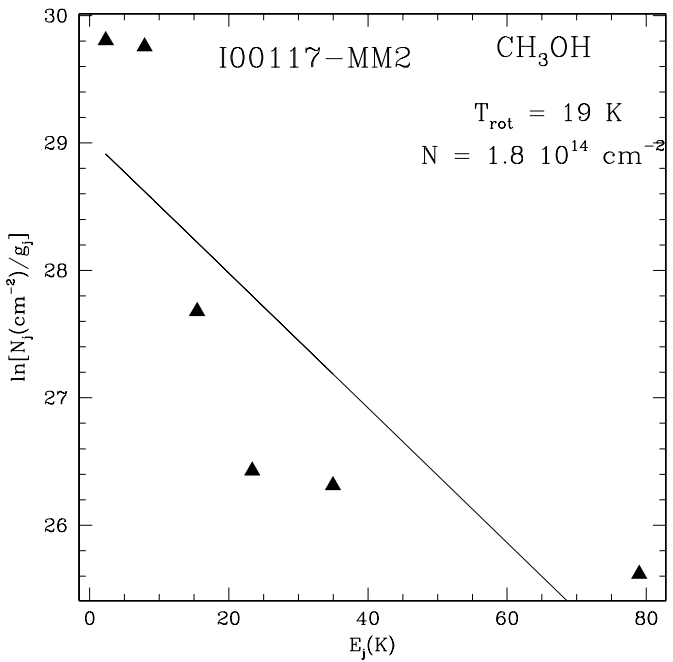

Fig. C.1. Rotation diagram obtained from the lines of $\mathrm{CH}_{3} \mathrm{OH}$ for core I00117-MM2.
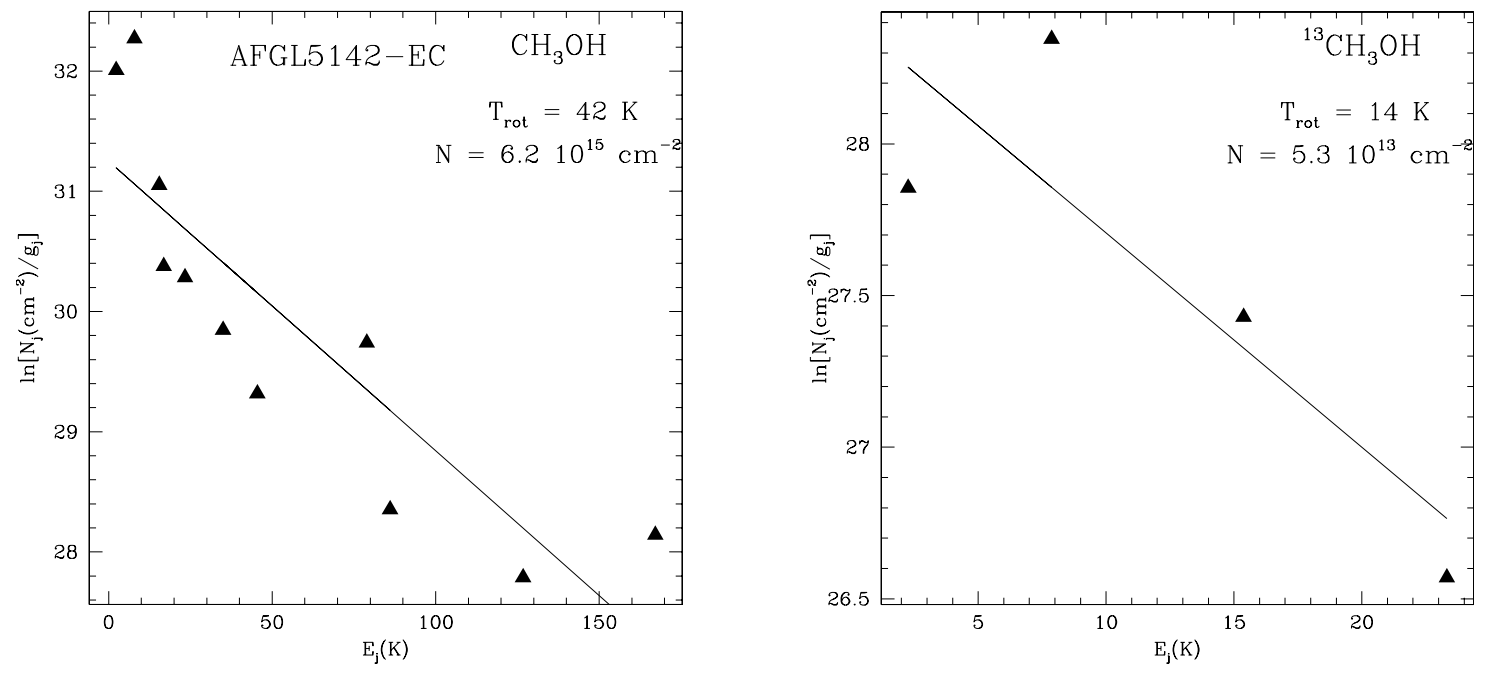

Fig. C.2. Rotation diagram obtained from the lines of $\mathrm{CH}_{3} \mathrm{OH}$ and ${ }^{13} \mathrm{CH}_{3} \mathrm{OH}$ for core AFGL5142-EC.
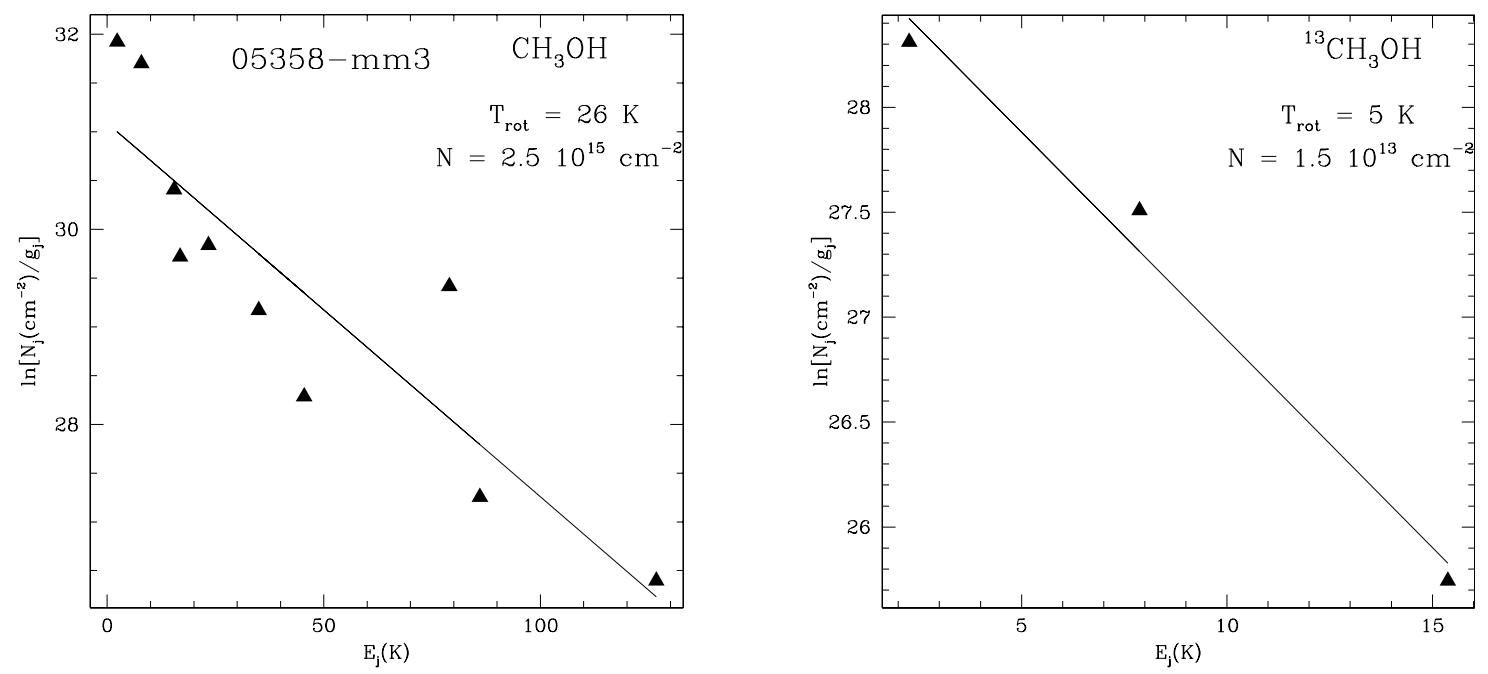

Fig. C.3. Same as Fig. C.2 for core 05358-mm3. 
F. Fontani et al.: Deuteration in massive star formation

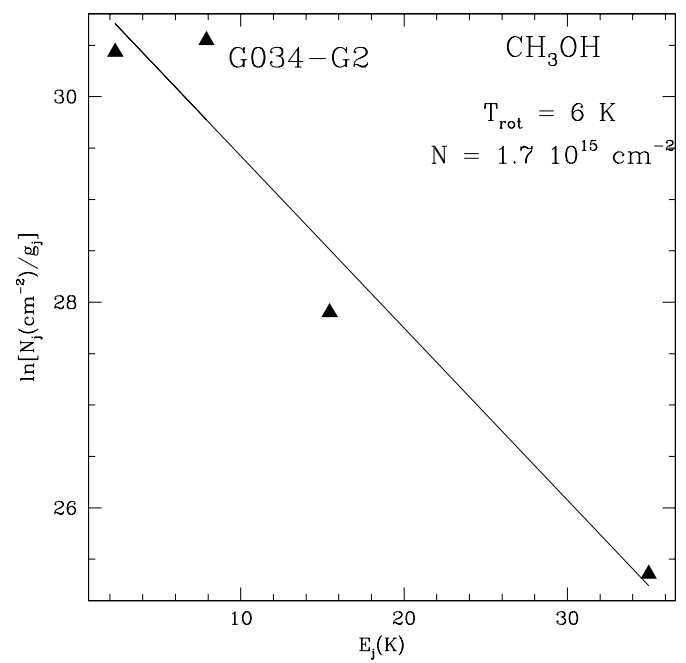

Fig. C.4. Same as Fig. C.1 for core G034-G2.

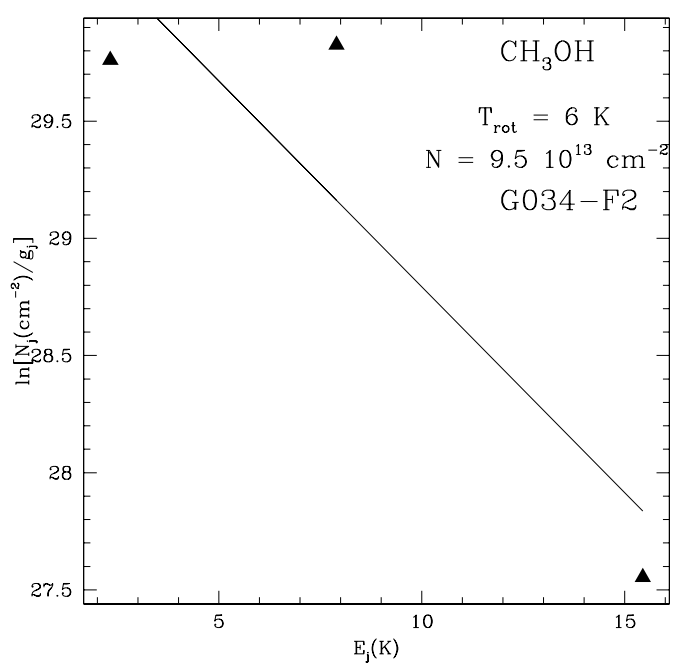

Fig. C.5. Same as Fig. C.1 for core G034-F2.

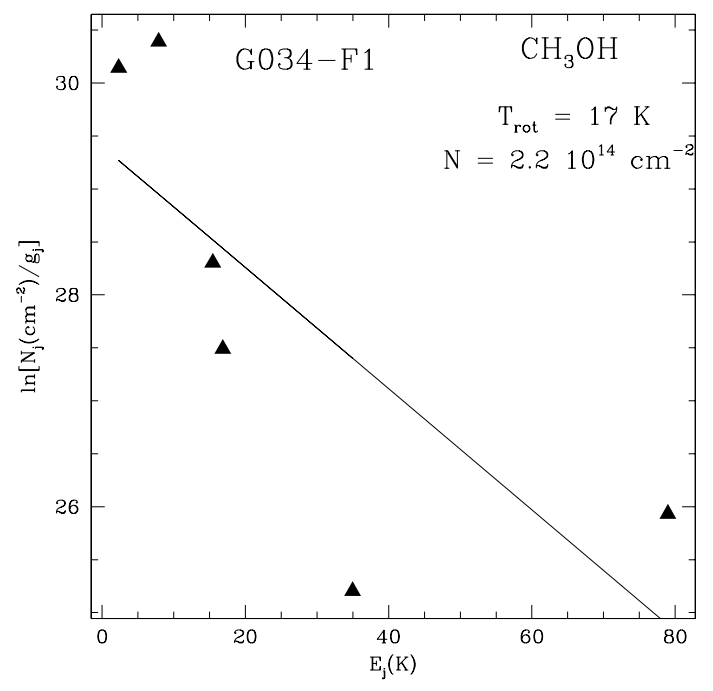

Fig. C.6. Same as Fig. C.1 for core G034-F1.
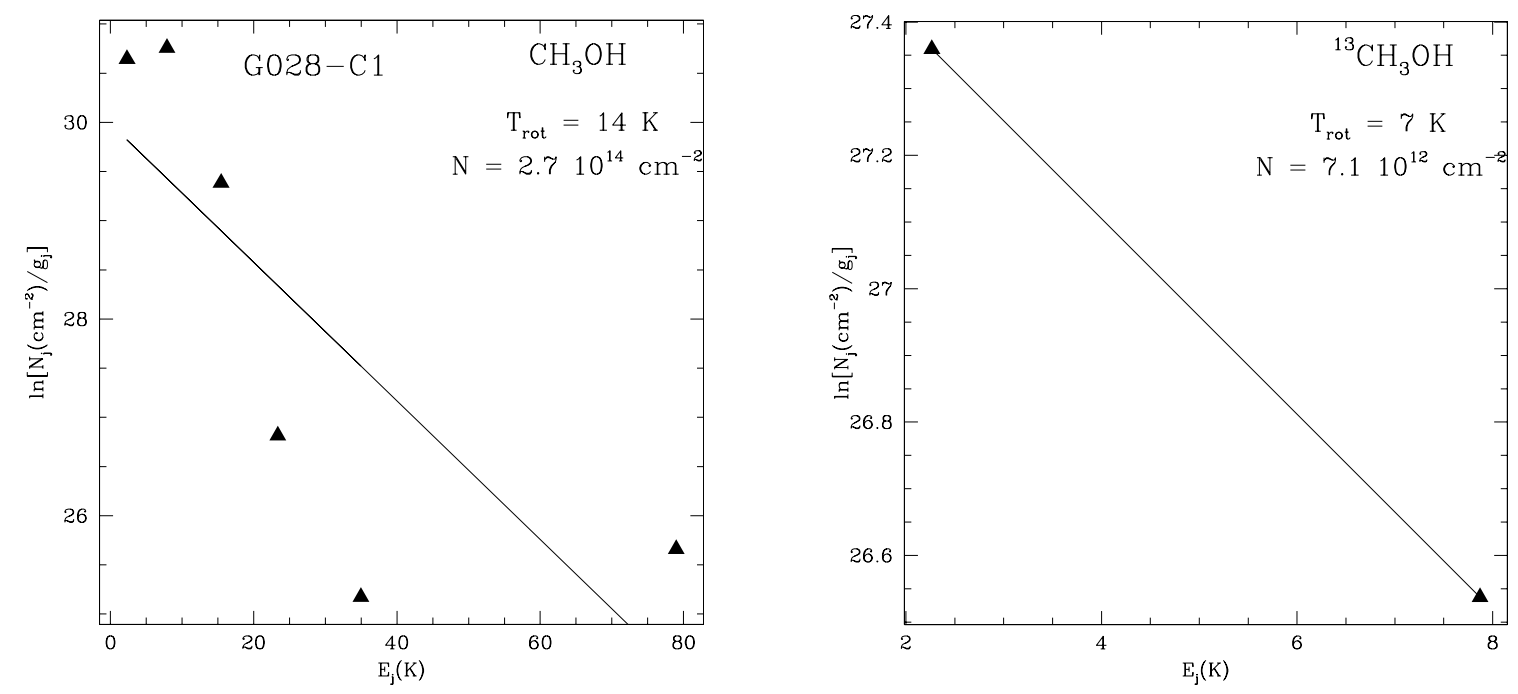

Fig. C.7. Same as Fig. C. 2 for core G028-C1. 
A\&A 575, A87 (2015)

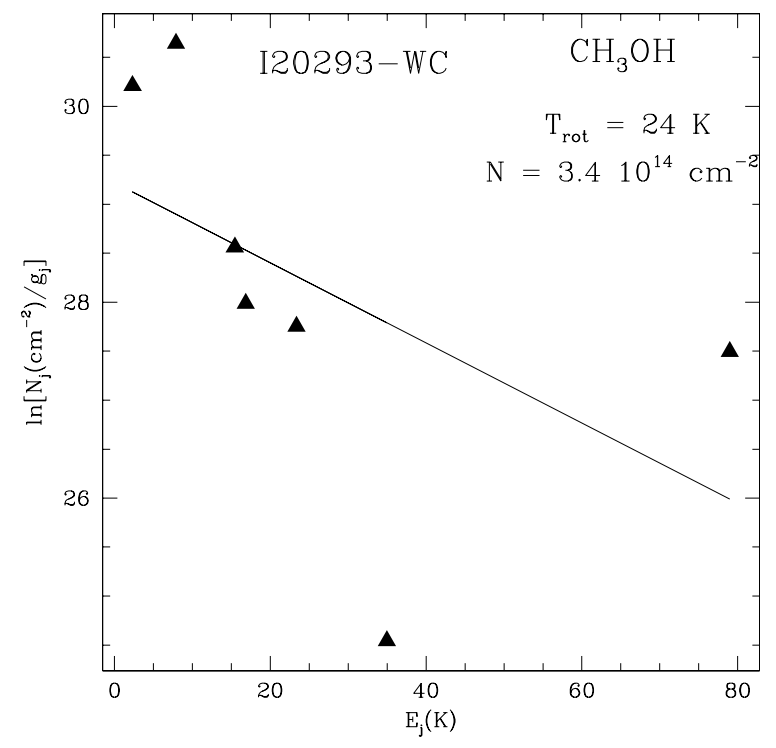

Fig. C.8. Same as Fig. C.1 for core I20293-WC.

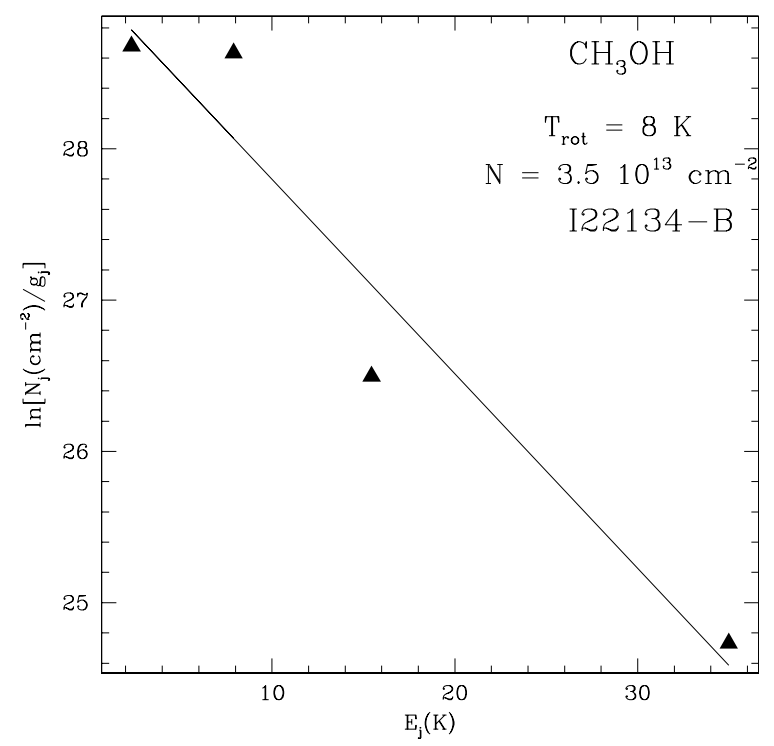

Fig. C.10. Same as Fig. C.1 for core I22134-B.

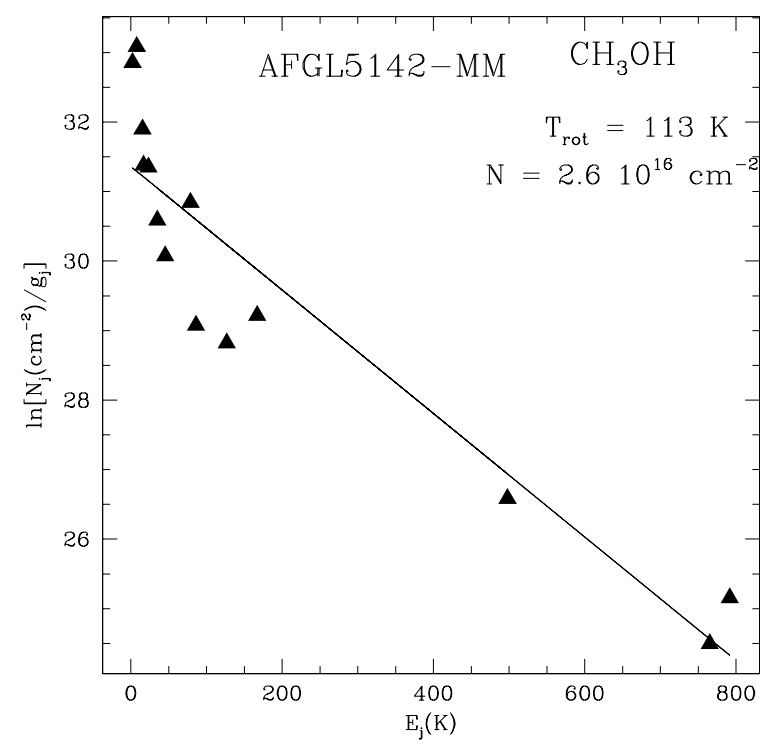

Fig. C.12. Same as Fig. C.2 for core AFGL5142-MM.

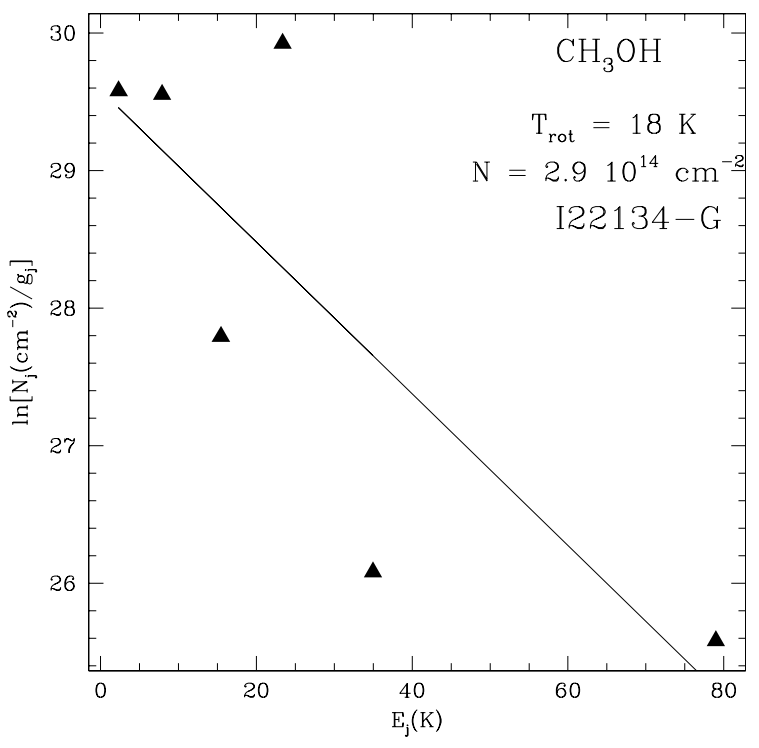

Fig. C.9. Same as Fig. C.1 for core I22134-G.

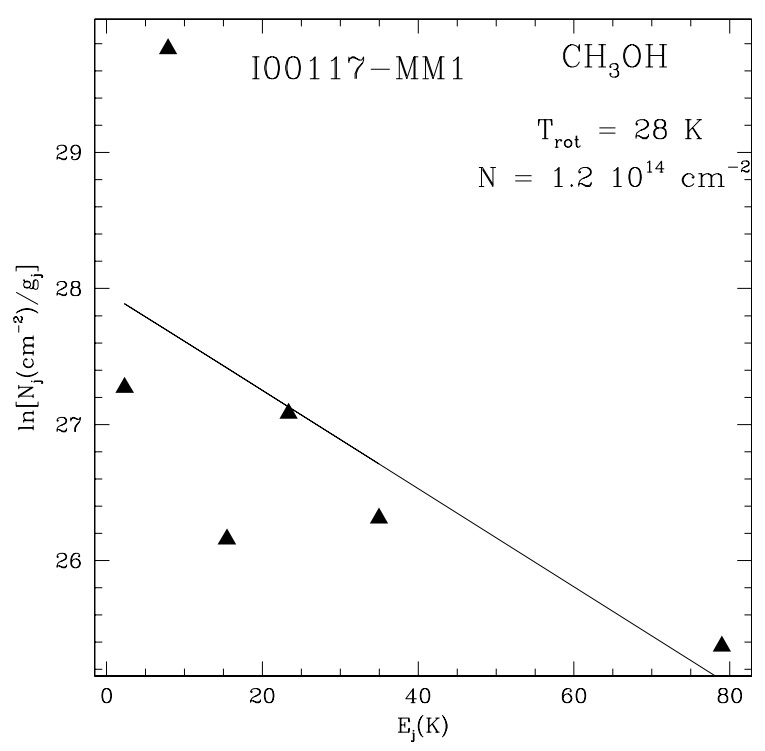

Fig. C.11. Same as Fig. C.1 for core I00117-MM1.

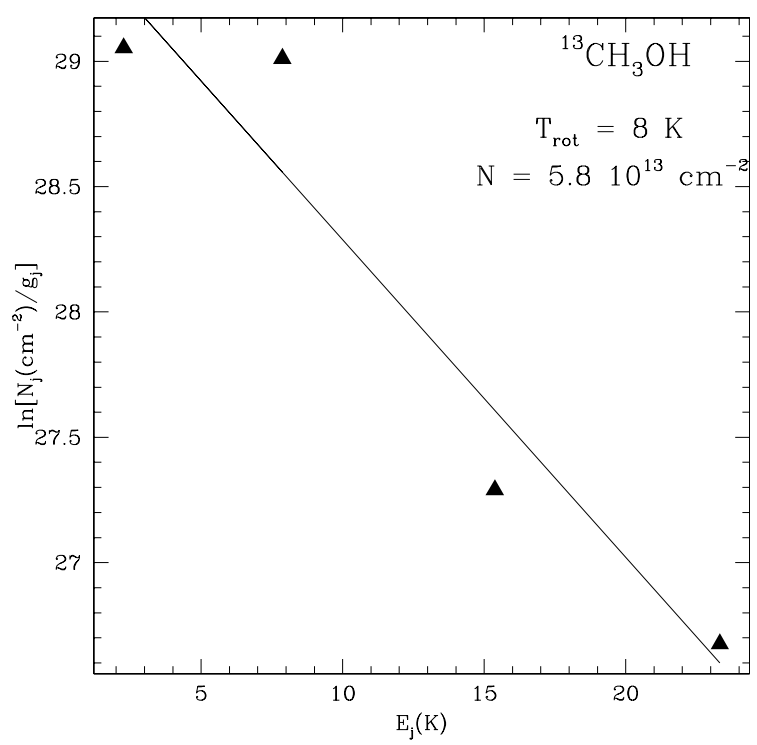


F. Fontani et al.: Deuteration in massive star formation

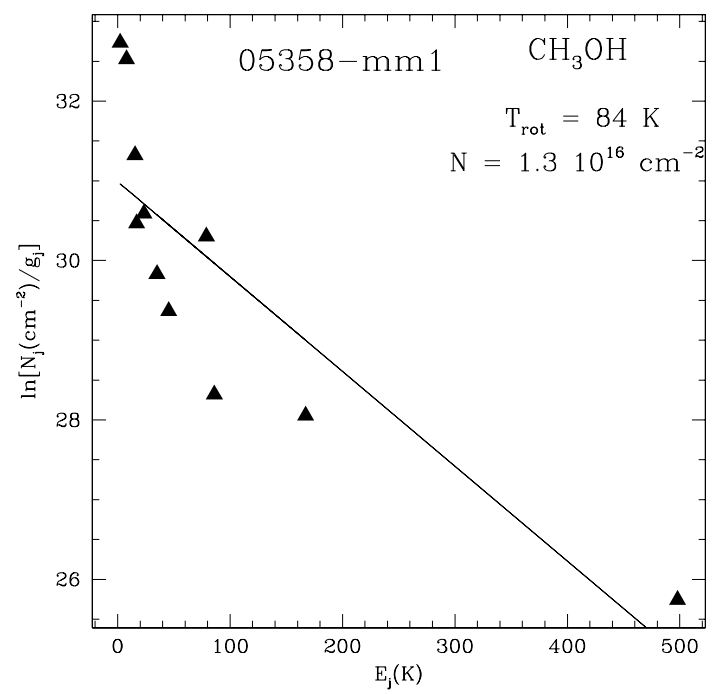

Fig. C.13. Same as Fig. C.1 for core 05358-mm1.
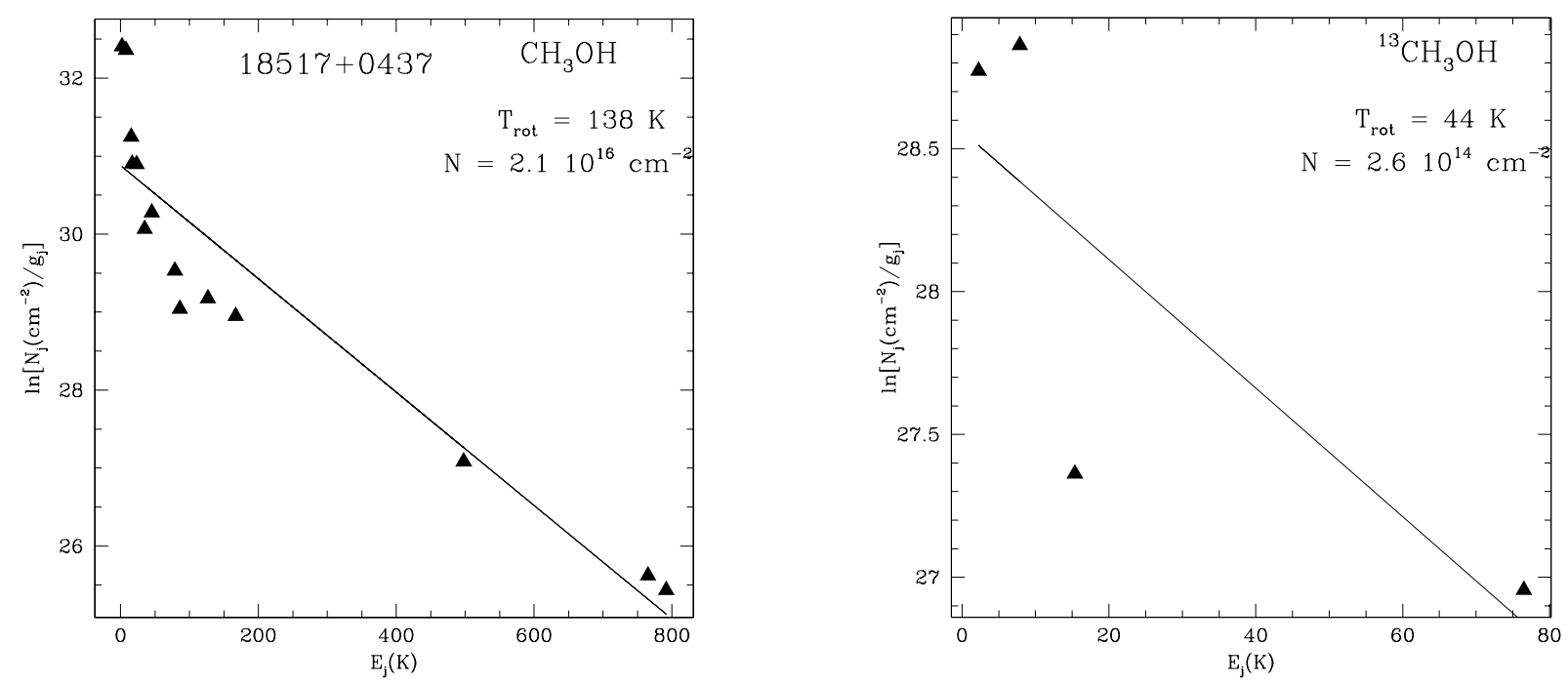

Fig. C.14. Same as Fig. C.2 for core 18517+0437.

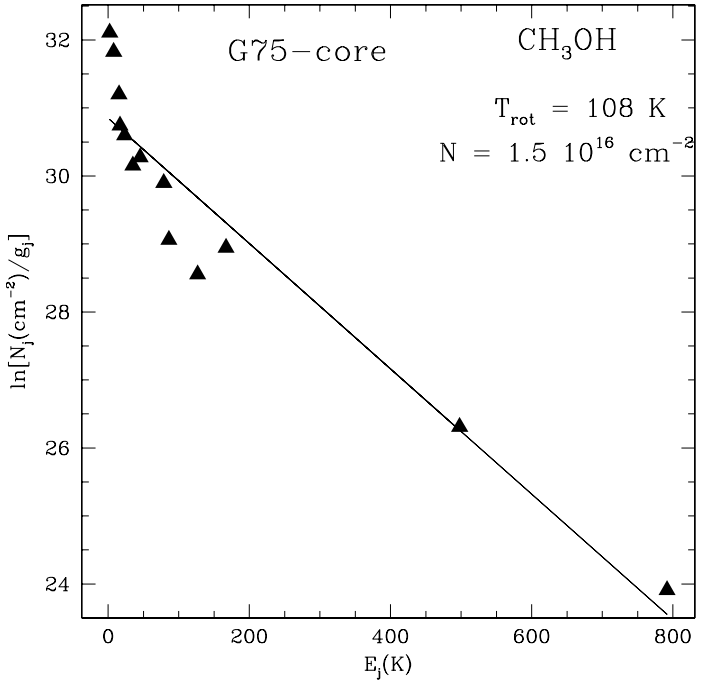

Fig. C.15. Same as Fig. C.1 for core G75-core.

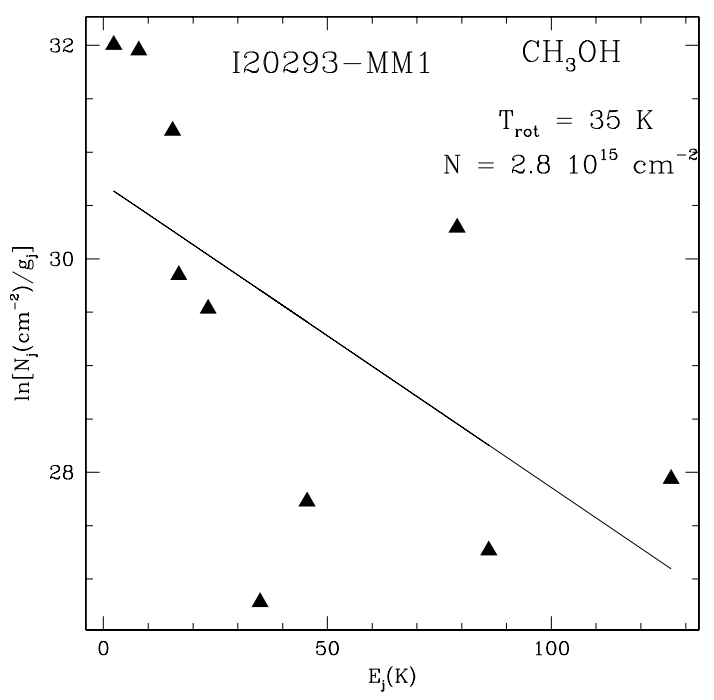

Fig. C.16. Same as Fig. C.1 for core I20293-MM1. 
A\&A 575, A87 (2015)

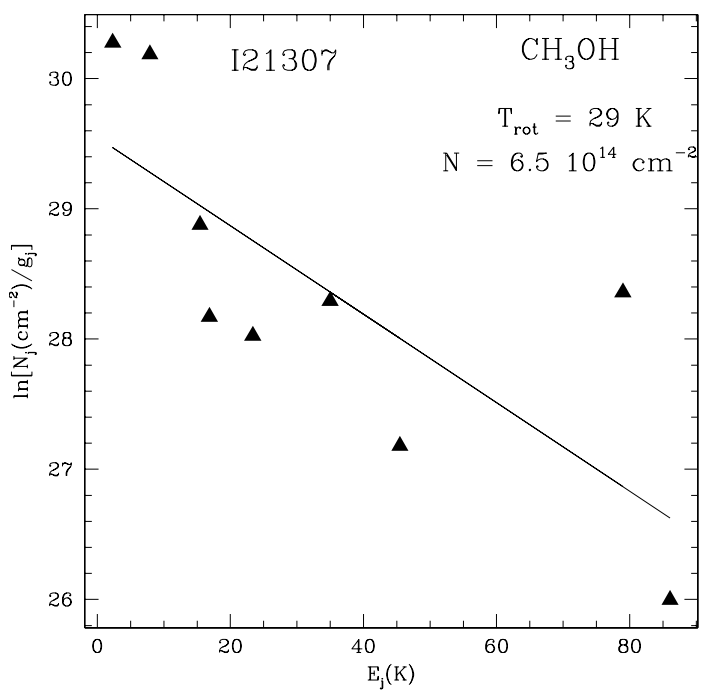

Fig. C.17. Same as Fig. C.1 for core I21307.

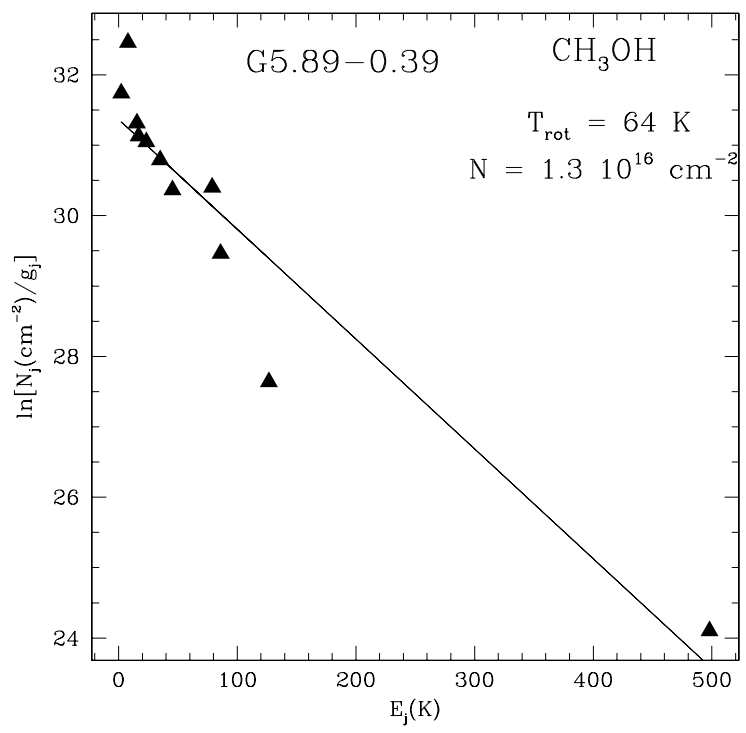

Fig. C.19. Same as Fig. C.14 for core G5.89-0.39.

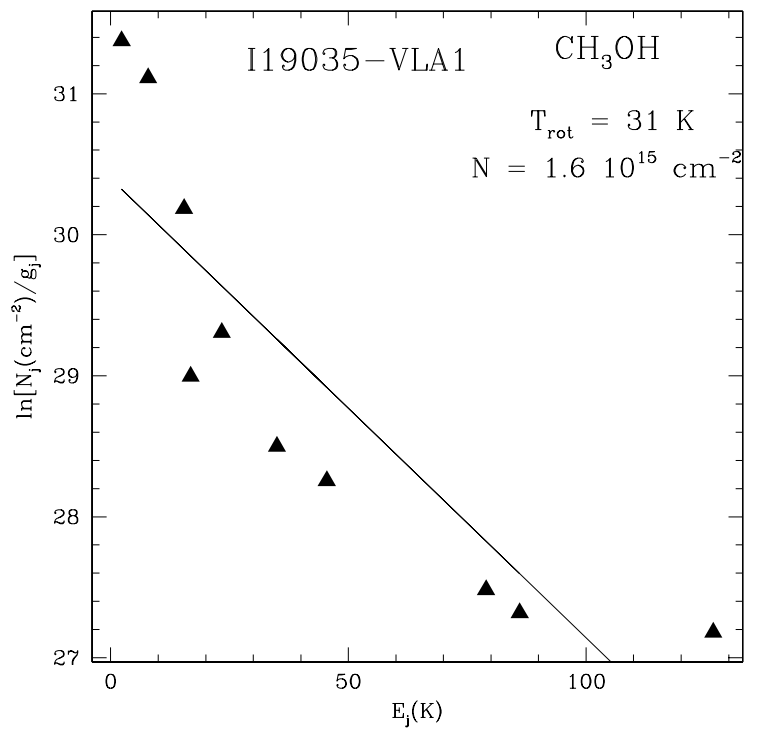

Fig. C.20. Same as Fig. C.14 for core I19035-VLA1.

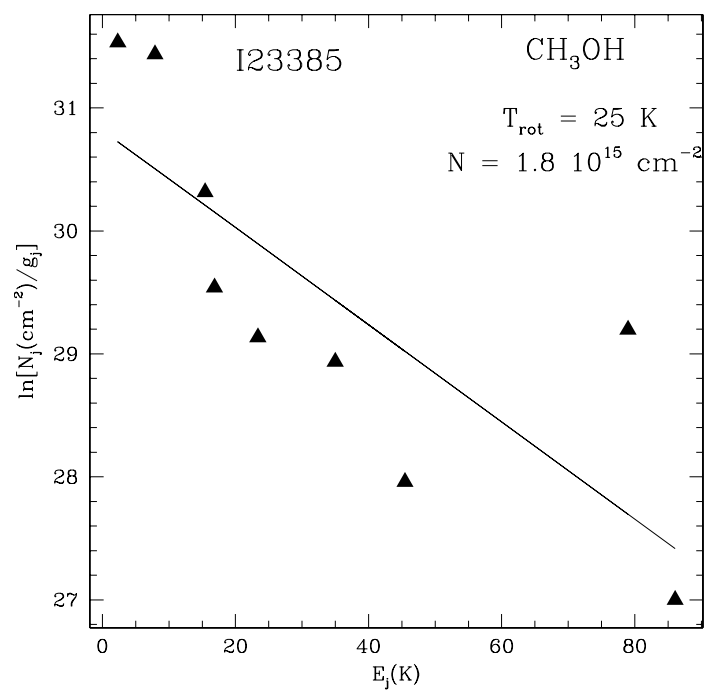

Fig. C.18. Same as Fig. C.1 for core I23385.
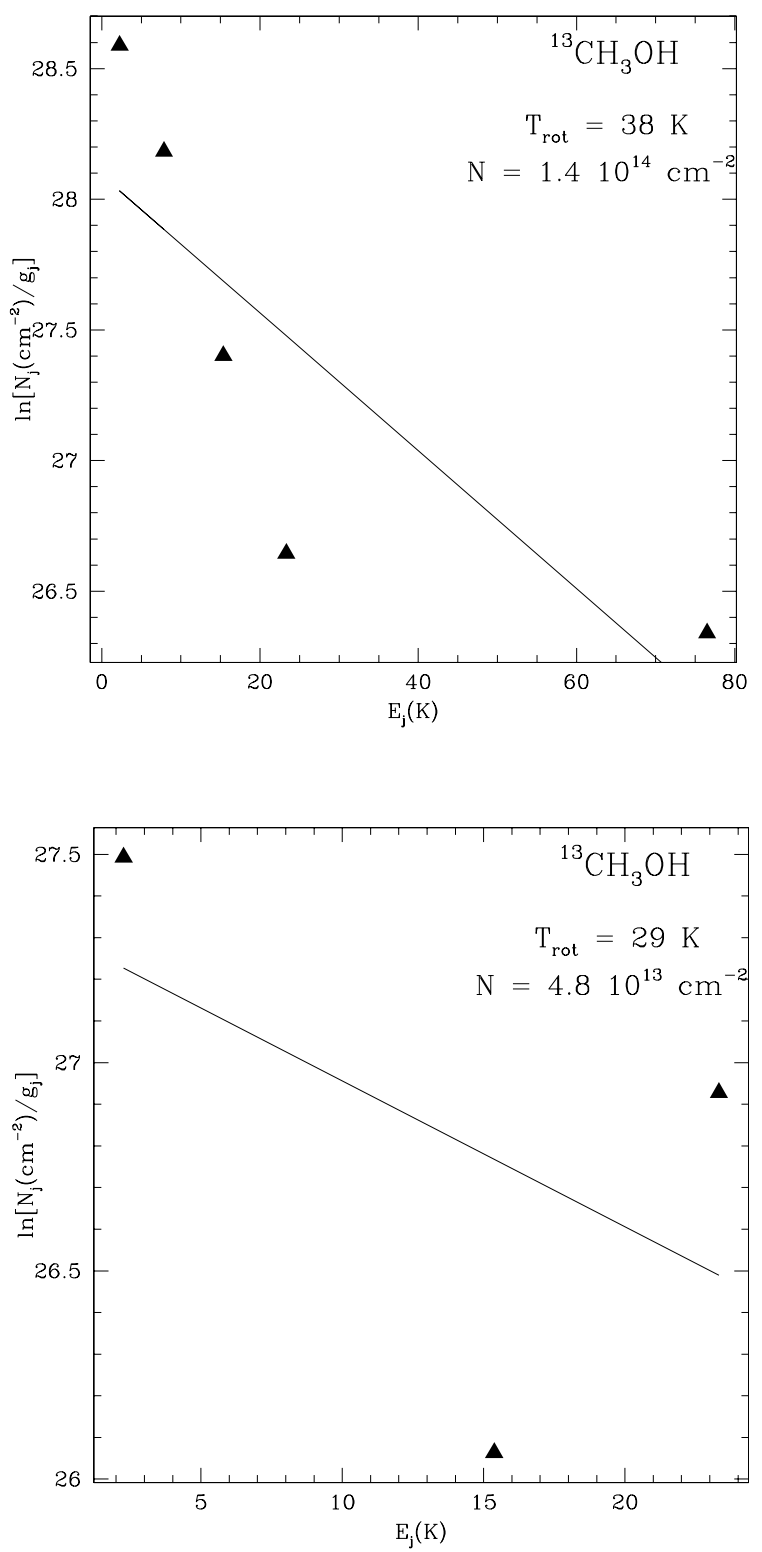
F. Fontani et al.: Deuteration in massive star formation
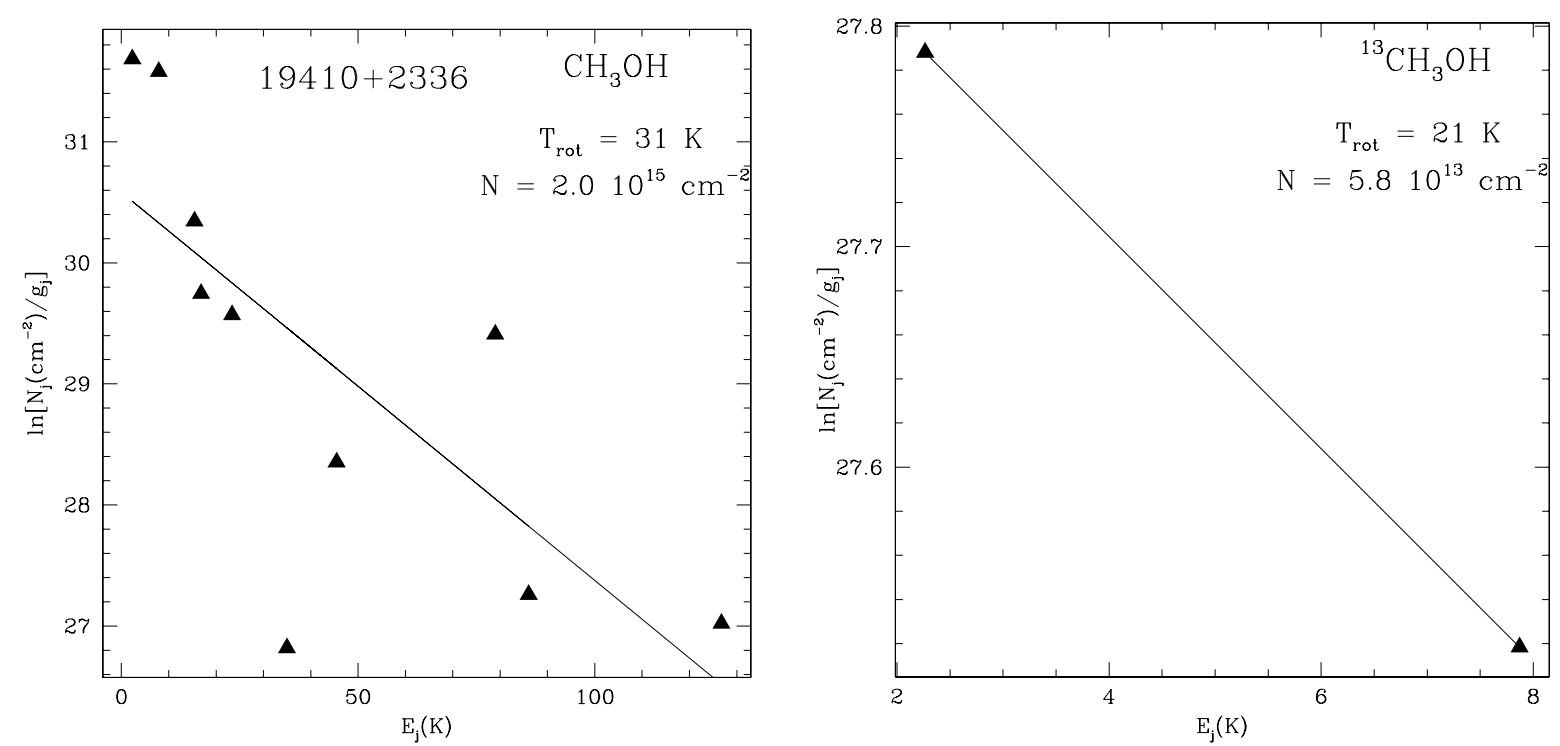

Fig. C.21. Same as Fig. C.14 for core 19410+2336.
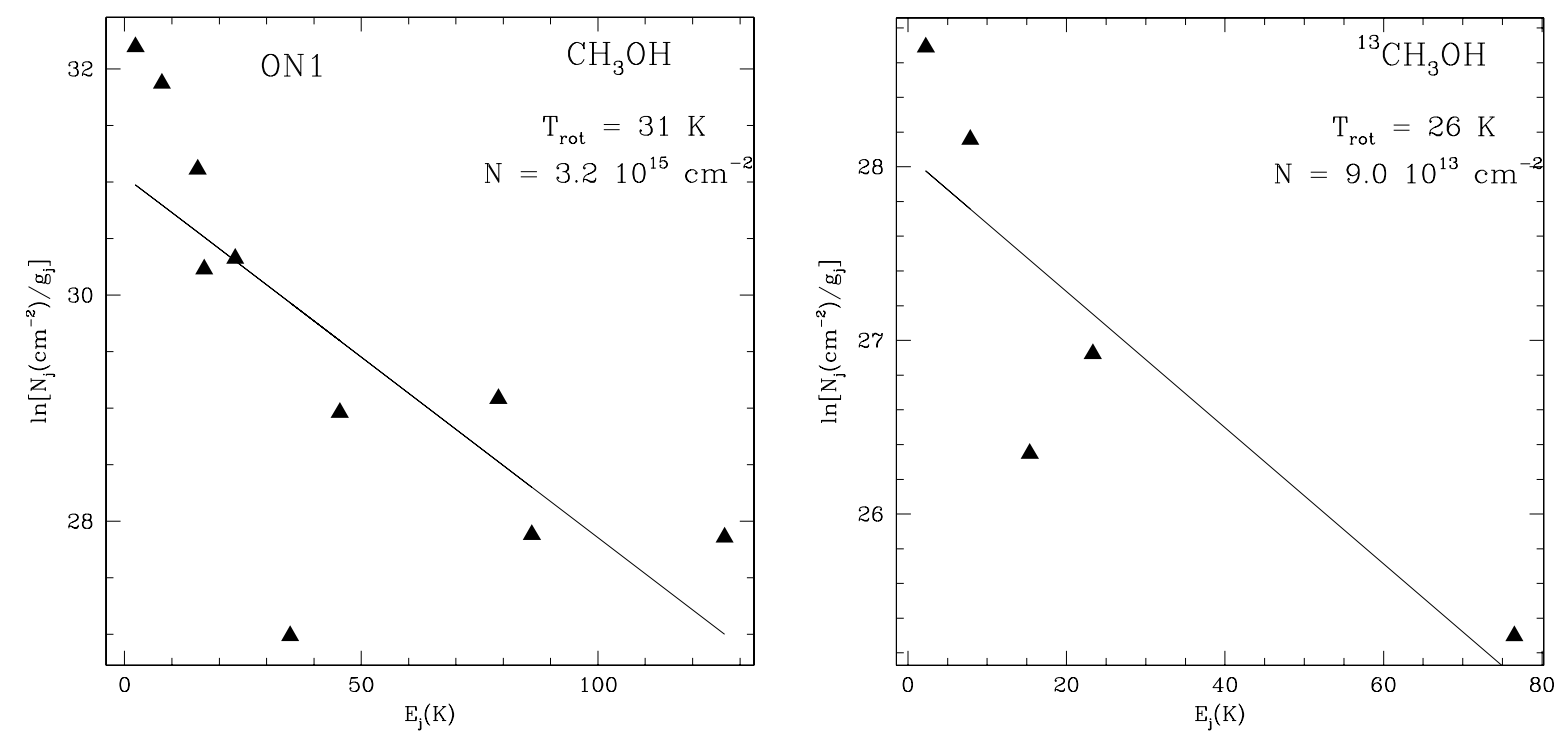

Fig. C.22. Same as Fig. C.14 for core ON1.

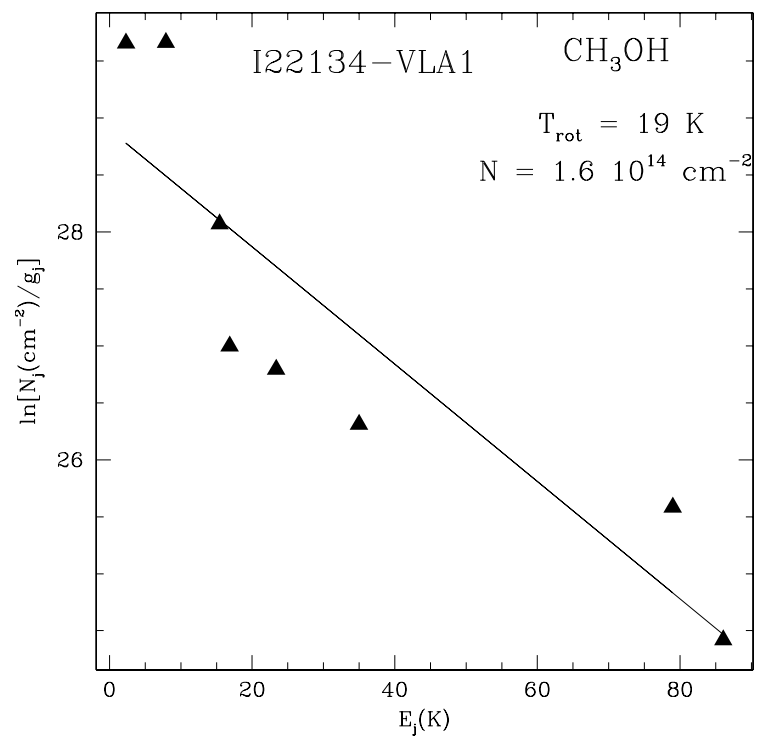

Fig. C.23. Same as Fig. C.1 for core I22134-VLA1. 
A\&A 575, A87 (2015)
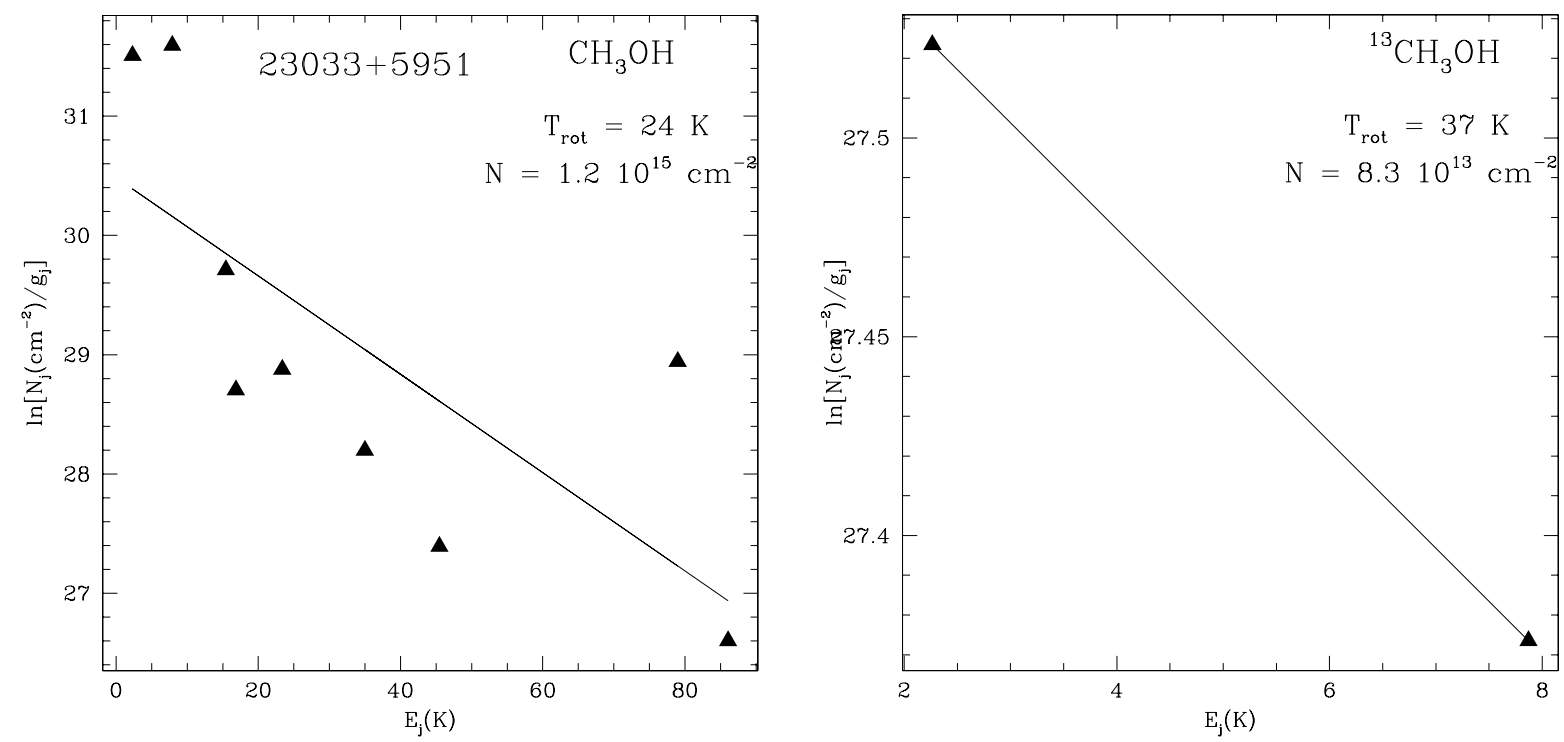

Fig. C.24. Same as Fig. C.14 for core 23033+5951.

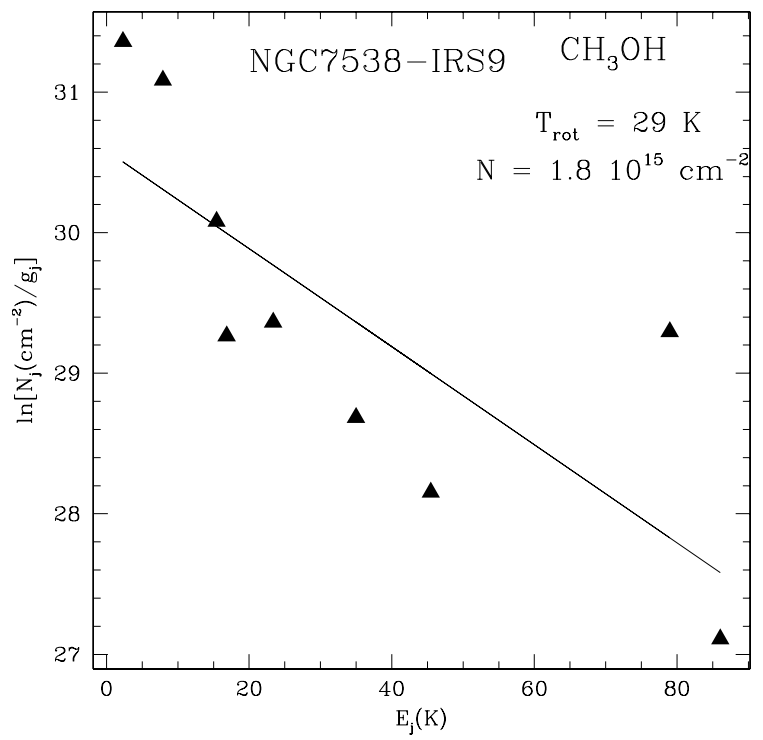

Fig. C.25. Same as Fig. C.1 for core NGC7538-IRS9. 